WALDEN

UNIVERSITY

A higher degree. A higher purpose.

Walden University

ScholarWorks

Walden Dissertations and Doctoral Studies

Walden Dissertations and Doctoral Studies

Collection

$1-1-2011$

\title{
A Mixed Methods Examination of the Influence of Dimensions of Support on Training Transfer
}

Laura A. Schindler

Walden University

Follow this and additional works at: https://scholarworks.waldenu.edu/dissertations

Part of the Business Administration, Management, and Operations Commons, Management Sciences and Quantitative Methods Commons, Organizational Behavior and Theory Commons, and the Psychology Commons

This Dissertation is brought to you for free and open access by the Walden Dissertations and Doctoral Studies Collection at ScholarWorks. It has been accepted for inclusion in Walden Dissertations and Doctoral Studies by an authorized administrator of ScholarWorks. For more information, please contact ScholarWorks@waldenu.edu. 


\title{
Walden University
}

COLLEGE OF SOCIAL AND BEHAVIORAL SCIENCES

This is to certify that the doctoral dissertation by

\author{
Laura A. Schindler
}

has been found to be complete and satisfactory in all respects, and that any and all revisions required by the review committee have been made.

Review Committee

Dr. Gary Burkholder, Committee Chairperson, Psychology Faculty Dr. Gwynne Dawdy, Committee Member, Psychology Faculty Dr. John Schmidt, University Reviewer, Psychology Faculty

Chief Academic Officer

Eric Riedel, Ph.D.

Walden University

2012 


\begin{abstract}
A Mixed Methods Examination of the Influence of Dimensions of Support on Training Transfer
\end{abstract}

by

Laura A. Schindler

MS, Walden University, 2007

BS, Towson University, 2001

\author{
Dissertation Submitted in Partial Fulfillment \\ of the Requirements for the Degree of \\ Doctor of Philosophy \\ Psychology
}

Walden University

December 2012 


\begin{abstract}
Organizations invest a significant amount of time and money on training; however, most employees do not transfer what they learned in training to the specific tasks required in their job. While extant research suggests that supervisor support may facilitate training transfer, the influence of specific types or dimensions of support is still unknown. The purpose of this mixed methods sequential explanatory study was to examine how specific dimensions of support (mentoring, coaching, social support, and task support) influence training transfer. Organizational support theory and the theory of planned behavior served as the theoretical framework for this study. Quantitative data were collected first, via an online survey, from participants $(n=48)$ who developed curriculum at a large, educational organization. The correlation analysis revealed significant positive relationships between the dimensions of support and training transfer. A bootstrap analysis revealed that transfer motivation mediates the relationships between mentoring, coaching, social support, and training transfer, but does not mediate the relationship between task support and transfer. Qualitative data were collected from additional participants $(n=10)$ at the organization, via in-depth interviews. A phenomenological analysis of the interview transcripts partially corroborated the quantitative results, suggesting that mentoring influences both transfer motivation and training transfer, coaching influences training transfer, and social support influences transfer motivation. Implications for positive social change include an increase in the transfer of learned knowledge and skills among employees who develop curriculum, which may help them develop higher-quality courses and degree programs that increase student learning and contribute to the integrity and success of universities.
\end{abstract}



A Mixed Methods Examination of the Influence of Dimensions of Support on Training Transfer

by

Laura A. Schindler

MS, Walden University, 2007

BS, Towson University, 2001

\author{
Dissertation Submitted in Partial Fulfillment \\ of the Requirements for the Degree of \\ Doctor of Philosophy \\ Psychology
}

Walden University

December 2012 
All rights reserved

INFORMATION TO ALL USERS

The quality of this reproduction is dependent upon the quality of the copy submitted.

In the unlikely event that the author did not send a complete manuscript and there are missing pages, these will be noted. Also, if material had to be removed, a note will indicate the deletion.

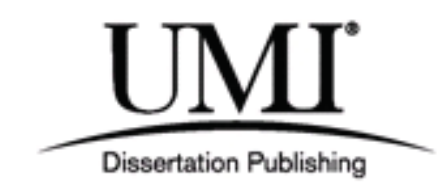

UMI 3547454

Published by ProQuest LLC (2012). Copyright in the Dissertation held by the Author. Microform Edition (C) ProQuest LLC.

All rights reserved. This work is protected against unauthorized copying under Title 17, United States Code

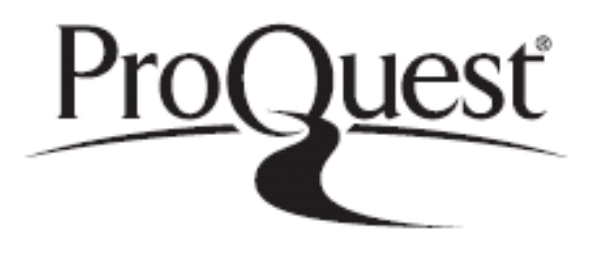

ProQuest LLC.

789 East Eisenhower Parkway

P.O. Box 1346

Ann Arbor, MI 48106 - 1346 


\section{Dedication}

I dedicate my dissertation to my husband, Ed del Sordo. You are the most compassionate and nonjudgmental person on the planet, and you inspire me to be a better person every day. Thank you for always making me laugh, for loving and supporting me throughout this entire process, and for believing that this was a goal worthy of sacrifice. 


\section{Acknowledgments}

I would like to thank my chairperson, Dr. Gary Burkholder. Thank you for giving me the "push" I needed to recommit to my dissertation. It was a crucial turning point in my doctoral journey, and ultimately served as the impetus for me to complete my $\mathrm{PhD}$. Also, thank you for your constant reassurance, patience, guidance, and support throughout this entire process. I could not have asked for a better chair.

I would also like to thank my committee members: Dr. Gwynne Dawdy and Dr. John Schmidt. Thank you for your support and guidance throughout this process.

I would like to thank my parents, Francis and Janice Schindler, for making the sacrifices necessary so that I had the opportunity to study psychology as an undergraduate student. This laid the groundwork for my $\mathrm{PhD}$. Also, thank you for your unwavering support and encouragement throughout my graduate studies.

I would also like to thank my in-laws, Carlos and Astrid del Sordo. Your passion for education and learning is an inspiration to me. Your enthusiasm and support served as a beacon of light on the darkest days.

I would like to thank my sister, Sarah Schindler. You always saw me as the person I aspired to be and you believed in me when I did not believe in myself. Thank you for always listening and for always saying the right thing. I could not have done this without you.

Finally, I would like to thank all of my family members, friends, and coworkers who supported me throughout this process. It takes a village. 
Table of Contents

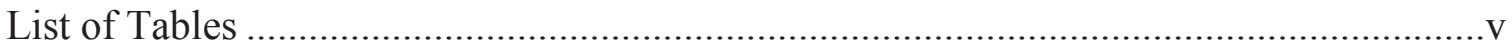

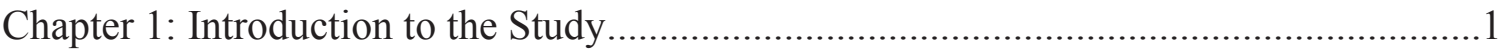

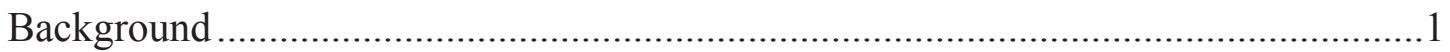

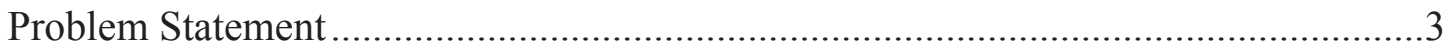

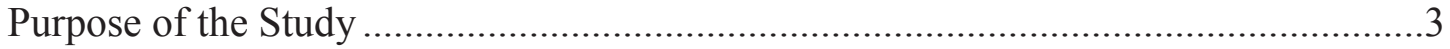

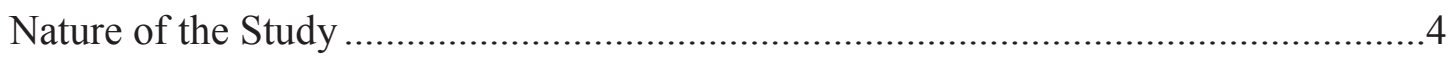

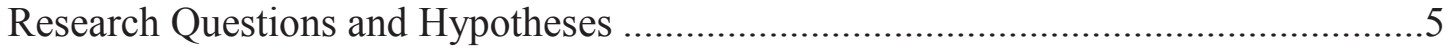

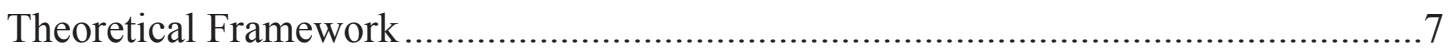

Organizational Support Theory.................................................................. 7

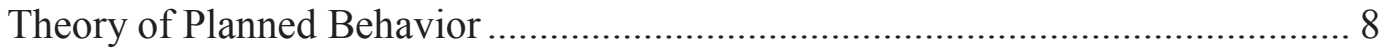

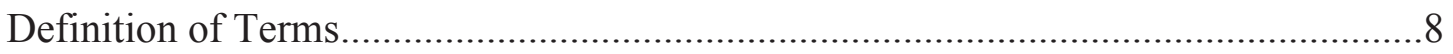

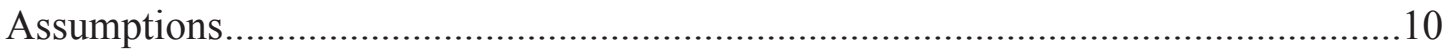

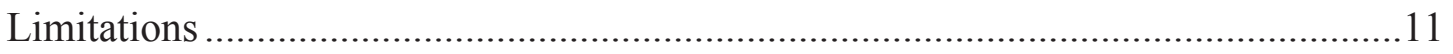

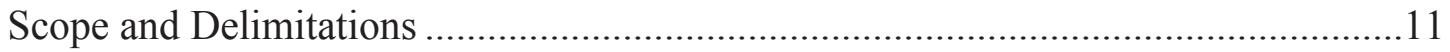

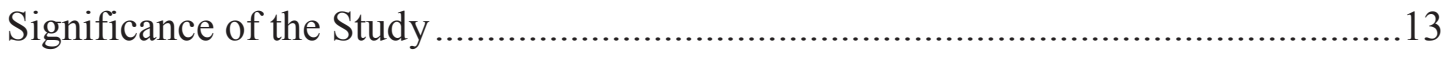

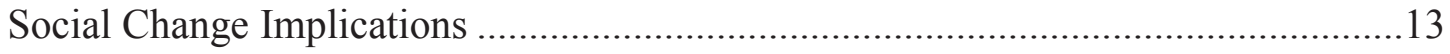

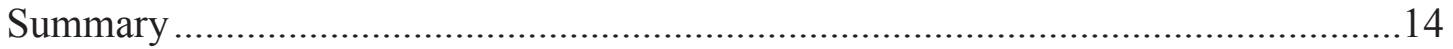

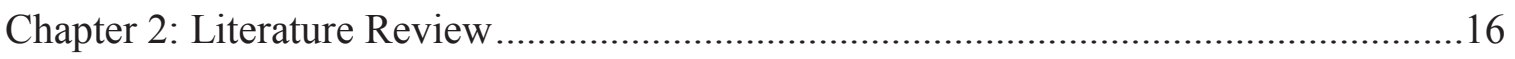

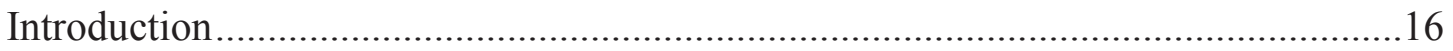

Organization of the Chapter.................................................................... 17

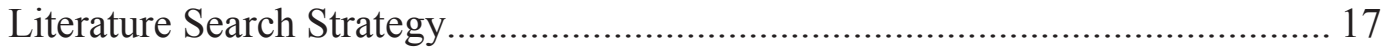




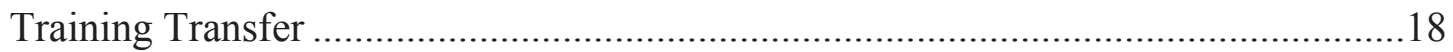

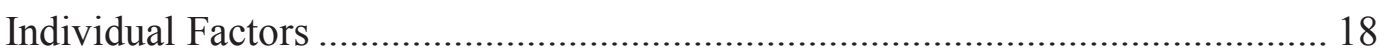

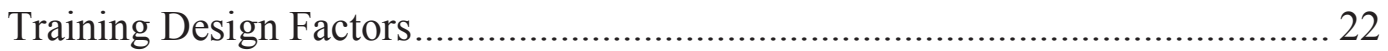

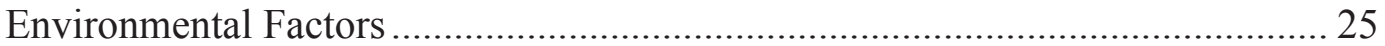

Limitations of Existing Transfer Research ...................................................... 31

Summary of Transfer Research ..................................................................... 35

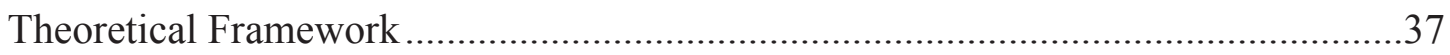

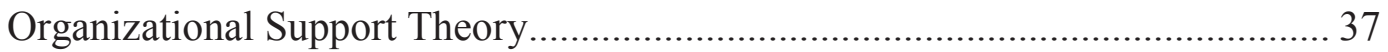

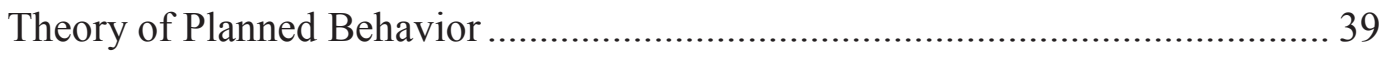

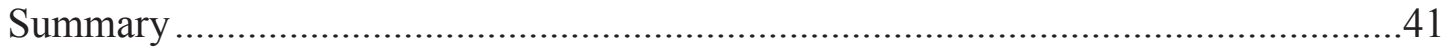

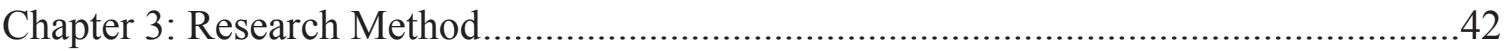

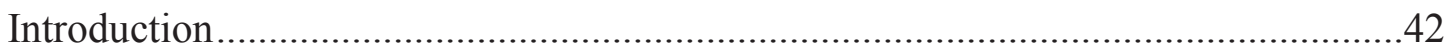

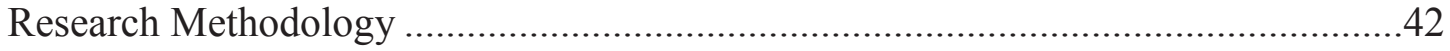

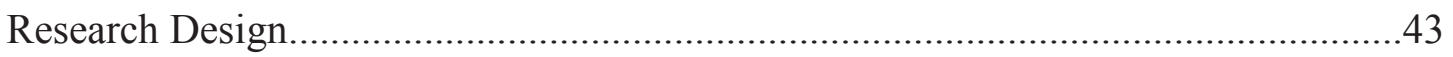

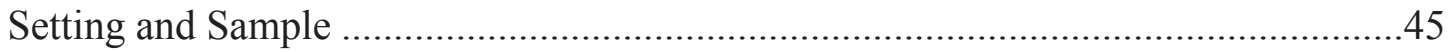

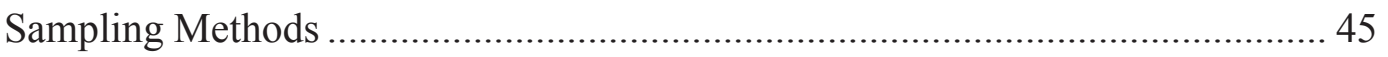

Sample Size

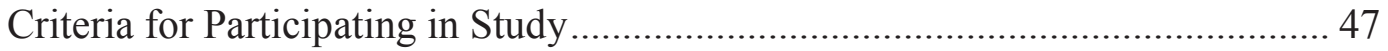

Phase 1: Quantitative Data Collection and Analysis ................................................47

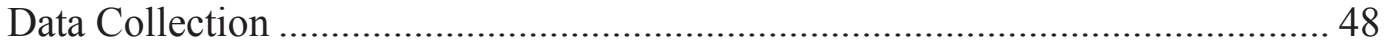

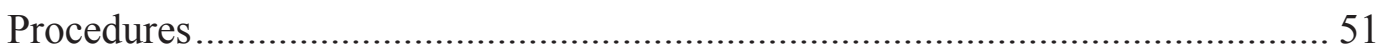

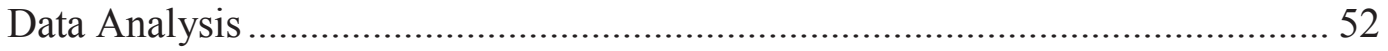




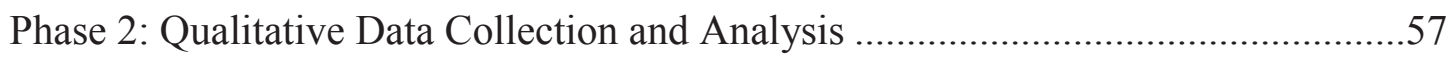

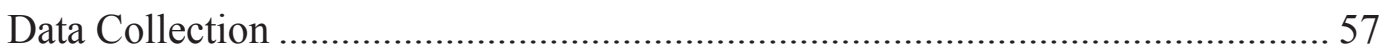

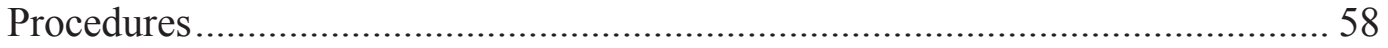

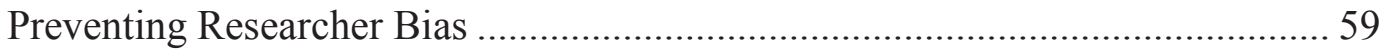

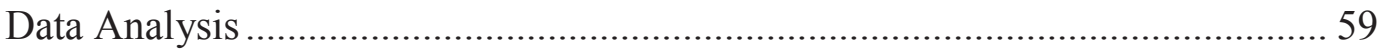

Phase 3: Integration of Quantitative and Qualitative Results ..................................61

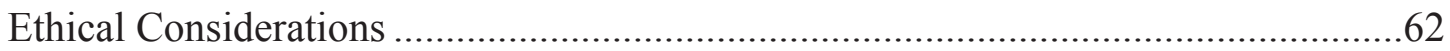

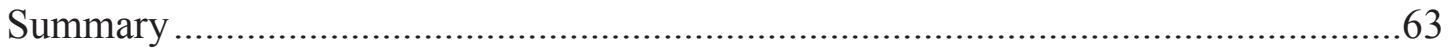

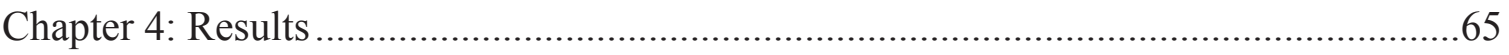

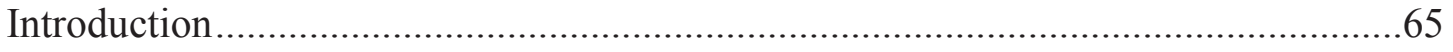

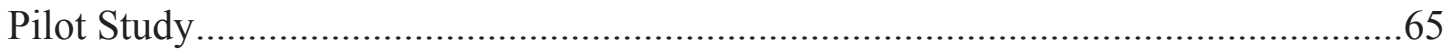

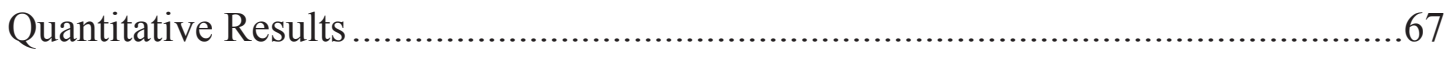

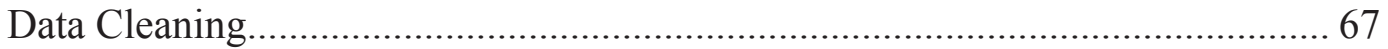

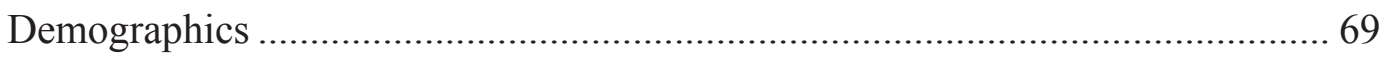

Reliability of Mentoring and Communication Support Scale........................... 71

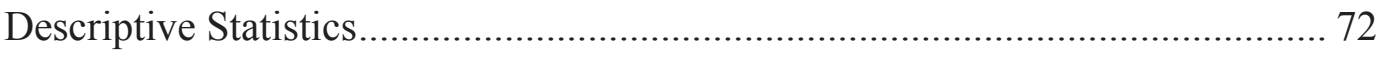

Dimensions of Support and Training Transfer ............................................ 73

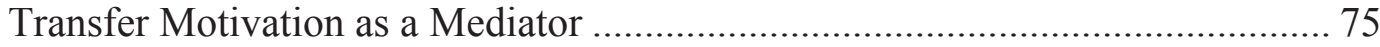

Types of Training and Training Transfer....................................................... 76

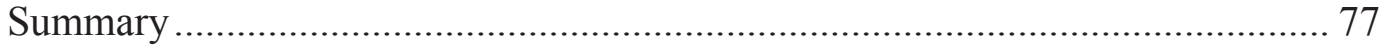

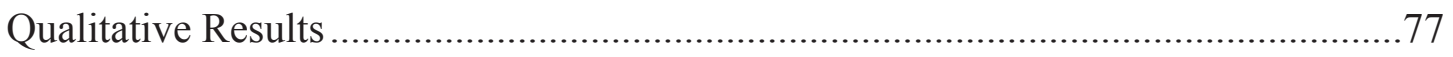

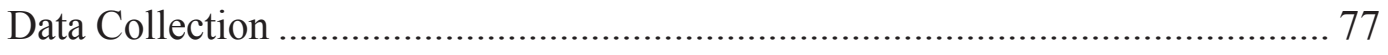




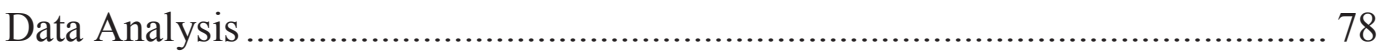

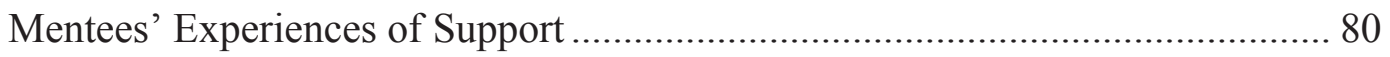

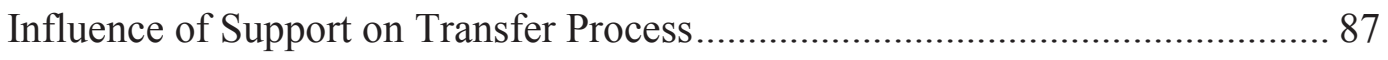

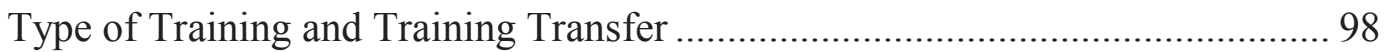

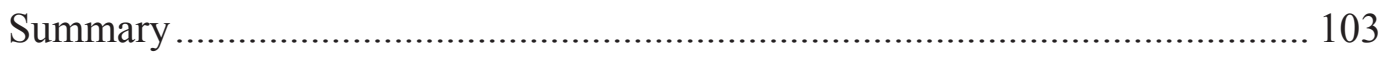

Chapter 5: Discussion, Conclusions, and Recommendations ..........................................104

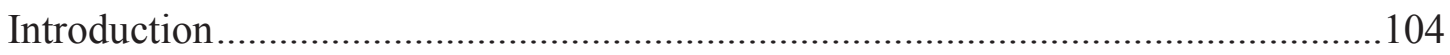

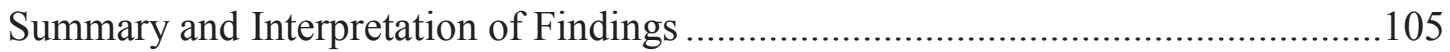

Dimensions of Support and Training Transfer .................................................. 105

The Mediating Role of Transfer Motivation......................................................... 106

Type of Training and Training Transfer ........................................................... 109

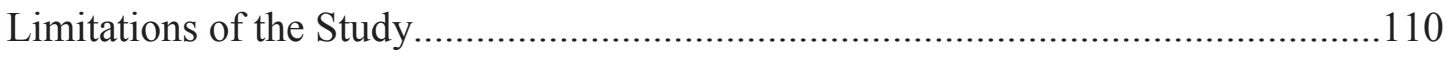

Recommendations for Future Research ...............................................................113

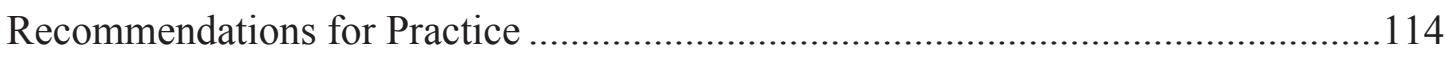

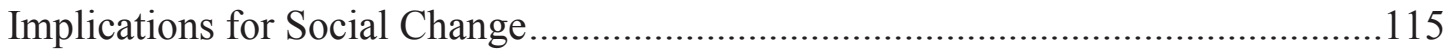

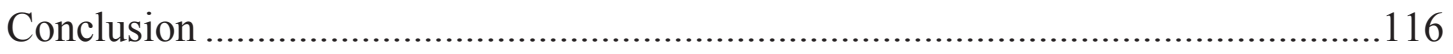

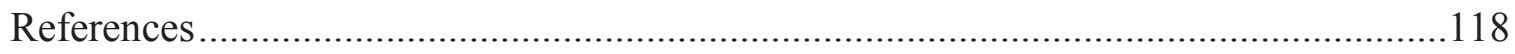

Appendix A: Demographic Survey Questions.............................................................139

Appendix B: Interview Questions for Mentees ………………....................................142

Appendix C: Interview Questions for Mentors...............................................................143

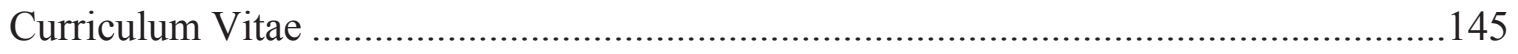




\section{List of Tables}

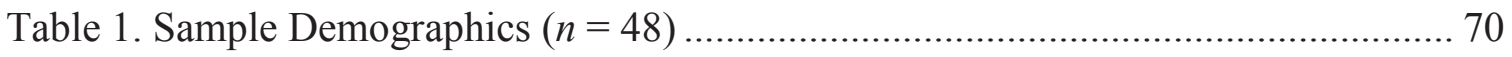

Table 2. Test-Retest Coefficients, Significance Values, and Bootstrapped Confidence Intervals for the Mentoring and Communication Scale and subscales $(n=31) \ldots \ldots . .72$

Table 3. Descriptive Statistics for Transfer Motivation, Training Transfer, and

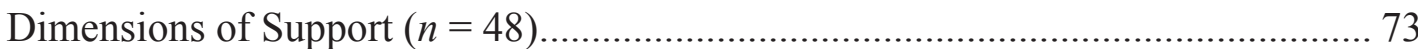

Table 4. Themes and Exemplar Quotes related to Mentees' Experiences of Support (n= 5) 86

Table 5. Themes and Exemplar Quotes related to Effects of Mentoring and Social Support on Transfer Motivation $(n=5)$

Table 6. Themes and Exemplar Quotes related to the Effects of Mentoring and Coaching on Training Transfer $(n=5)$ 97

Table 7. Themes and Exemplar Quotes related to the Effects of Formal Training on Training Transfer $(n=5)$ 102 
Chapter 1: Introduction to the Study

\section{Background}

Despite an unstable economic climate, organizations have continued to invest time and money in employee training programs (Paradise \& Patel, 2009; Nikandrou, Brinia, \& Bereri, 2009). Recent reports indicate that organizations spend approximately 125 billion dollars a year on training, which averages nearly 32 hours of training and one thousand dollars per employee per year (Patel, 2010). While many organizations invest in training programs to bolster their competitiveness, improve their performance, and adapt to social, political, and technological changes, few know whether they have achieved a return on their investment because they do not conduct proper evaluations (Chiaburu, Van Dam, \& Hutchins, 2010; Nikandrou et al., 2009; Phillips \& Phillips, 2010; Yamnill \& McClean, 2001).

Many organizations rely on the Kirkpatrick (1976) model as a framework to evaluate their training programs (Bates, 2004; Patel, 2010; Salas \& Cannon-Bowers, 2001). Kirkpatrick's model consists of four levels of evaluation: reaction (whether the employee liked the training program), learning (how much the employee learned during the training program), behavior, also referred to as training transfer (whether the employee transferred what they learned in the training program once back on the job), and results (the impact of the training program on organizational goals) (Kirkpatrick, 1976). Organizations typically collect data related to trainee reaction and/or learning (Patel, 2010). Reaction and learning are poor indicators of training effectiveness because they do not reflect the behavioral changes of trainees once back on the job (Alliger, Tannenbaum, Bennett, Traver, \& Shotland, 1997; Bates, 1994). Training transfer, 
however, is a far more accurate indicator of training effectiveness because it signifies whether employees are applying learned knowledge and skills to the job (Baldwin \& Ford, 1998; Sookhai \& Budworth, 2010). Given that training transfer is a viable indicator of training effectiveness, it has received considerable attention in the training literature and among training professionals in recent decades (Burke \& Hutchins, 2007; Cheng \& Hampson, 2008; Cheng \& Ho, 2001; Salas \& Cannon-Bowers, 2001).

Existing research reveals some significant findings about training transfer. Among the most significant are that training transfer is a complex phenomenon and that it is influenced by a multitude of factors (Baldwin \& Ford, 1988; Blume, Ford, Baldwin, \& Huang, 2010; Burke \& Hutchins, 2007; Cheng \& Hampson, 2008; Salas \& CannonBowers, 2001). Predictors of training transfer include individual factors, such as transfer motivation (Bates, Kauffeld, Holton, 2007; Chiaburu \& Lindsay, 2008; Devos, Dumay, Bonami, Bates, \& Holton, 2007; Van den Bossche, Segers, \& Jansen, 2010) and conscientiousness (Colquitt, Lepine, \& Noe, 2000; Tziner, Fisher, Senior, \& Weisburg, 2007); training design factors, such as the use of active training (Bell \& Kozlowski, 2008; Keith, Richter, \& Naumann, 2010) and error management training (EMT) (Keith \& Frese, 2008); and environmental factors, such as organizational culture (Gilpin-Jackson \& Busche, 2006; Nikandrou et al., 2009), transfer climate (Lim \& Morris, 2006; Martin, 2010b; Nijman, Nijhof, Wognum, \& Beldkamp 2006; Sookhai \& Budworth, 2010), and peer support (Gilpin-Jackson \& Busche, 2006; Hawley \& Barnard, 2005; Martin, 2010a). The influence of these and other individual, design, and environmental factors on training transfer is discussed in greater depth in Chapter 2. 


\section{Problem Statement}

Despite the proliferation of transfer research, the influence of supervisor support on training transfer is still unclear. Some studies suggest that supervisor support influences training transfer directly (Austin, Weisner, Schrandt, Glezos-Bell, \& Murtaza, 2006; Gilpin-Jackson \& Busche, 2006; Saks \& Belcourt, 2006). Other studies suggest that it influences training transfer indirectly (Chiaburu et al., 2010; Nijman et al., 2006) or not at all (Devos et al., 2007; Velada, Caetano, Michel, Lyons, \& Kavanagh, 2007). Also, of the existing studies, none have identified the types or dimensions of support that influence training transfer or have explored how employees experience support in the context of transferring learned knowledge and skills. This study addresses these gaps in the research by examining how specific dimensions of support influence training transfer and by exploring how employees experience support.

\section{Purpose of the Study}

The primary purpose of this mixed methods sequential explanatory study was to understand the influence of specific dimensions of support (coaching, mentoring, task support, and social support) on training transfer. The secondary purpose was to determine whether training transfer differs depending on the types of training offered. In the quantitative portion of this study, the relationships between dimensions of support and training transfer were examined and the degree to which transfer motivation mediates those relationships was determined. In addition, the difference in training transfer scores between employees who participated in both formal and informal new hire training and employees who participated in informal new hire training alone were examined. In the qualitative portion of this study, mentees' experiences of support were explored and 
mentors' perceptions of training transfer among mentees who participated in different types of training were investigated.

\section{Nature of the Study}

The study took place at a large, educational organization located in the MidAtlantic region of the United States. It consisted of employees who developed collegelevel curriculum for the organization. These employees, referred to as mentees in this study, were assigned mentors who were responsible for training them and providing them with feedback about their performance. Mentors also participated in this study.

This study employed a mixed methods sequential explanatory research design in which survey research was conducted and analyzed first followed by phenomenological research. In the first phase, correlation methods were used to examine the relationships between the dimensions of support and training transfer. Next, regression coefficients were computed and bootstrapping methods were conducted to determine if transfer motivation mediated those relationships. Finally, an independent samples $t$-test was computed to determine if there was a difference in training transfer between mentees who participated in formal and informal new hire training and mentees who participated in informal new hire training alone. In the second phase of this study, phenomenological interviews were conducted with mentees to explore their experiences of support and how those experiences influenced transfer motivation and training transfer. Interviews also were conducted with mentors to examine their perceptions of training transfer among mentees who participated in both formal and informal new hire training and mentees who participated in informal new hire training alone. 


\section{Research Questions and Hypotheses}

The overall research question that guided this study was: How do dimensions of support (mentoring, coaching, social support, and task support) influence training transfer?

The hypotheses for the quantitative portion of this study were as follows:

$\mathrm{H} 1_{0}$ : There is no correlation between mentoring, as measured by the Mentoring and Communication Support Scale, and training transfer, as measured by the Importance, Transfer Achieved, and Performance Improvement (ITAPI) Scale.

$\mathrm{H} 1_{1}$ : There is a positive correlation between mentoring, as measured by the Mentoring and Communication Support Scale, and training transfer, as measured by the ITAPI Scale.

$\mathrm{H} 2_{0}$ : There is no correlation between coaching, as measured by the Mentoring and Communication Support Scale, and training transfer, as measured by the ITAPI Scale.

$\mathrm{H} 2_{1}$ : There is a positive correlation between coaching, as measured by the Mentoring and Communication Support Scale, and training transfer, as measured by the ITAPI Scale.

$\mathrm{H} 3_{0}$ : There is no correlation between task support, as measured by the Mentoring and Communication Support Scale, and training transfer, as measured by the ITAPI Scale.

$\mathrm{H} 3_{1}$ : There is a positive correlation between task support, as measured by the Mentoring and Communication Support Scale, and training transfer, as measured by the ITAPI Scale. 
$\mathrm{H} 4_{0}$ : There is no correlation between social support, as measured by the Mentoring and Communication Support Scale, and training transfer, as measured by the ITAPI Scale.

$\mathrm{H}_{4}$ : There is a positive correlation between social support, as measured by the Mentoring and Communication Support Scale, and training transfer, as measured by the ITAPI Scale.

$\mathrm{H}_{0}$ : Transfer motivation, as measured by the Transfer Motivation Scale, does not mediate the relationship between mentoring, coaching, task support, and social support, as measured by the Mentoring and Communication Support Scale, and training transfer, as measured by the ITAPI Scale.

$\mathrm{H} 5_{1}$ : Transfer motivation, as measured by the Transfer Motivation Scale, does mediate the relationship between mentoring, coaching, task support and social support, as measured by the Mentoring and Communication Support Scale, and training transfer, as measured by the ITAPI Scale.

$\mathrm{H6}_{0}$ : There is no statistically significant difference between training transfer, as measured by the ITAPI Scale, of mentees who participated in formal and informal new hire training and mentees who participated in informal new hire training alone.

$\mathrm{H6}_{1}$ : There is a statistically significant difference between training transfer, as measured by the ITAPI Scale, of mentees who participated in formal and informal new hire training and mentees who participated in informal new hire training alone.

The research questions for the qualitative portion of this study were as follows:

1. How do mentees experience specific dimensions of support (mentoring, 
coaching, task support, and social support), exhibited by their mentors, as they attempt to transfer learned knowledge and skills?

2. How do mentees' experiences of specific dimensions of support (mentoring, coaching, task support, and social support) influence their motivation to transfer learned knowledge and skills and their attempts to transfer learned knowledge and skills?

3. How does participation in formal and informal new hire training versus participation in informal new hire training alone influence training transfer among mentees, as perceived by mentors?

\section{Theoretical Framework}

\section{Organizational Support Theory}

Organizational support theory suggests that, when employees are treated well, they will reciprocate in some way to help the organization. Specifically, employees develop perceptions about the degree to which the organization supports them and cares about their well-being. If their perceptions are positive, they feel obligated to engage in activities and exhibit behaviors that will benefit the organization (Eisenberger, Huntington, Hutchison, \& Sowa, 1986; Eisenberger, Stinglhamber, Vandenberghe, Sucharski, \& Rhoades, 2002). Employee perceptions of organizational support originate from their perceptions of their supervisors, whom they often believe personify the organization (DeConinck \& Johnson 2009; Levinson, 1965; Rhodes \& Eisenberger, 2002; Shanock \& Eisenberger, 2006). Both perceived organizational support and perceived supervisor support have led to numerous positive employee outcomes, such as improved job performance and organizational commitment (Pazy \& Ganzach, 2008; Ng \& Sorensen, 2008; Rhodes \& Eisenberger, 2002; Riggle, Edmonson, \& Hansen, 2009). 
Organizational support theory supports the hypothesized relationships between dimensions of support and training transfer.

\section{Theory of Planned Behavior}

The theory of planned behavior asserts that the stronger an employee's intention or motivation to perform a specific behavior, the more likely he or she is to perform that behavior (Ajzen, 1991). Intentions to perform a behavior are influenced by the following factors: attitudes about the behavior; perceptions of how easy or difficult the behavior is to perform; and the degree to which referent individuals in the organization approve or disapprove of the behavior (Arnold et al., 2006; Rise, Sheeran, \& Hukkelberg, 2010; Rivis, Sheeran, \& Armitage, 2009; White, Smith, Terry, Greenslade, \& McKimmie, 2009). The theory of planned behavior supports the hypothesis that transfer motivation mediates the relationships between dimensions of support and training transfer. Employees who have supportive supervisors may be more likely to have positive attitudes and perceptions about training transfer, and therefore possess a stronger motivation to transfer learned knowledge and skills.

\section{Definition of Terms}

The following definitions were used to operationalize the items in this study:

Coaching: Coaching refers to the practice of teaching a mentee about the rules, goals, and politics of the organization and was measured using the Mentoring and Communication Support Scale (Hill, Bahniuk, Dobos, \& Rouner, 1989).

Formal new hire training: Formal new hire training, as defined by the organization in which this study occurred, refers to a structured two-week training program held in a classroom-like setting that is facilitated by a trainer. 
Informal new hire training: Informal new hire training, as defined by the organization in which this study occurred, refers to unstructured training that occurs on the job in the absence of a formal trainer. For example, informal training may include shadowing peers and/or mentors, observing meetings and other job-related activities, and asking questions.

Mentee: A mentee, as defined by the organization in which this study occurred, refers to an employee who develops curriculum and who has participated in formal and/or informal new hire training.

Mentor: A mentor, as defined by the organization in which this study occurred, refers to an employee who performs various supervisory functions in the curriculum development department, namely training and developing mentees and providing them with feedback about their performance.

Mentoring: Mentoring refers to the practice of supporting, guiding, and facilitating a mentee's career development and was measured using the Mentoring and Communication Support Scale (Hill, Bahniuk, \& Dobos, 1989).

Task support: Task support refers to the practice of assisting a mentee with work assignments and was measured using the Mentoring and Communication Support Scale (Downs, 1994; Hill, Bahniuk, Dobos, \& Rouner, 1989).

Social support: Social support refers to the practice of assisting a mentee with personal and professional challenges and problems and was measured using the Mentoring and Communication Support Scale (Downs, 1994; Hill, Bahniuk, Dobos, \& Rouner, 1989). 
Transfer motivation: Transfer motivation refers to the degree to which one desires to use knowledge and skills learned in training once back on the job and was measured using the Transfer Motivation Scale (Noe \& Schmitt, 1986; Yamkovenko, Holton, \& Bates, 2007).

Training transfer: Training transfer refers to the effective and continuous application of knowledge and skills learned in training once back on the job and was measured using the ITAPI (Baldwin \& Ford, 1988; Broad \& Newstrom, 1992; Handy, 2008).

\section{Assumptions}

There are several assumptions associated with this study. First, it is assumed that participants responded truthfully and accurately. Mentees may have been tempted to inflate their training transfer responses because they feared that low training transfer reflects poorly on them and/or their mentors. Similarly, mentors may have also been tempted to inflate their responses regarding mentees' training transfer because they feared that low training transfer reflects poorly on their performance as mentors. In addition, mentees may have inflated their responses regarding the degree to which their mentor exhibited support if they feared that their mentors would discover how they responded. To promote truthful and accurate responses, all participants were assured that their identities would be kept confidential.

Second, it is assumed that the instruments used in this study accurately measured training transfer, transfer motivation, and dimensions of support. Careful consideration was made in selecting instruments that accurately reflected the meaning of the constructs included in this study. For instance, one of the most widely used training transfer 
measures includes items that assess the influence of training transfer on employee outcomes, such as absenteeism, morale, and turnover (Facteau, Dobbins, Russell, Ladd, \& Kudisch, 1995). A more appropriate instrument was selected that measures whether training transfer has occurred, rather than how it influenced employee outcomes.

\section{Limitations}

The results of this study should be considered in light of the following limitations. First, convenience sampling was used to select the participants for the quantitative portion of this study and the sample size was relatively small $(n=48)$. As a result, the sample was not representative of all employees and the results cannot be generalized to employees who work in other organizations or professions. Second, given the correlational nature of this study, a cause and effect relationship between the dimensions of support and training transfer cannot be established. However, testing the mediation of transfer motivation on the relationships between dimensions of support and training transfer provided some evidence of a cause and effect relationship. The results from the qualitative portion of the study also provided additional support for this relationship.

\section{Scope and Delimitations}

The scope of this study was limited to examining how one type of environmental factor, supervisor support, influenced transfer motivation and training transfer. Other factors, such as conscientiousness, peer support, and transfer climate, which have been found to influence transfer motivation and/or training transfer (Colquitt et al., 2000; Gilpin-Jackson \& Busche, 2006; Hawley \& Barnard, 2005; Lim \& Morris, 2006; Martin, 2010a; Martin, 2010b; Nijman et al., 2006; Sookhai \& Budworth, 2010; Tziner et al., 2007) were not taken into account or controlled. The decision to limit the scope to 
supervisor support was based on the exploratory nature of this study. To date, there are no studies that conceptualize and measure supervisor support as a multidimensional construct. As a result, the goal of this study was to determine if relationships exist between the dimensions of support and training transfer. Additional research is needed to determine if the dimensions of support relate to other individual, design, and environmental factors and to examine how they fit into the larger transfer system, as illustrated in training transfer models (Baldwin \& Ford, 1988; Holton 1996; Lim \& Morris, 2006; Nijman et al., 2009). The scope of this study also was limited to examining the influence of four specific dimensions of support (mentoring, coaching, social support, and task support) on training transfer. Other dimensions may exist that may also influence training transfer.

Finally, perceptions of training transfer were measured in this study, instead of actual training transfer. Measuring actual training transfer would require researchers to correctly evaluate participants' applications of learned knowledge and skills which would require subject matter expertise. As a result, the majority of studies conducted on training transfer have included measures of perceived training transfer, rather than actual training transfer (Chiaburu \& Lindsay, 2008; Chiaburu et al., 2010; Devos et al., 2007; GilpinJackson \& Bushe, 2006; Liebermann \& Hoffman, 2008; Lim \& Morris, 2006; Martin 2010a; Martin 2010b; Nijman et al., 2006; Van den Bossche et al., 2010; Velada et al., 2007). Measuring perceived training transfer may not be as accurate as measuring actual training transfer because participants may be tempted to falsely inflate the degree to which they transferred learned knowledge and skills. 


\section{Significance of the Study}

Organizations invest a significant amount of time and money in training programs, yet research indicates that the majority of employees do not transfer what they learned once back on the job (Baldwin \& Ford, 1988; Burke \& Hutchins, 2007; Devos et al., 2007; Georgenson, 1982). Low training transfer rates signify a poor return on investment in training programs and represent missed opportunities for performance improvement (Chiaburu et al., 2010; Yamnill \& McClean, 2001). Over the past several decades, researchers have discovered that a number of individual, training design, and environmental factors influence training transfer; however, the influence of supervisor support, and more specifically dimensions of supervisor support, is unknown. As a result, researchers have called for additional studies that identify the types or dimensions of support that influence training transfer (Chiaburu, 2010; Cromwell \& Kolb, 2004; Sookhai \& Budworth, 2010).This study provides new insights about how specific dimensions of support influence training transfer.

\section{Social Change Implications}

This study has several implications for positive social change. Specifically, it contributes to a better understanding of the support supervisors and mentors should exhibit to help employees successfully transfer learned knowledge and skills to the job. The successful transfer of learned knowledge and skills may help employees improve their job performance. Improved job performance is associated with a number of positive employee and organizational outcomes including increased job satisfaction, productivity, innovation, and quality of work (Kahya, 2008; Van Scotter, 2000). In the context of curriculum development, such outcomes may translate into more committed and 
productive employees who develop innovative, high-quality courses and degree programs that increase student learning and help students meet professional goals. Developing high-quality courses and degree programs also may contribute to the integrity, reputation, and ultimate success of the university.

\section{Summary}

Over the past several decades, researchers have attempted to determine the conditions under which successful training transfer occurs. In doing so, they found that training transfer is influenced by a number of individual, training design, and environmental factors (Burke \& Hutchins, 2007; Blume et al., 2010; Cheng \& Hampson, 2008; Cheng \& Ho, 2001). Despite the wealth of research that has been conducted, the influence of supervisor support and specific dimensions of support, on training transfer are still unknown (Chiaburu, 2010; Cromwell \& Kolb, 2004; Sookhai \& Budworth, 2010). The goal of this mixed methods study was to examine the influence of specific dimensions of support (coaching, mentoring, task support, and social support) on training transfer.

Chapter 2 includes an overview of the existing training transfer literature, the gaps and limitations of the existing literature, and the theoretical framework for this study. Chapter 3 provides an explanation of the research methodology, design, and the data collection and analysis methods that were used for this study. It also includes a description of the population from which the sample was drawn and the criteria that were used to select participants for this study. Chapter 4 contains a presentation of the results from the quantitative and qualitative portions of the study. Finally, Chapter 5 includes the major outcomes of the study based on the integration of the quantitative and qualitative 
results. It also provides a description of the limitations of the study and explanation of the implications of the findings on future research, practice, and social change. 


\section{Chapter 2: Literature Review}

\section{Introduction}

Organizations spend over a billion dollars per year on training (Patel, 2010). Despite this investment, many employees do not transfer what they learned in training once they are back on the job. For example, reported transfer rates indicate that as little as 10 to $20 \%$ of employees transfer what they learned (Baldwin \& Ford, 1988; Devos et al., 2007, Georgenson, 1982). To make matters worse, transfer rates also tend to decrease over time. Saks and Belcourt (2006) found that transfer rates decreased by 50\% approximately one year after training.

Low transfer rates pose significant problems for both organizations and employees. Organizations rely on training, and subsequent transfer of learned knowledge and skills, to improve organizational performance; stay abreast of and implement new technologies; quickly adapt to political, economic, and social changes; and remain competitive in a global economy. Employees rely on training, and subsequent transfer, to improve their performance, be innovative, and continually develop their skills and expertise (Blackler, 1995; Drucker, 1999; Martin, 2010b). Failure to transfer learned knowledge and skills jeopardizes the organization's investment in training and may result in missed opportunities to improve individual and organizational performance (Chiaburu et al., 2010; Yamnill \& McClean, 2001). Given the negative implications of low transfer rates, it important to determine why employees are not transferring learned knowledge and skills, and explore what might be done to ensure that transfer occurs. 


\section{Organization of the Chapter}

The chapter begins with a review of the research related to training transfer. The review is organized around three sets of factors that influence training transfer: individual factors (e.g., motivation, personality, etc.), training design factors (e.g., training content and instructional methods), and environmental factors (e.g., organizational culture, transfer climate, etc.). At the end of the review, the limitations of existing transfer research are described, followed by a summary of the transfer research. Finally, the theoretical framework that guided the study is described.

\section{Literature Search Strategy}

Print and electronic resources for this study were retrieved from the Walden University and Towson University libraries. The following online research databases were accessed as part of this search: PsycINFO, PsycARTICLES, Academic Search Complete/Premier, Business Source Complete/Premier, Emerald Management Journals, ProQuest Central, Psychology: a SAGE full-text collection, and Management \& Organization: a SAGE full-text collection. The initial search included the following terms: transfer, transfer of training, transfer of learning, and transfer motivation. That search yielded 60 articles. A second search was conducted and included a combination of the following terms: support, supervisor support, supervisor sanctions, supervisor feedback, transfer, transfer of training, transfer of learning, and transfer motivation. That search yielded 37 articles. The years searched in both cases primarily ranged from 2005 2012. 


\section{Training Transfer}

Training transfer is the effective and continuous application of knowledge and skills learned in training once back on the job (Baldwin \& Ford, 1988; Broad \& Newstrom, 1992). It encompasses two dimensions: generalization and maintenance (Blume et al., 2010). Generalization occurs when employees transfer learned knowledge and skills to a variety of different job settings and situations. Maintenance occurs when employees transfer learned knowledge and skills over an extended period of time.

Successfully transferring learned knowledge and skills is a complex process that is influenced by a number of factors. Transfer researchers have focused on identifying those factors that facilitate or hinder successful transfer (Blume et al., 2010; Burke \& Hutchins, 2007; Cheng \& Hampson, 2008; Salas \& Cannon-Bowers, 2001). Baldwin and Ford (1988) were among the first researchers to develop a theoretical framework for examining training transfer and the factors that influence it. The framework indicates that three broad categories of factors influence transfer: individual factors, training design factors, and work environment factors. Their seminal framework has served as the basis for numerous studies on training transfer. The following section contains a review of the research related to the influence of specific factors on training transfer.

\section{Individual Factors}

Research suggests that individual factors, such as personality traits and motivation, affect a variety of employee outcomes, including training proficiency and job performance (Barrick \& Mount, 1991; Judge \& Ilies, 2002; Kaplan, Bradley, Luchman, \& Haynes, 2009; Sackett, Gruys, \& Ellingson, 1998). Such factors also influence training transfer. The transfer research indicates that transfer motivation, personality, and self- 
efficacy, in particular, influence training transfer directly and/or indirectly (Burke \& Hutchins, 2007; Cheng \& Hampson, 2008; Cheng \& Ho, 2001; Colquitt, LePine, \& Noe, 2000).

Transfer motivation. Upon returning to the workplace after training, employees may have many opportunities to apply learned knowledge and skills; however, some may choose not to because they lack transfer motivation (Noe \& Schmidt, 1986). Transfer motivation is the degree to which individuals desire and plan to use knowledge and skills learned in training once they are back on the job (Noe, 1986; Yamkovenko, Holton, \& Bates, 2007). According to the theory of planned behavior, the stronger one's motivation or intention is to engage in a behavior, such as training transfer, the more likely he or she is to perform the behavior (Ajzen, 1991).

Recent research on transfer motivation is consistent with the theory of planned behavior, indicating that transfer motivation predicts training transfer (Chiaburu \& Lindsay; 2008; Bates et al., 2007; Devos et. al., 2007; Van den Bossche et al., 2010). For instance, Lieberman and Hoffman (2008) surveyed bank employees following their participation in a customer service training program and found that those who reported high levels of transfer motivation were more likely to transfer learned knowledge and skills one to three months after training compared to those who reported low levels of transfer motivation. Similarly, Axtell, Maitlis, and Yearta (1997) found that employees who reported the highest levels of transfer motivation had the greatest sustained transfer approximately one year after training.

Personality. In addition to transfer motivation, specific personality traits influence training transfer (Blume et al., 2010; Burke \& Hutchins, 2007; Cheng \& 
Hampson, 2008; Cheng \& Ho, 2001; Colquitt et al., 2000; Tziner, Risher, Senior, \& Weisberg, 2007). For example, Blume et al. and Tziner et al. found that employees who score high on conscientiousness are more likely to successfully transfer learned knowledge and skills once back on the job. Conscientiousness is a broad personality trait that encompasses several characteristics, such as being dependable, responsible, hardworking, and persistent (Colquitt et al., 2000; Tziner et al., 2007). Persistence may be particularly important for transfer, especially when employees must repeatedly practice applying learned knowledge and skills during and after training.

Locus of control, the degree to which individuals believe they can control life circumstances, also influences training transfer; however, it is unclear whether an internal or external locus of control is more effective (Burke \& Hutchins, 2007). Colquitt et al. (2000) conducted a meta-analysis on antecedents of training outcomes and found that trainees with an external locus of control, characterized by the belief that outcomes are the result of an external source rather than an individual's own actions, were more likely to transfer learned knowledge and skills compared to trainees with an internal locus of control. Conversely, Cheng and Ho (2001) reviewed 10 years of transfer research and found that trainees with an internal locus of control are more likely to transfer learned knowledge and skills. Cheng and Ho's (2001) findings are more consistent with other organizational research which suggests that an internal locus of control produces more favorable work outcomes, such as better job performance (Chen \& Silverthorne, 2008; Judge \& Bono, 2001; Ng, Sorensen, \& Eby, 2006). This may be because individuals with an internal locus of control tend to be more motivated and more confident in their 
abilities to achieve desired outcomes than individuals with an external locus of control (Ng et al., 2006).

Specific personality traits also influence transfer motivation (Machin \& Fogarty, 2004; Nacquin \& Holton, 2002; Rowold, 2007; Yamkovenko \& Holton, 2010). For instance, Nacquin and Holton (2002) found that extraversion is a significant predictor of transfer motivation. Extraverts may be more motivated to participate in transfer activities compared to introverts, especially if such activities require group work and interaction with others (Nacquin \& Holton, 2002). In addition, Rowold found that emotional stability influences transfer motivation. Emotionally stable individuals tend to be calmer and better able to handle stress, which may foster motivation to engage in transfer behaviors that may be unfamiliar and/or challenging (Nacquin \& Holton, 2002). Finally, Yamkovenko and Holton (2010) found there was a significant relationship between conscientiousness and transfer motivation.

Self-efficacy. Another individual factor that has emerged in the transfer literature is self-efficacy. Self-efficacy is defined as "people's judgments of their capabilities to organize and execute courses of action required to attain designated types of performances" (Bandura, 1986, p. 391). Individuals with high self-efficacy are more likely to adopt goals and persist in achieving goals (Pugh \& Bergin, 2006). They also are more likely to put forth the effort required to adopt and apply new behaviors, which is necessary for successful transfer (Noe, 1986).

The research findings regarding the influence of self-efficacy on training transfer are mixed (Chiaburu \& Lindsay, 2008; Devos et al., 2007; Pugh \& Bergin, 2006; Tziner et al., 2007; Velada et al., 2007). This may be because researchers used different 
measures of self-efficacy, such as performance self-efficacy and training self-efficacy. Velada et al. (2007) examined the influence of performance self-efficacy on training transfer. Performance self-efficacy is the degree to which an individual believes that he or she can improve his or her performance when desired (Holton, Bates, \& Ruona, 2000). Velada and colleagues found that performance self-efficacy is a significant predictor of training transfer, confirming that the more confident employees are in their ability to improve their performance, the more likely they are to transfer learned knowledge and skills.

Chiaburu and Lindsay (2008) examined the influence of training self-efficacy on training transfer. Training self-efficacy is one's beliefs about his or her capabilities to succeed in training (Al-Eisa, Furayyan, \& Alhemound, 2008). Chiaburu and Lindsay (2008) found that training self-efficacy did not predict training transfer; rather it influenced training transfer indirectly through transfer motivation. Similarly Al-Eisa and colleagues found that training self-efficacy was a significant predictor of transfer motivation. These results suggest that the more confident an employee is in his or her abilities to succeed in training, the more motivated he or she will be to learn new skills in training and apply them once back on the job.

\section{Training Design Factors}

According to Holton (1996), the design of training programs may prevent, rather than facilitate, training transfer. For instance, programs that focus on knowledge or skill acquisition alone are not sufficient for transfer. In order for transfer to occur, employees must be taught how newly learned knowledge and skills relate to their job and, if possible, be given opportunities to practice applying what they learned within a job 
context (Holton, 1996). There are two areas of research regarding the influence of training design on transfer. The first area focuses on the influence of training design, as a general construct, on transfer. The second area focuses on the independent influence of two factors related to training design: training content and instructional methods. Next is a review of the literature regarding the influence of training design on training transfer, followed by the influence of training content and instructional methods on training transfer.

Training Design. Training design, often referred to in the literature as transfer design, refers to the degree to which training provides instruction on how to transfer learned knowledge and skills to the job (Holton, 1996). Research confirms that training design directly influences training transfer (Devos et al., 2007; Velada et al., 2007); that is, when employees understand how to use learned knowledge and skills once back on the job, they are more likely to engage in successful transfer (Velada et al., 2007). Training design also influences transfer motivation and performance self-efficacy (Kirwan \& Birchall, 2006). This suggests that when employees understand how to apply learned knowledge and skills within in a job context, they are more motivated and confident in their abilities to do so (Bhatti \& Kaur, 2010).

Training content. In addition to examining the general influence of training design on transfer, researchers also have begun to focus attention on how the relevance of training content influences transfer (Bates et al., 2007; Devos et al., 2007; Kirwan \& Birchall, 2006; Liebermann \& Hoffman, 2009; Nikandrou et al., 2009). For instance, Bates et al. (2007) found that training content validity, defined as the extent to which training content reflects job requirements, is a significant predictor of training transfer. 
This finding is consistent with what would be predicted from identical elements theory which suggests that the greater the similarity between trainings tasks and job tasks, the more likely successful transfer will occur (Baldwin \& Ford, 1988; Thorndike \&Woodworth, 1901).

Training content also influences transfer motivation (Gegenfurtner, Veermans, Festner, \& Gruber, 2010; Kirwan \& Birchall, 2006; Nikandrou et al., 2009). For instance, Nikandrou et al. (2009) suggested that employees who perceive that training content is related to their jobs, and therefore may help them improve their performance and achieve career goals, are more likely to be motivated to transfer. The findings regarding the influence of training content on transfer motivation are consistent with the expectancy theory of motivation. This theory suggests that employees are more likely to be motivated to engage in a specific behavior, such as training transfer, if they believe that doing so will help them achieve desired results, for example, improved job performance, a promotion, increase in pay, etc. (Noe, 1986; Vroom, 1964).

Instructional methods. In addition to the relevance of training content, the methods trainers use to deliver content also influences transfer (Bell \& Kozlowski, 2008; Burke \& Hutchins, 2007; Keith et al., 2010; Keith \& Frese, 2008). Two methods in particular have received attention in recent transfer research. The first is active training. Active training, also referred to as exploratory training, is based on the premise that learners should be active, rather than passive, participants in the learning process. That is, they should explore and experiment with training content and tasks with very little direction from trainers (Keith et al., 2010). This method contrasts with the traditional guided training approach in which the trainer provides all necessary information to 
learners about training content, including detailed instructions for how to complete training tasks. Research indicates that active training positively influences training transfer, particularly when employees are required to apply learned knowledge and skills to new situations, tasks, and/or problems not covered in training (Bell \& Kozlowski, 2008; Keith et al., 2010).

The other method that has been linked to training transfer in recent research is error management training (EMT). EMT falls under the umbrella of active training and encourages learners to make errors as they explore and experiment with training content (Keith \& Frese, 2008). Supporters of EMT argue that making errors, and then receiving feedback on such errors, leads to increased learning (Keith \& Frese, 2005). In a metaanalysis on the effectiveness of EMT, Keith and Frese (2008) found that EMT led to greater training transfer compared to instructional methods that discouraged employees from making errors and that provided detailed instructions about how to complete tasks. Keith and Frese (2005) suggested that EMT may be more effective than other more traditional instructional methods because it requires employees to continuously monitor and evaluate their approaches for completing tasks and develop and adapt solutions for solving problems. Continuously monitoring one's correct application of learned knowledge and skills is particularly useful for successful training transfer (Keith \& Frese, 2005).

\section{Environmental Factors}

In their seminal article on training transfer, Baldwin and Ford (1988) called for more research on environmental factors that influence transfer. Other researchers echoed this request, stating that transfer should be studied from a systems perspective (Rouiller 
\& Goldstein, 1993; Salas \& Cannon-Bowers, 2001). Since then, researchers have conducted extensive research on the influence of environmental factors on training transfer (Burke \& Hutchins, 2007). Two overarching environmental factors emerged as influencers of training transfer: organizational culture and transfer climate.

Organizational culture. Organizational culture is a pattern of shared assumptions, attitudes, beliefs, and values of an organization, developed over time, that influence how members of the organization perceive, think, and feel (Egan, 2008; Schein, 1990). According to Elangovan and Karakowsy (1999), an organizational culture that fosters employee development and intellectual advancement, and encourages employees to be innovative, will positively influence training transfer. The research supports this assertion. For instance, Gilpin-Jackson and Busche (2006) and Nikandrou et al. (2009) found that organizational culture may facilitate or hinder transfer, depending on whether the culture is supportive of training initiatives and new ways of working. Specifically, they found that participants were less likely to transfer learned knowledge and skills if they believed they would be ridiculed or encounter disapproval for doing so (GilpinJackson \& Busche, 2006).

Researchers also found that specific types of organizational cultures and subcultures influence training transfer (Egan, 2008; Tracey, Tannenbaum, \& Kavanagh, 1995). For instance, Tracey et al. (1995) found that a continuous-learning culture, one in which members share perceptions that learning is important, positively influences training transfer. In addition, Egan (2008) found that specific subcultures influence transfer motivation. According to Hofstede (1998), there may be several subcultures in an organization, in which a subset of employees share a common set of assumptions, 
attitudes, beliefs, and values that are distinct from those in the organizational culture. Egan (2008) found that innovative subcultures, characterized by experimentation and entrepreneurialism, and supportive subcultures, characterized by collaboration and encouragement, positively influence transfer motivation. He also found that bureaucratic subcultures, characterized by rules, compliance, and formality, prevent transfer motivation.

Transfer climate. Transfer climate, sometimes referred to organizational climate in the literature, is one's perceptions of various features of the work environment, such as supervisor support, peer support, and the degree to which there are opportunities to use learned knowledge and skills once back on the job (Denison, 1996; Holton, Bates, Seyler, \& Carvalho, 1997). While the terms climate and culture often have been used interchangeably in the literature, there are marked differences between them. Transfer climate reflects individual perceptions of the work environment at a single in point in time. These perceptions are malleable and subject to change. Conversely, organizational culture reflects a set of shared norms that have evolved over time and are relatively stable (Denison, 1996).

Transfer climate mediates the relationship between the larger organizational context and employee attitudes (Holton et al., 2000). Some researchers have examined the influence of transfer climate as a unidimensional construct that subsumes several dimensions of the work environment, such as supervisor and peer support (Lim \& Morris, 2006; Martin, 2010b; Nijman, Nijhof, Wognum, \& Veldkamp, 2006; Sookhai \& Budworth, 2010; Tziner et. al., 2007). Other researchers have examined the independent influence of specific dimensions of transfer climate on training transfer (Al-Eisa et. al., 
2008; Austin et al., 2006; Chiaburu et al., 2010; Gilpin-Jackson \& Bushe, 2006;

Liebermann \& Hoffman, 2008; Saks \& Belcourt, 2006; Van den Bosshe et. al., 2010;

Velada et. al., 2007). The next review begins with the literature regarding transfer climate as a unidimensional construct followed by a review of the literature regarding specific dimensions of transfer climate.

Rouiller and Goldstein (1993) were the first researchers to clearly define and operationalize transfer climate. They defined transfer climate as a series of situational cues and consequences that either facilitate or inhibit training transfer. Situational cues (e.g., observing co-workers using learned knowledge and skills, etc.) remind trainees to apply what they learned in training while on the job. Consequences (e.g., positive and negative feedback, punishment, etc.) encourage or discourage trainees' use of learned knowledge and skills.

Numerous research studies have included Rouiller and Goldstein's (1993) transfer climate measure but have yielded inconsistent results (Machin \& Fogarty, 2004; Roberson, Kulik, \& Pepper, 2009; Tracey et al., 1995). This may be because the transfer climate measure lacked construct validity. For example, Holton et al., (1997) found that situational cues do not accurately reflect transfer climate. Instead, they found that organizational referents, such as supervisor and peer support, more accurately reflect transfer climate. More recently developed transfer climate measures include such referents (Lim \& Morris, 2006; Smith-Jentsch, Salas, Brannick, 2001; Tracey \& Tews, 2005).

Recent research studies on transfer climate have yielded consistent results, indicating that transfer climate directly influences training transfer (Lim \& Morris, 2006; 
Martin, 2010b; Nijman et. al., 2006; Sookhai \& Budworth, 2010). While each study used a different measure of transfer climate, all included items that assessed the degree to which supervisors and/or peers were supportive of trainees' transferring learned knowledge and skills. This suggests that employees in a supportive transfer climate are more likely to transfer. Only one recent study on transfer climate indicates that it influences motivation to learn. Motivation to learn is the extent to which trainees intend to invest effort in a training program (Tziner et. al., 2007).

Opportunity to use. One of the dimensions of transfer climate is opportunity to use, which refers to the degree to which employees are assigned tasks that allow them to apply what they learned in training (Holton et al., 2000). Opportunity to use influences training transfer (Devos et al., 2007; Gilpin-Jackson \& Busche, 2006; Holton, 2005; Holton et al., 2000) and transfer motivation (Kirwan \& Birchall, 2006). When employees do not have opportunities to use learned knowledge and skills, skill decay may occur, making training transfer difficult and unlikely. For instance, Arthur, Bennet, Stanush, and McNelly (1998) found in a meta-analysis that the length of time between training and the opportunity to use learned knowledge and skills has a significant influence on skill decay. The authors noted that skill decay begins immediately after training and the more time that elapses between the acquisition of knowledge or a skill and the opportunity to use, the more likely that skill decay will occur. As a result, Lim and Johnson (2002) suggested that supervisors assign employees tasks that require the application of learned knowledge and skills soon after training to prevent skill decay and increase the likelihood of transfer.

Peer support. Another dimension of transfer climate is peer support, which refers to the degree to which peers reinforce and support employee use of knowledge and skills 
learned in training once they are back on the job (Holton et al., 2000). Research findings indicate that peer support influences training transfer (Hawley \& Barnard, 2005; GilpinJackson-Busche, 2006; Martin, 2010a; Martin, 2010b) and transfer motivation (Kirwan \& Birchall, 2006). Peer support also can mitigate the negative effects of an unfavorable transfer climate. For instance, Martin (2010b) found that participants who had high peer support and worked in an unfavorable transfer climate had higher levels of transfer compared to participants who had low peer support and worked in an unfavorable transfer climate.

Supervisor support. The most widely studied dimension of transfer climate is supervisor support (Burke \& Hutchins, 2007). Supervisor support refers to "the extent to which supervisors support and reinforce the use of training on the job" (Holton et al., 2000, p. 345). Despite the abundance of research on supervisor support, its relationship to training transfer is still unclear. Some studies suggest that supervisor support influences training transfer directly (Austin, Weisner, Schrandt, Glezos-Bell, \& Murtaza, 2006; Gilpin-Jackson \& Busche, 2006; Saks \& Belcourt, 2006). Other studies suggest that it influences training transfer indirectly (Chiaburu et al., 2010; Nijman et al., 2006) or not at all (Devos et al., 2007; Velada, Caetano, Michel, Lyons, \& Kavanagh, 2007).

Supervisors play an important role in transfer process (Martin, 2010a). They can ease employees' anxiety regarding training and increase the likelihood that they transfer learned knowledge and skills by openly supporting training initiatives and by encouraging them to apply what they learned in training. For instance, Austin et al. (2006) found that employees were more likely to transfer when they had supervisors who supported training initiatives and helped them identify barriers to transfer. Other research 
indicates that supervisor support influences transfer motivation (Al-Eisa et al., 2008; Chiaburu et al., 2010; Nijman et al., 2006). This suggests that supervisors influence how trainees feel about transferring learned knowledge and skills as well as the amount of effort they plan to put forth to do so.

While many studies suggest that supervisor support influences training transfer or transfer motivation, some studies suggest that there is no relationship between supervisor support and transfer (Devos et al., 2007; Liebermann \& Hoffman, 2008; Velada et al., 2007). These findings are contradictory to other organizational research that suggests that supervisor support influences employee attitudes, thoughts, and behaviors. For instance, studies have confirmed that supervisor support influences job satisfaction $(\mathrm{Ng} \&$ Sorensen, 2008), turnover cognitions (Maertz, Griffeth, Campbell, \& Allen, 2007), organizational citizenship behaviors (Chen \& Chiu, 2008), and job performance (Pazy \& Ganzach, 2009).

\section{Limitations of Existing Transfer Research}

The existing transfer research indicates that a multitude of factors may facilitate or hinder the degree to which employees successfully transfer learned knowledge and skills once they are back on the job. While the transfer research provides important insights about the conditions under which transfer occurs, there are several limitations of the research that threaten the validity of the findings. The following sections provide an examination of the negative influence of rating sources, common method variance, and time of transfer assessment on existing transfer findings.

Rating sources. Transfer researchers have relied on a number of rating sources to assess training transfer. Such sources include trainees (self-report), supervisors, peers, 
and subordinates (Taylor, Russ-Eft, \& Taylor, 2009). While some transfer researchers are beginning to use more than one rating source to assess training transfer (Austin et al., 2006; Gilipin-Jackson \& Busche, 2006; Martin 2010a ; Nijman et al., 2006), many are still relying on self-report ratings alone (Chiaburu et al., 2010; Chiaburu \& Lindsay, 2008; Chiaburu \& Marinova, 2005; Chiaburu \& Tekleab, 2005; Devos et al., 2007; Liebermann \& Hoffman, 2009; Lim \& Morris, 2006; Van den Bossche et al., 2010; Velada et al., 2007). This is problematic because self-report ratings may be biased. For instance, trainees may be more inclined than other raters to falsely report successful training transfer because they think they will be viewed more favorably. This is referred to as the social desirability problem (Podsakoff \& Organ, 1986).

Research shows that self-report ratings yield the largest training transfer effects compared to ratings from supervisors, peers, and subordinates (Taylor et al., 2009). For instance, Blume et al. (2010) found that studies that used self-report ratings of transfer reported stronger relationships between predictor variables and transfer than studies that used other or multiple ratings of transfer. Such findings may lead researchers and practitioners to falsely believe that there is a stronger relationship between predictor variables and transfer than one exists. To avoid the bias associated with self-report ratings of transfer, future research should include more than one rating source of training transfer (Taylor et al., 2009).

Common method variance. Another limitation of existing transfer research is the presence of common method variance. Common method variance (CMV) occurs when the relationship between variables is inflated or deflated because of the method used to assess the variables (Spector \& Brannick, 2009). CMV is problematic because it can lead 
researchers to believe that there is a relationship between variables when one does not exist (Type I error) or that there is not a relationship between variables when one does exist (Type II error) (Podsakoff, MacKenzie, Lee, \& Podsakoff, 2003). Podsakoff and colleagues found that CMV significantly inflated the strength of the relationships between variables in several studies. Specifically, they noted that the variance was 35\% when CMV was present and $11 \%$ when it was not present.

While there are many sources of CMV, there are two that pose the biggest threats to existing transfer research (Blume et al., 2010). The first is called single-source bias, also referred to as common rater effects. Single-source (SS) bias occurs when inflated or deflated relationships between variables are the result of using a single or common source to assess variables. For instance, in a study on the influence of transfer climate on training transfer, researchers may decide to survey trainees on their perceptions of transfer climate and their perceptions about degree to which they transferred learned knowledge and skills. If the trainees believe that there is a relationship between transfer climate and training transfer (referred to as illusory correlations), they may respond to items in the survey accordingly, despite whether or not they actually transferred learned knowledge and skills (Podsakoff et al., 2003). After reviewing the responses, researchers may believe that there is a stronger relationship between transfer climate and training transfer than one exists.

The second source of CMV that poses a threat to existing transfer research is called same-measurement-context (SMC) bias (Blume et al., 2010). SMC bias occurs when predictor and criterion variables are measured at the same point in time. Like SS bias, SMC bias may also lead to illusory correlations in which participants form beliefs 
about the relationships between predictor and criterion variables and respond to survey items based on this belief, whether or not it is consistent with the truth (Podsakoff et al., 2003).

$\mathrm{SS} / \mathrm{SMC}$ bias inflated the relationships between predictor variables and training transfer in 89 studies by approximately .20 to .30 (Blume et al., 2010). For instance, the correlation between transfer motivation and transfer when SS/SMC bias was not present was .23; however, when SS/SMC bias was present, the correlation increased to .41. To avoid SS/SMC bias in the future, researchers should measure variables at different times, using different sources (Podsakoff et al., 2003). They also should use at least two methods to measure each variable (Campbell \& Fiske, 1959). Using a mixed method approach to researching transfer may be one way to do this. Burke and Hutchins (2007) argued that more transfer researchers should use both qualitative methods, such as focus group and in-depth interviews, and quantitative methods, such as surveys, which would allow for triangulation of data.

Time of transfer assessment. In addition to rating sources and CMV, the point in time at which transfer is assessed also may pose threats to the validity of existing transfer research (Blume et al., 2010). The time at which transfer has been assessed in studies ranges from a few weeks or months after training (Bates et al., 2007; Chiaburu et al., 2010; Chiaburu \& Marinova, 2005; Chiaburu \& Tekleab, 2005; Devos et al., 2007; Lieberman \& Hoffman, 2008; Martin 2010a; Martin 2010b; Tziner et al., 2007; Velada et al., 2007) to a year or more after training (Axtell et al., 1997; Chiaburu \& Lindsay, 2008). Studies in which transfer was assessed shortly after training produced greater transfer effects compared to those in which there was a time lag (Blume et al., 2010). As the time 
between the training and the assessment of transfer increased, training transfer decreased. These findings are consistent with other research that suggests that transfer decreases over time (Saks \& Belcourt, 2006).

To avoid inflated transfer effects as the result of assessing transfer too soon after training, future transfer studies should include a time lag between training and the transfer assessment. Including a time lag also will provide employees with ample time to apply learned knowledge and skills and it will help researchers determine whether or not transfer maintenance has occurred. Transfer maintenance refers to the length of time in which employees continue to use learned knowledge and skills while on the job (Baldwin \& Ford, 1988). Organizations will receive the most return on their investment in training if employees continue to use what they learned in training on the job, over an extended period of time.

\section{Summary of Transfer Research}

Given the limitations of the existing transfer research, researchers and practitioners should be cautious about making conclusions about the strength of the relationships between predictor variables and transfer (Blume et al., 2010). The existing transfer research suggests that a number of individual, training design, and environmental factors influence training transfer and/or transfer motivation. For instance, research suggests that transfer motivation (Bates et al., 2007; Chiaburu \& Lindsay; 2008; Lieberman \& Hoffman, 2008; Van den Bossche et al., 2010), performance self-efficacy (Devos et al., 2007; Velada et al., 2007), opportunity to use (Devos et al., 2007; Holton et al., 2000; Holton, 2005), active training (Bell \& Kozlowski, 2007; Keith et al., 2010), error-management training (Keith \& Frese, 2005; Keith \& Frese, 2008), organizational 
culture (Gilpin-Jackson \& Busche, 2006; Nikandrou et al., 2009) and transfer climate (Lim \& Morris, 2006; Martin, 2010b; Nijman et. al., 2006; Sookhai \& Budworth, 2010) influence training transfer. The research also suggests that extraversion (Nacquin \& Holton, 2002), conscientiousness (Colquitt et al., 2000; Tziner et al., 2007), emotional stability (Machin \& Fogarty, 2004; Rowold, 2007), training self-efficacy (Al-Eisa et al., 2008; Chiaburu \& Lindsay, 2008), and organizational subcultures (Egan, 2008) influence transfer motivation. Finally, the research suggests that training design (Devos et al., 2007; Kirwan \& Birchall, 2006; Velada et al., 2007), training content (Bates et al., 2007;

Gegenfurtner et al., 2010; Nikandrou et al., 2009), and peer support (Hawley \& Barnard, 2005; Kirwan \& Burchall, 2006; Martin, 2010a; Martin, 2010b) influences both training transfer and transfer motivation.

While many studies suggest that one's environment may facilitate or hinder successful transfer (Burke \& Hutchins, 2007; Cheng \& Hampson, 2008; Egan, 2008; Lim \& Morris, 2006; Martin, 2010a; Martin, 2010b; Sookhai \& Budworth, 2010), it is still unclear to what degree supervisor support influences training transfer, if at all. Some studies suggest that it influences training transfer (Austin et al., 2006; Gilpin-Jackson \& Busche, 2006; Saks \& Belcourt, 2006) and transfer motivation (Al-Eisa et al., 2008; Chiaburu et al., 2010). Other studies suggest supervisor support does not transfer influence transfer at all (Devos et al., 2007; Velada et al., 2007).

The inconsistent findings on the influence of supervisor support may be the result of how supervisor support was conceptualized and measured in existing studies. For instance, supervisor support was conceptualized and measured as an all-encompassing, unidimensional construct (Al-Eisa et al., 2008; Chiaburu et al., 2010; Devos et al., 2007; 
Liebermann \& Hoffman, 2008; Nijman et al., 2006; Saks \& Belcourt, 2006; Velada et al., 2007) rather than a multidimensional construct. Despite the call for research on how specific dimensions of support influence training transfer (Cromwell \& Kolb, 2004; Egan, 2008; Sookhai \& Budworth, 2010), no studies to date answer this call. In addition, there are no studies that use mixed methods research to address the limitations of single source bias and common method variance associated with the existing transfer research.

In this study, these gaps in the research were addressed. Specifically, a mixed methods sequential explanatory design was used to examine the influence of specific dimensions of support (coaching, mentoring, task support, and social support) on transfer motivation and training transfer. Survey research was conducted in the first phase of the study, via correlation methods, to examine the relationship between the dimensions of support and training transfer. Bootstrapping methods were conducted to determine if transfer motivation mediates the relationships between the dimensions of support and training transfer. Phenomenological research was conducted in the second phase of this study to explore employees' experiences of support. Pattern coding, memoing, and mapping were used to identify themes among employees' experiences. A more detailed account of the methodology, research design, setting and sample, and data collection and analysis procedures is included in Chapter 3.

\section{Theoretical Framework}

\section{Organizational Support Theory}

As discussed in Chapter 1, organizational support theory suggests that employees develop perceptions about the degree to which the organization is concerned for their welfare, values and recognizes their contributions, and rewards their work efforts, all of 
which contribute to their overall perception of organizational support (Eisenberger et al., 1986; Eisenberger et al., 2002). When employees perceive that the organization is supportive, they are more likely to feel obligated to engage in behaviors that help the organization reach its goals (Eisenberger, Armeli, Rexwinkey, Lynch, \& Rhoades 2002; Rhoades \& Eisenberger, 2002). This is consistent with the norm of reciprocity which indicates that when people are treated favorably they will reciprocate the favorable treatment (Gouldner, 1960). Perceived organizational support is related to a number of positive work outcomes. For instance, research indicates that employees who perceive that the organization is supportive have higher levels of organizational commitment, job satisfaction, job involvement, and job performance (Rhodes \& Eisenberger, 2002; Riggle et al., 2009).

One of the strongest predictors of perceived organizational support is perceived supervisor support (DeConinck \& Johnson 2009; Eisenberger et al., 2002; Maertz et al., 2007; Pazy \& Ganzach, 2008; Rhodes \& Eisenberger, 2002; Shanock \& Eisenberger, 2006). This may be because employees tend to view agents of the organization, such as supervisors, as a personification of the organization itself (Levinson, 1965). Therefore, employees are likely to view supervisor support as a derivative of organizational support, rather than of supervisors' personal motives or inclinations (Eisenberger et al., 2002; Shanock \& Eisenberger, 2006). Similar to perceived organizational support, perceived supervisor support is positively related to favorable work outcomes, such as job performance (Pazy \& Ganzach, 2008), organizational commitment (Ng \& Sorensen, 2008), decreased turnover (Maertz et al.), and organizational citizenship behaviors (Chen \& Chiu, 2008), 
In the context of training transfer, organizational support theory suggests that employees who perceive that their supervisors are supportive are more likely to perceive that the organization is supportive (Eisenberger et al., 1986). As a result, they are more likely to feel obligated to reciprocate by engaging in behaviors that ultimately benefit the organization. One such behavior is training transfer. Transferring learned knowledge and skills once back on the job may help employees improve their performance and ultimately help the organization meet its goals (Holton, 1996; Holton, 2005). This assumption aligns with current research that confirms that both perceived organizational support and perceived supervisor support predict greater job performance (Pazy \& Ganzach, 2008; Rhodes \& Eisenberger, 2002; Riggle, Edmonson, \& Hansen, 2009).

\section{Theory of Planned Behavior}

The theory of planned behavior suggests that the stronger one's intention to perform a specific behavior, the more likely he or she is to perform that behavior. Intentions encompass motivational factors and indicate how much effort one is willing to put forth to perform a behavior (Ajzen, 1991). Intentions are influenced by three factors: attitudes towards the behavior, perceptions of behavioral control, and subjective norms (Arnold et al., 2006; Rise et al., 2010; Rivis et al., 2009; White et al., 2009). An attitude toward a behavior refers to the degree to which one feels favorably about the behavior. Perceptions of behavior control refer to the degree to which one believes that the behavior will be easy or difficult to perform. Such perceptions are based on one's past experience performing the behavior, available resources that may aid him or her in performing the behavior, and obstacles or barriers related to performing the behavior. Subjective norms refer to social pressure to perform the behavior. Subjective norms are 
influenced by the degree to which referent individuals approve or disapprove of the behavior (Ajzen, 1991).

There is strong empirical support for the theory of planned behavior. Research findings indicate that motivation predicts a wide variety of behaviors, including but not limited to alcohol consumption (Elliot \& Ainsworth, 2012; Huchting, Lac, \& LaBrie, 2008), reckless driving (Elliott, Armitage, \& Baughan, 2007), academic misconduct (Stone, Jawahar, \& Kisamore, 2009), physical activity (Rhodes, Blanchard, \& Matheson, 2006), and healthy eating (Murnaghan, Blanchard, Rodgers, LaRosa, MacQuarrie, MacLellan, \& Gray, 2010). To date, however, no research has examined the validity theory of planned behavior as it relates to transfer motivation and training transfer. Cheng and Hampson (2008) suggested that the theory of planned behavior may help researchers and practitioners gain a better understanding of training transfer and the factors that influence it.

The theory of planned behavior may help explain how supervisor support influences transfer motivation. By displaying supportive behaviors, such as mentoring and coaching, following employee participation in training, supervisors may positively influence how employees feel about transferring learned knowledge and skills (attitudes) and the extent to which they feel they have the resources necessary to succeed in transferring learned knowledge and skills (perceived behavioral control). Supervisors may also signal to employees, through supportive behaviors, that transferring learned knowledge and skills is important (subjective norms). An employee's attitudes about transfer, perceptions of behavior control, and interpretation of subjective norms may, in 
turn, influence his or her motivation to transfer and ultimately whether or not he or she actually attempts to transfer learned knowledge and skills (Ajzen, 1991).

\section{Summary}

The research on training transfer and the factors that influence it has increased steadily in the past several decades. Research findings suggest that a number of individual, training design, and environmental factors facilitate or hinder training transfer (Blume et al., 2010; Burke \& Hutchins, 2007; Cheng \& Hampson, 2008). While supervisor support has been studied extensively, its influence on training transfer is still unknown. Existing studies have produced inconclusive evidence regarding if and how supervisor support influences training transfer. Furthermore, none of the studies assessed supervisor support as a multidimensional construct (Al-Eisa et al., 2008; Chiaburu et al., 2010; Devos et al., 2007; Liebermann \& Hoffman, 2008; Nijman et al., 2006; Saks \& Belcourt, 2006; Velada et al., 2007). Therefore, the influence of specific dimensions or types of supervisor support on training transfer is still unknown. The primary purpose of this study was to address these gaps in research by examining the relationship between specific dimensions of supervisor support (mentoring, coaching, social support, and task support) and training transfer and to determine if transfer motivation mediates these relationships.

In Chapter 3, the setting and sample for study are described and the research methods that were used to conduct the study are explained. In Chapter 4, the quantitative and qualitative findings are presented. Finally, in Chapter 5, the quantitative and qualitative findings are integrated and the major outcomes of the study are discussed in the context of existing research. 
Chapter 3: Research Method

\section{Introduction}

Despite the widespread attention supervisor support has received in the transfer literature, its influence on transfer motivation and training transfer is still unclear (Blume et al., 2010; Burke \& Hutchins, 2007). One reason may be because supervisor support has been conceptualized and measured as an all-encompassing, unidimensional construct (AlEisa et al., 2008; Chiaburu et al., 2010; Devos et al., 2007; Liebermann \& Hoffman, 2008; Nijman et al., 2006; Saks \& Belcourt, 2006; Velada et al., 2007) rather than a multidimensional construct. In this study, the influence of specific dimensions of supervisor support (mentoring, coaching, social support, and task support) on training transfer was examined.

This chapter is organized into four sections. The first section includes a description of the research methodology, research design, and setting and sample that were used in this study. The second section includes an explanation of how the quantitative portion of this study was conducted. The third section contains a description

of the qualitative methods. The fourth section includes an explanation of how the quantitative and qualitative results were integrated. The fifth section provides a description of ethical considerations related to this study.

\section{Research Methodology}

In this study, a mixed methods research design was used. Mixed methods research is "a type of research in which a researcher or team of researchers combines elements of qualitative and quantitative research approaches (e.g., use of qualitative and quantitative viewpoints, data collection, analysis, inference techniques) for the broad purposes of 
breadth and depth of understanding and corroboration" (Johnson, Onwuegbuzie, \& Turner, 2007, p. 123). Conducting mixed methods research has several advantages compared to conducting quantitative or qualitative research alone, many of which are particularly significant to this study. First, mixed methods research allows for a more complete understanding of complex phenomena. Second, it allows the researcher to compensate for the weaknesses of one method with the strengths of another. For instance, qualitative data can help explain, clarify, and provide meaning to quantitative data.

Similarly, quantitative data can limit the influence of confounding variables and increase the generalizability of results. Third, mixed methods research can add to the credibility and validity of findings through the corroboration of qualitative and quantitative findings and by reducing bias related to using one type of methodology (Bryman, 2006; Johnson \& Onwuegbuzie, 2004; Kelle, 2006).

\section{Research Design}

A sequential explanatory research design was employed in this study.

Quantitative data were collected and analyzed during the first phase of research and qualitative data were collected and analyzed during the second phase of research. In the third phase of research, quantitative and qualitative findings were integrated to determine the major outcomes of the study. During the quantitative portion of the study, survey research was used. Survey research is useful for measuring attitudes, perceptions, and behaviors (Fowler, 2009; Nardi, 2003) and has been used widely to measure training transfer and its antecedents (Al-Eisa et al., 2008; Chiaburu \& Lindsay, 2008; Chiaburu et al., 2010; Devos et al., 2007; Egan, 2008; Lieberman \& Hoffman, 2008; Lim \& Morris, 2006; Martin, 2010b; Nijman et al., 2006; Tziner et al., 2007; Velada et al., 2007). 
During the qualitative portion of the study, phenomenology was used.

Phenomenology is the study of human experiences regarding specific concepts or phenomena (Creswell, 1998; Sanders, 1982). It requires the researcher to uncover the structure and essence of described experiences through intuition, self-reflection, and interpretation, and without judgment and supposition (Moustakas, 1994). Phenomenology was appropriate for this study because it allowed for a better understanding of mentees' experiences of support and training transfer which helped to clarify the role of support in the transfer process. Much of the existing transfer research has taken a quantitative approach, therefore, little is known about individuals' experiences of support and to what degree, if any, their experiences influence transfer motivation and training transfer (Blume et al., 2010; Burke \& Hutchins, 2007).

The participant selection model, a variation of the sequential explanatory design, also was used in this study. This model allows for the purposeful selection of participants for the qualitative portion of this study, based on the quantitative results (Creswell \& Plano Clark, 2007). In this study, the survey results were examined to identify mentees with the highest support, transfer motivation, and training transfer scores. These mentees were invited to participate in structured open-ended interviews during the qualitative portion of the study.

The mixed methods sequential explanatory design was appropriate for this study for several reasons. First, it allowed for the purposeful selection of participants for the qualitative portion of the study so that experiences of support and training transfer could be better understood. Second, it increased the creditability and validity of findings and prevented single-source (SS) bias because two different measurement methods were used 
and two different types of data were collected (Bryman, 2006; Jick, 1979; Johnson \& Onwuegbuzie, 2004). This is particularly important given that existing research on the influence of support on training transfer is inconclusive and relies on either quantitative or qualitative data alone (A1-Eisa et al., 2008; Chiaburu et al., 2010; Devos et al., 2007; Liebermann \& Hoffman, 2008; Nijman et al., 2006; Saks \& Belcourt, 2006; Velada et al., 2007).

\section{Setting and Sample}

This study was conducted at a large educational organization located in the MidAtlantic region of the United States. Employees who developed curriculum for this organization and participated in formal and/or informal new hire training were asked to participate. Such employees are referred to as mentees. In addition, employees in leadership roles, who were responsible for conducting informal on-the-job training with mentees, were also asked to participate. These employees are referred to as mentors. Written permission to collect data in the curriculum development department of the organization was granted from the vice president of the department, the executive director training and development, and the executive director in the Human Resources department. In addition, IRB approval was granted (03-09-12-0024334) prior to data collection and analysis.

\section{Sampling Methods}

For the quantitative portion of this study, convenience sampling was used. Convenience sampling entails obtaining samples that are easily accessible. One of the major limitations of convenience sampling is that one cannot be sure that the sample is representative of the population being studied. To address this limitation, the sample from 
this study was compared to larger random samples in the training transfer literature based on characteristics such as age, gender, and education level to determine if similarities existed (Gravetter \& Forzano, 2011).

For the qualitative portion of this study, criterion sampling was used. Criterion sampling is a type of purposive sampling that often is used for phenomenological studies. It entails selecting participants that meet a specific criterion. Typically, the criterion in phenomenological studies is that participants must have experienced the phenomena being studied (Creswell, 1998). The criterion for selecting mentees was that they must have experienced support, transfer motivation, and training transfer. The criterion for selecting mentors was that they must have mentored mentees who participated in both formal and informal training and mentees who have participated in informal training only.

\section{Sample Size}

The sample for the quantitative portion of this study consisted of mentees who participated in formal and/or informal new hire training. The sample size $(n=44)$ was determined by using the following formula: $n=\left(8 / f^{2}\right)+(m-1)$, where $f^{2}=R^{2} /\left(1-R^{2}\right)$, and $m$ is the number of predictor variables (Tabachnick \& Fidell, 2001). The value of $\mathrm{R}^{2}$ (.17) was determined by computing and averaging $R^{2}$ values from recent studies in which supervisor support, transfer motivation, and training transfer were included as variables (Al-Eisa et al., 2008; Chiaburu, 2010; Chiaburu et al., 2010; Chiaburu \& Tekleab, 2005; Nijman et al., 2006; Saks \& Belcourt, 2006). In addition, there were five predictor variables: transfer motivation, mentoring, coaching, task support, and social support. The sample for the qualitative portion of this study consisted of five mentees and five 
mentors. Appropriate sample sizes for phenomenological studies range from one to ten participants (Creswell, 1998; Sanders, 1982; Starks \& Trinidad, 2007).

\section{Criteria for Participating in Study}

To be eligible to participate in the quantitative portion of this study, mentees must have participated in formal and/or informal new hire training at least three months prior to their participation in this study. Including a time lag between training and transfer assessment was advantageous because it provided mentees with time to apply what they learned, helped determine if transfer maintenance occurred, and helped prevent inflated transfer effects. Studies that assessed transfer too soon after training produced inflated transfer effects compared to those in which there was a time lag (Blume et al., 2010). Many recent training transfer studies have included a time lag ranging from several months (Chiaburu \& Lindsay, 2008; Chiaburu et al., 2010; Liebermann \& Hoffman, 2008; Velada et al., 2007) to two years (Nijman et al., 2006). To be eligible to participate in the qualitative portion of this study, mentees must have experienced high levels of support, transfer motivation, and training transfer as indicated by the scores from the survey. Mentors must have mentored mentees who participated in formal and informal training, as well as mentees who participated in informal training alone.

\section{Phase 1: Quantitative Data Collection and Analysis}

During the first phase of this study, quantitative survey data were collected and analyzed. The methods, instruments, and procedures that were used for data collection and the statistics that were used for data analysis are discussed, in detail, in the following subsections. 


\section{Data Collection}

A self-administered survey was used to elicit demographic information from participants and measure transfer motivation, training transfer, and dimensions of support exhibited by mentors. The survey was available, via SurveyMonkey, and consisted of 39 items. They survey took approximately 10-15 minutes to complete.

Demographics. The demographic portion of the survey (Appendix A) included a request for information from participants regarding their name, age, gender, education level, organizational tenure, job tenure, years of experience, whether they participated in formal and/or informal new hire training, and if applicable, how many months/years it has been since they participated in formal and/or informal new hire training. This portion of the study also included a reminder that participants' identities would be kept confidential.

Transfer motivation. Transfer motivation was assessed using a six-item scale developed by Noe and Schmitt (1986). This scale uses a 5-point, Likert scale and includes six items. A sample item is "I know of work situations in which I plan to use what I have learned during formal and/or informal new hire training." The possible responses for the items are as follows: $1=$ strongly disagree, $2=$ disagree, $3=$ neither agree nor disagree, $4=$ agree, and $5=$ strongly agree. Item responses were summed to determine an overall score. Scores may range from 6 to 30, with higher scores representing a stronger degree of transfer motivation than lower scores. Previous research indicates that the scale has a high level of internal consistency $(\alpha=.76)$ (Martineau, 1995). 
Training transfer. Training transfer was assessed using items from the ITAPI Scale. The ITAPI Scale uses a 5-point, Likert scale. There are three that items that assess training transfer that were used for this study. A sample item is "I frequently apply my newly acquired knowledge and skills to my job." The possible responses for the items are as follows: 1 = strongly disagree, $2=$ disagree, $3=$ neither agree nor disagree, $4=$ agree, and 5 = strongly agree. One of the items, "I have not had opportunities to apply my newly acquired knowledge and skills to my job", was reverse scored. Item responses were summed to determine an overall score. Scores may range from 3 to 15, with higher scores representing a stronger degree of training transfer than lower scores. The Transfer subscale has high internal consistency $(\alpha=.74)$ in previous research (Handy, 2008).

Dimensions of Support. Dimensions of support were measured using the Mentoring and Communication Support Scale developed by Hill, Bahniuk, Dobos, \& Rouner (1989). The scale includes 15 items and uses a 5-point Likert scale. The scale has a high internal consistency, with Cronbach alphas from previous research ranging from .75 to .89 . In addition, results from a factor analysis indicated that the scale has construct validity (Hill et al, 1989).

The Mentoring and Communication Support Scale includes four subscales that measure the following dimensions of support: mentoring, coaching, social support, and task support. The Mentoring subscale contains four items that measure supportive behaviors from someone of a higher rank. A sample of an item from the Mentoring subscale is "Someone of higher rank frequently devotes extra time and consideration to me." The Coaching subscale contains three items that reflect teaching and coaching behaviors related to the job as well as the profession. A sample of an item from the 
Coaching subscale is "I have had an associate teach me the informal rules of my organization" (Downs, 1994; Hill et al., 1989).

The Social Support subscale contains four items that measure social behaviors in which the sharing of personal problems and confidences occur. A sample of an item from the Social Support subscale is "My associates and I share confidences with each other." The Task Support subscale contains four items that assess collaborative behaviors in which the sharing of work assignments and ideas occur. A sample of an item from the Task Support subscale is "I frequently exchange ideas with my associates." The possible responses for the items in each of the subscales are as follows: $1=$ strongly disagree, $2=$ disagree, $3=$ neither agree nor disagree, $4=$ agree, and $5=$ strongly agree. Item responses for the subscales were summed to determine an overall score for each dimension of support (mentoring, coaching, social support, and task support). Higher scores represent a stronger degree of support compared to lower scores (Downs, 1994; Hill et al., 1989).

The items in the Mentoring and Communication Support Scale were revised slightly to reflect the dimensions of support exhibited by participants' mentors. For instance, phrases and words such as "someone of higher rank" and "my associates" were replaced with the word "mentor." A pilot study of the revised items was conducted to ensure reliability. Given the small target population from which the sample for this study was drawn, the participants for the pilot study $(N=12)$ were drawn from a different population of employees within the organization. Details about the recruitment of these participants are included in the Procedures section. The participants were administered the revised Mentoring and Communication Support Scale twice, one week apart, to 
determine test-retest reliability. Cronbach's alpha was calculated for each of the subscales for internal consistency. In addition, Pearson correlation coefficients $(p<.05)$ were calculated for each of the subscales to determine test-retest reliability.

\section{Procedures}

Pilot tests. A list of potential participants for the pilot test of the revised Mentoring and Communication Support Scale were drawn from a departmental organizational chart. Potential participants included employees involved in developing curriculum for the organization. These participants were not included in the sampling frame for the quantitative or qualitative portions of this study.

I sent potential participants an email inviting their participation in the pilot study. The email included a copy of the informed consent form, a link to the revised Mentoring and Communication Support Scale available via SurveyMonkey, and instructions for completing the survey. The informed consent form included background information about the study, procedures for participating, and assurance that participation was voluntary and that participants' identities would be kept confidential. At the beginning of the survey, participants were asked to acknowledge agreement with the informed consent form. After one week, I sent nonresponders a reminder email. Each week after, I sent additional reminder emails to nonresponders until the desired sample size $(n=10)$ was met.

Quantitative phase. A list of potential participants for the quantitative phase of this study was drawn from a departmental organizational chart. I sent potential participants an email inviting them to participate in the study. The email included a copy of the informed consent form, a link to the survey offered through SurveyMonkey, and 
instructions for completing the survey. The informed consent form included background information about the study, procedures for participating, and assurance that participation was voluntary and that participants' identities would be kept confidential. At the beginning of the survey, participants were asked to acknowledge agreement with the informed consent form. After one week, I sent nonresponders a reminder email. Each week after, I sent additional reminder emails to nonresponders until the desired sample size for the study $(n=44)$ was met.

\section{Data Analysis}

Once the surveys were completed, the responses were reviewed to ensure that mentees had engaged in formal and/or informal new hire training at least three months prior to their participation in this study. Mentees who had not engaged in formal or informal new hire training at least three months prior to their participation were disqualified from the study. The data from the surveys were exported from SurveyMonkey and imported into the Statistical Package for the Social Sciences (SPSS), version 20, for analysis.

Data cleaning. Once the data set was imported into SPSS, histograms, means, and standard deviations were computed and examined for each variable. Then, the data set was analyzed to identify outliers and to assess normality, linearity, and homoscedasticity. Mahalanobis distance was computed to identify outliers. A normal probability plot was created, skewness and kurtosis coefficients were computed, and the Shapiro-Wilk test was computed to assess normality. Residual plots were created to 
assess linearity between the independent and dependent variables as well as homoscedasticity.

Demographics. Descriptive statistical analyses were performed to describe the sample. Frequency statistics were computed for the participants' ages, gender, level of education, years worked at the organization, years worked in the current job, years of experience, months/years since participation in formal and/or informal new hire training, and months/years of support. In addition, a Pearson's correlation coefficient $(p<.05)$ was computed to determine if there was a significant relationship between any of the demographic variables (age, gender, level of education, years worked at the organization, years worked in current job, years of experience, months/years since participation in formal and/or informal new hire training, months/years of support) and the dependent variables (transfer motivation, training transfer).

Correlation hypotheses testing. The first set of hypotheses for this study pertained to the relationship between specific dimensions of support (mentoring, coaching, social support, and task support) and training transfer. The hypotheses are included in the subsection below and the data analysis methods used to test the hypotheses are explained.

$\mathrm{H}_{0}$ : There is no correlation between mentoring, as measured by the Mentoring and Communication Support Scale, and training transfer, as measured by the Importance, Transfer Achieved, and Performance Improvement (ITAPI) Scale. 
$\mathrm{H} 1_{1}$ : There is a positive correlation between mentoring, as measured by the Mentoring and Communication Support Scale, and training transfer, as measured by the ITAPI Scale.

$\mathrm{H} 2_{0}$ : There is no correlation between coaching, as measured by the Mentoring and Communication Support Scale, and training transfer, as measured by the ITAPI Scale.

$\mathrm{H} 2_{1}$ : There is a positive correlation between coaching, as measured by the Mentoring and Communication Support Scale, and training transfer, as measured by the ITAPI Scale.

$\mathrm{H} 3_{0}$ : There is no correlation between task support, as measured by the Mentoring and Communication Support Scale, and training transfer, as measured by the ITAPI Scale.

$\mathrm{H} 3_{1}$ : There is a positive correlation between task support, as measured by the Mentoring and Communication Support Scale, and training transfer, as measured by the ITAPI Scale.

$\mathrm{H} 4_{0}$ : There is no correlation between social support, as measured by the Mentoring and Communication Support Scale, and training transfer, as measured by the ITAPI Scale.

$\mathrm{H} 4_{1}$ : There is a positive correlation between social support, as measured by the Mentoring and Communication Support Scale, and training transfer, as measured by the ITAPI Scale.

Pearson correlation. A Pearson correlation coefficient $(p<.05)$ was computed to determine the strength and direction of the correlations between mentoring, coaching, task support, and social support, and training transfer. Given the small sample size in this 
study, bootstrapping methods were used to confirm the results. Bootstrapping is a computer-generated, nonparametric resampling method in which random samples are drawn, with replacement, from the original data set. For this test, five thousand bootstrap samples were drawn, the Pearson's correlation coefficient was computed for each sample, and $95 \%$ confidence intervals were generated. If zero was not within confidence intervals, the results were considered statistically significant (Efron \& Tibshirani, 1993; Preacher \& Hayes, 2004).

Mediation hypothesis testing. The next set of hypotheses in this study related to the role of transfer motivation as a mediator in the relationships between the dimensions of support and training transfer. The hypotheses are included below and the data analysis methods used to test the hypotheses are presented.

$\mathrm{H} 5_{0}$ : Transfer motivation, as measured by the Transfer Motivation Scale, does not mediate the relationship between mentoring, coaching, task support, and social support, as measured by the Mentoring and Communication Support Scale, and training transfer, as measured by the ITAPI Scale.

H5 $5_{1}$ Transfer motivation, as measured by the Transfer Motivation Scale, does mediate the relationship between mentoring, coaching, task support and social support, as measured by the Mentoring and Communication Support Scale, and training transfer, as measured by the ITAPI Scale.

Bootstrapping Methods. Preacher and Hayes' (2004) SPSS script for simple mediation (using the nonparametric bootstrapping procedure) was used to determine if transfer motivation mediated the relationships between mentoring, coaching, task support, and social support, and training transfer. The script is used to assess mediation 
by computing regression coefficients for the direct and total effects and by assessing the difference between the total and direct effects. While the Sobel test traditionally has been used for this purpose, bootstrapping is more appropriate for this study because it can be used with smaller sample sizes (Shrout \& Bolger, 2002). For this test, five thousand bootstrap samples were drawn, regression coefficients were computed for each sample, and $95 \%$ confidence intervals were generated for the indirect effects. If zero was not within confidence intervals, the results were considered statistically significant (Efron \& Tibshirani, 1993; Preacher \& Hayes, 2004).

Independent samples $t$-test hypothesis testing. The final set of hypotheses in this study pertained to differences in training transfer scores between mentees who participated in formal and informal new hire training and mentees who participated in informal training only. The hypotheses are presented below and the data analysis methods used to test the hypotheses are explained.

$\mathrm{H6}_{0}$ : There is no statistically significant difference between training transfer, as measured by the ITAPI Scale, of mentees who participated in formal and informal new hire training and mentees who participated in informal new hire training alone.

$\mathrm{H}_{1}$ : There is a statistically significant difference between training transfer, as measured by the ITAPI Scale, of mentees who participated in formal and informal new hire training and mentees who participated in informal new hire training alone.

Independent-samples t-test. An independent-samples $t$-test $(p<.05)$ was computed to determine if there was a significant difference between the mean training transfer scores of mentees who participated in both formal and informal new hire training $(n=41)$ and mentees who in participated in informal new hire training alone $(n=7)$. The 
required sample size for each group $(n=4)$ was determined using the average effect size $(d=.58)$ from prior research (Kauffeld \& Lehmann-Willenbrock, 2009; Keith et al., 2010; Keith \& Frese, 2005; Keith \& Frese, 2008), a statistical power value of .80, and an alpha level of .05. Given the large difference in sample sizes between groups, bootstrapping methods were used to confirm the results. For this test, five thousand bootstrap samples were drawn for each group, independent $t$-tests were computed to compare the means of the group samples, and 95\% confidence intervals were generated. If zero was not within confidence intervals, the results were considered statistically significant (Efron \& Tibshirani, 1993; Preacher \& Hayes, 2004).

\section{Phase 2: Qualitative Data Collection and Analysis}

\section{Data Collection}

The qualitative data for this study were collected by conducting standardized open-ended interviews with five mentees and five mentors. Standardized open-ended interviews are characterized by the predetermination of interview questions and the order in which the questions will be asked. This type of interview offers several advantages compared to less structured interviews. For instance, because all participants were asked the same questions, the breadth and depth of the data were consistent which allowed comparisons to be made between and among the experiences of participants (Patton, 2002).

Interviews with mentees included questions that focused on their experiences of support, transfer motivation, and training transfer. The questions also focused on how their experiences of support influenced their motivation and attempts to transfer learned knowledge and skills. A list of the interview questions is available in Appendix B. 
Interviews with mentors included questions that focused on their experiences as mentors and their perceptions of training transfer among mentees. A list of interview questions is available in Appendix C.

\section{Procedures}

Participants for mentee interviews were identified using the survey results from the quantitative portion of this study. Mentees with the highest scores on the support, training transfer, and transfer motivation portions of the survey were selected to participate in interviews. Participants for mentor interviews were selected by reviewing an organizational chart and speaking with the executive director of training and development to identify the mentors who had worked with mentees who participated in formal and informal new hire training and with mentees who have participated in informal new hire training alone. Of the mentees and mentors identified, anyone I mentored was eliminated from the list and replaced.

I sent potential participants an email about the purpose of this study and invited them to participant in an interview. The email indicated that the interview would take approximately one hour, take place via Skype, and be audio recorded and transcribed. The email also included a copy of the informed consent form, which assured participants that their participation was voluntary and that their identity would be kept confidential. I informed participants that their names would be replaced with pseudonyms during the data analysis and results sections of the study. After one and two weeks respectively, I sent nonresponders a reminder email. I contacted participants who agreed to participate to determine a date and time for the interview that worked best for them. 


\section{Preventing Researcher Bias}

I spent a number of years working in the curriculum development department in the organization in which I collected data. During my employment, I was actively involved in developing curriculum and in training and mentoring those who develop curriculum. As a result, I am acutely aware of the challenges that exist regarding the successful transfer of curriculum development knowledge and skills. While my experiences may have helped me empathize and relate to participants, particularly during the qualitative portion of this study, they also could have created opportunities for bias in interpretation.

To prevent bias associated with my personal experiences, I used the following strategies. First, I engaged in the epoche process which required that I consciously bracketed or set aside preconceived ideas, prejudgments, biases, and presuppositions during the data collection, analysis, and interpretation phases of this study. Engaging in the epoche process increased the likelihood that I was receptive to a new awareness and understanding of support and training transfer (Moustakas, 1994). Second, I disqualified participants from interviews if I had mentored them. Third, I validated the qualitative findings using member checking. Member checking entails sending qualitative data and findings to participants to verify that they are representative of participants' experiences (Creswell \& Plano Clark, 2007). I sent interview transcripts and narratives to participants for member checking.

\section{Data Analysis}

After the interviews were transcribed, transcripts were emailed to the participants for member checking to ensure that what was recorded and transcribed was accurate. 
Research question 1: How do mentees experience specific dimensions of support (mentoring, coaching, task support, and social support), exhibited by their mentors, as they attempt to transfer learned knowledge and skills?

Research question 2: How do mentees' experiences of specific dimensions of support (mentoring, coaching, task support, and social support) influence their motivation to transfer learned knowledge and skills and their attempts to transfer learned knowledge and skills?

Research question 3: How does participation in formal and informal new hire training versus participation in informal new hire training alone influence training transfer among mentees, as perceived by mentors?

Descriptive coding. Descriptive coding was used to label and organize data that pertained to the variables in the study (Miles \& Huberman, 1994). Statements and segments of the interview that were relevant to specific dimensions of support, transfer motivation, and training transfer were coded accordingly.

Pattern coding, mapping, and memoing. Pattern coding was used to cluster statements and segments of the interview according to descriptive codes to identify themes, causes/explanations, and relationships between the variables (Miles \& Huberman, 1994). The themes, causes/explanations, and relationships between the variables were mapped to determine how they interrelate. During pattern coding and mapping, memoing was used to capture spontaneous ideas and thoughts about data (Miles \& Huberman, 1994).

Narratives. Individual narratives representing each participant's experiences were be constructed. Included in the narrative were the structures, meanings, and essences of 
each experience. The individual narratives were sent to participants for member checking. Then, a composite narrative was constructed that represents the collective experiences of the group as a whole (Moustakas, 1994).

Effects matrices. Using themes developed from the pattern coding, mapping, and memoing, effects matrices were created. The first effects matrix was created, using themes and exemplar quotations, to illustrate how mentees experienced the dimensions of support (mentoring, coaching, task support, and social support). The second and third effects matrices were created, using themes and exemplar quotations, to illustrate the influence of specific dimensions of support on transfer motivation and training transfer respectively. The fourth effects matrix was created, using themes and exemplar quotations, to illustrate the effects of types of training on training transfer (Miles \& Huberman, 1994).

\section{Phase 3: Integration of Quantitative and Qualitative Results}

After the quantitative and qualitative data were collected and analyzed, it was integrated during the third and final phase. There are two methods used to integrate quantitative and qualitative data in a mixed methods study. The first method requires that the researcher transform qualitative data into quantitative data and analyze the results. The second method requires that the researcher analyze the quantitative and qualitative data separately and integrate the results to present the outcomes for the entire study (Creswell \& Plano Clark, 2007; Ivankova, Creswell, Stick, 2006).

The second method is more appropriate for this study than the first. The sequential explanatory research design used in this study provides the researcher with an opportunity to explain quantitative findings with qualitative results and use qualitative 
results to fill in any gaps that exist in quantitative results. This warrants the use of rich narratives of mentees' and mentors' experiences as opposed to reducing such experiences to dichotomous variables (Creswell \& Plano Clark, 2007). Transforming narratives into numbers would diminish their breadth and depth (Driscoll, Appiah-Yeboah, Salib, \& Rupert, 2007).

The integration of quantitative and qualitative results is presented in two sections in Chapter 5. The first is organized around the four dimensions of support examined in this study: coaching, mentoring, task support, and social support. For each dimension of support, the results from the correlation and mediation analyses were integrated with the results from coding, narratives, and effects matrix to explain if and how that particular dimension of support influences transfer motivation and training transfer. The aim of this section is to answer the research question guiding this study which is, "How do specific dimensions of support influence transfer motivation and training transfer?" The second section is organized around the types of training in which mentees participated. The results from the $t$-test were integrated with the results from the coding, narratives, and effects matrix to explain whether the type of training offered influences training transfer.

\section{Ethical Considerations}

All participants were asked to complete an informed consent form prior to participating in this study. The informed consent form made participants aware of the purpose of this study, their right to refuse to participate in this study, and who to contact should they have any questions. It also assured participants that their refusal to participate in the study or their withdrawal from the study would not result in any penalties. 
Participants who agreed to be in this study may have experienced minimal stress when responding to survey or interview questions. In particular, mentees who reported low transfer of learned knowledge and skills may have feared that their responses would damage their reputation. In addition, mentees who report that their mentors are unsupportive may have feared that their mentors would discover how they responded. To alleviate such stress, participants were assured that their identities would be kept confidential and that pseudonyms would be used when reporting study results. Upon completion of this study, the participants and organizational stakeholders will be emailed an executive summary of the results.

Data from this study will be stored securely for at least five years. Survey data will be stored on the Internet via a password-protected Survey Monkey account. Audio files and transcripts from interviews will be stored on a password-protected computer. Handwritten notes from interviews will be stored in a locked file cabinet.

\section{Summary}

This study employed a sequential explanatory design in which quantitative data were collected and analyzed in the first phase, qualitative data were collected and analyzed in the second phase, and quantitative and qualitative results were integrated to present outcomes in the third phase. This study addressed many of the limitations of existing transfer research. First, it included both quantitative and qualitative methods which prevented common method bias in which results are due to using a single methodology rather than the actual relationships between variables (Spector \& Brannick, 2009). Second, two sources of transfer were collected which prevented the possibility of inflated results due to using self-report ratings alone (Blume et al., 2010; Taylor et al., 
2009). Third, there was a time lag between training and the assessment of training transfer. Including a time lag prevented inflated transfer results and ensured that transfer maintenance was assessed (Blume et al., 2010).

In Chapter 4, the quantitative and qualitative results are presented. In Chapter 5, the quantitative and qualitative results are integrated and the major outcomes of the study are presented. In addition, the limitations of the study are described and the implications of the findings on future research, practice, and social change are explained. 
Chapter 4: Results

\section{Introduction}

The primary purpose of this sequential explanatory study was to determine the influence of specific dimensions of support on training transfer. The secondary purpose was to determine the effects of the type of training offered to participants on training transfer. Quantitative data were collected and analyzed during the first phase of research and six hypotheses were tested using a variety of statistical techniques. Qualitative data were collected and analyzed during the second phase of the research and three research questions were addressed by coding interview transcripts and identifying themes. In this chapter, the quantitative results are presented first, followed by the qualitative results.

\section{Pilot Study}

The Mentoring and Communication Support Scale was piloted to determine internal consistency and test-retest reliability. Items in the scale were revised to reflect mentoring, coaching, social support, and task support behaviors exhibited by participants' mentors. Phrases and words in the original items, such as "someone of a higher rank" and "my associates," were replaced with the word "mentor." Sixteen employees, involved in developing curriculum for the organization in which this study took place, were recruited to participate in the pilot of the revised scale. Eleven surveys were completed for a response rate of $69 \%$. Participants completed the survey twice, at least one week apart.

Cronbach's alpha coefficients were computed for the Mentoring, Coaching, Social Support, and Task Support subscales to assess internal consistency. Subscales that achieved a Cronbach's alpha of .70 or higher were considered to be internally consistent (Nunnally \& Berstein, 1994 p. 265). The Task Support subscale had a Cronbach's alpha 
of .75. The Mentoring subscale had a Cronbach's alpha of .59; however, when item 1 was removed it increased to .81. Similarly, the Coaching subscale had a Cronbach's alpha of .64 ; however, when item 6 was removed it increased to .75. The Social Support subscale had a Cronbach's alpha of .50.

A Pearson product-moment correlation analysis also was performed to determine the test-retest reliability of each subscale. The test-retest correlation for the Task Support subscale was significant, $r(9)=.69, p=.02$. However, the test-retest correlations for the other subscales were not significant: Mentoring, $r(9)=.39, p=.24$, Coaching, $r(9)=.34$, $p=.31$, and Social Support, $r(9)=.14, p=.69$. The results suggest that Task Support is the only subscale that has test-retest reliability.

The results of the pilot test were considered in light of the limitations associated with small sample sizes. Given that the sample size for the pilot test $(n=11)$ was small, the power to detect true effects was reduced. As a result, items 1 and 6 were not removed from the Mentoring and Coaching subscales, as suggested in the internal consistency analysis. Also, the subscales were reviewed against the definitions of mentoring, coaching, social support, and task support, included in Chapter 1, to determine whether extra items should be added to increase internal consistency and test-retest reliability. The following items were added to the Mentoring subscale: "My mentor has helped me develop career goals" and "My mentor has shared his or her experiences with me to help guide my career." The following item was added to the Coaching subscale: "My mentor has coached me on how to improve my skills and performance." The revised Mentoring and Communication Support Scale was assessed for internal consistency and test-retest 
reliability during the quantitative phase of this study. The results are discussed later in this chapter.

\section{Quantitative Results}

The quantitative portion of this study involved testing six hypotheses that addressed the relationships between dimensions of support and training transfer, the role of transfer motivation as a mediator in those relationships, and the effect of training type on training transfer. In this section, the results of the data cleaning tests are presented first. Next, the sample demographics and descriptive statistics are presented followed by the reliability results of the revised Mentoring and Communication Support Scale. Finally, the results of the hypothesis tests are presented.

\section{Data Cleaning}

Prior to testing the hypotheses, the data set was assessed for outliers, normality, linearity, and homoscedasticity. The presence of outliers was determined by computing Mahalanobis distance. None of the cases exceeded the critical value of the chi-squared statistic, $X^{2}=20.52$, which suggests that there were no outliers. Normality was assessed by computing kurtosis and skewness coefficients. Values that fall within the range of \pm 1.00 indicate a normal distribution (Mertler \& Vannatta, 2005). The coefficient values for mentoring $($ kurtosis $=0.18$, skewness $=0.04)$, coaching $($ kurtosis $=0.16$, skewness $=$ $0.26)$, social support $($ kurtosis $=0.26$, skewness $=-0.21)$, and task support $($ kurtosis $=$ 0.44 , skewness $=-0.94)$ variables indicated a normal distribution. The coefficient values for training transfer (kurtosis $=-1.03$, skewness $=-0.07$ ) and transfer motivation (kurtosis $=1.82$, skewness $=-1.11$ ) variables indicated a nonnormal distribution, although the values fell only slightly outside of the acceptable range. 
Normality was also assessed using the Shapiro-Wilk test. The Shapiro-Wilk test was used, rather than the more commonly used Kolmogorow-Smirnov, test because it is more appropriate for small sample sizes (Shapiro \& Wilk, 1965). Significance levels that exceed .05 indicate a normal distribution. The significance levels of the mentoring $(W=$ $.971, p=.28)$, coaching $(W=.986, p=.22)$, and social support $(W=.973, p=.32)$ variables indicated a normal distribution; however, the significance levels of the transfer motivation $(W=.921, p=.003)$, training transfer $(W=.912, p=.002)$, and task support $(W=.907, p=.002)$ indicated a nonnormal distribution.

Scatter plots were created to assess the linearity between the independent and dependent variables. The scatter plots were generally oval-shaped, which suggests linearity. A residual scatter plot was created to assess homoscedasticity. The residuals were rectangular-shaped which suggests that variability is roughly the same across all of the variables (Tabachnick \& Fidell, 2007).

The results of the data cleaning tests indicated that the data set did not contain outliers and that it met the assumptions of linearity and homoscedasticity. However, these results also suggest that the transfer motivation, training transfer, and task support variables were not normally distributed. Given the small sample size and the violations of normality, bootstrapping methods were used to validate the results of the statistical tests. Bootstrapping methods are appropriate because they have high statistical power, a low risk of Type I errors, and are robust against violations of normality (MacKinnon, Lockwood, Hoffman, West, \& Sheets, 2002; Preacher \& Hayes, 2004; Preacher \& Hayes, 2008). 


\section{Demographics}

The population for this study consisted of mentees who develop curriculum for the organization $(N=59)$. To recruit participants, I sent an them email that included a brief description of the study, a link to the online survey, and a copy of the informed consent form. The survey elicited demographic information and assessed transfer motivation, training transfer, and dimensions of support exhibited by mentees' mentors. Fifty mentees completed the survey for a response rate of $85 \%$.

Two participants did not meet the criteria for participation in the study because they had participated in new hire training less than three months prior to completing the survey. Therefore, their cases were removed from the data set, making the final sample size 48. Including a 3-month time lag between new hire training and transfer assessment was necessary because it ensured that participants had time to apply what they learned, helped determine if transfer maintenance occurred, and helped prevent inflated transfer effects.

As shown in Table 1, the sample for this study $(n=48)$ included 17 men $(35.4 \%)$ and 31 women (64.6\%). Participants ranged in age from 28 to 63 years, with a mean age of 42 years. Most participants had a master's (58.3\%) or doctoral degree $(27.1 \%)$ and had been in their current job position for less than two years (93.3\%). Most participants had also participated in both formal and informal new hire training $(85.4 \%)$ less than one year ago $(66.7 \%)$ and had received less than one year of support following their participation in training $(91.7 \%)$. In terms of professional experience, most participants either had less than two years of experience (39.6\%) or more than seven years of experience (43.8\%). Preliminary analyses confirmed that none of the demographic 
variables (age, gender, level of education, years worked at the organization, years worked in current job, years of experience, and months/years since participation in formal and/or informal new hire training) were significantly correlated with training transfer.

Table 1

Sample Demographics $(n=48)$

\begin{tabular}{|c|c|c|}
\hline & Frequency & Percent \\
\hline \multicolumn{3}{|l|}{ Age (years) } \\
\hline $28-35$ & 13 & 27.1 \\
\hline $36-45$ & 18 & 37.5 \\
\hline $46-55$ & 11 & 22.9 \\
\hline $56+$ & 6 & 12.5 \\
\hline \multicolumn{3}{|l|}{ Gender } \\
\hline Female & 31 & 64.6 \\
\hline Male & 17 & 35.4 \\
\hline \multicolumn{3}{|l|}{ Education } \\
\hline Bachelor's & 7 & 14.6 \\
\hline Master's & 28 & 58.3 \\
\hline Doctorate & 13 & 27.1 \\
\hline \multicolumn{3}{|c|}{ Professional Experience (years) } \\
\hline $0-2$ & 19 & 39.5 \\
\hline $2-4$ & 5 & 10.4 \\
\hline $5-6$ & 3 & 6.3 \\
\hline $7+$ & 21 & 43.8 \\
\hline \multicolumn{3}{|l|}{ Job Tenure (years) } \\
\hline$<1$ & 31 & 64.5 \\
\hline 2 & 14 & 29.2 \\
\hline $3+$ & 3 & 6.3 \\
\hline \multicolumn{3}{|l|}{ Type of Training } \\
\hline Informal Only & 7 & 14.6 \\
\hline Formal and Informal & 41 & 85.4 \\
\hline \multicolumn{3}{|c|}{ Time Since Training (years) } \\
\hline$<1$ & 32 & 66.7 \\
\hline 2 & 12 & 25.0 \\
\hline $3+$ & 4 & 8.3 \\
\hline \multicolumn{3}{|l|}{ Amount of Support } \\
\hline$<6$ months & 15 & 31.3 \\
\hline 7-12 months & 29 & 60.4 \\
\hline$>1$ year & 4 & 8.3 \\
\hline
\end{tabular}




\section{Reliability of Mentoring and Communication Support Scale}

Thirty-one of the 50 participants completed the Mentoring and Communication Support Scale twice, at least one week apart, to assess the internal consistency and testretest reliability of the revised scale. Cronbach's alpha coefficients were computed for the Mentoring, Coaching, Social Support, and Task Support subscales, to assess internal consistency. The Mentoring and Coaching subscales both had a Cronbach's alpha of .84. The Social Support subscale had a Cronbach's alpha of .86 and the Task Support subscale had a Cronbach's alpha of .90. All of subscales were considered to be internally consistent because the Cronbach's alpha coefficients exceeded .70 (Nunnally \& Berstein, 1994 p. 265).

A Pearson product-moment correlation analysis was performed to determine the test-retest reliability of each subscale and the entire scale as a whole. As shown in Table 2, the test-retest correlation for the Task Support subscale was statistically significant. The bootstrapped, 95\% confidence intervals $[.08, .73]$ did not contain zero, confirming that the correlation was significant. Therefore, the Task Support subscale was considered to have test-retest reliability. Also shown in Table 2 are the test-retest correlations for the Mentoring, Coaching, and Social Support subscales and the Mentoring and Communication Support Scale, as a whole, which were not significant. The bootstrapped 95\% confidence intervals contained zero which confirms these findings. As a result, the Mentoring, Coaching, Social Support subscales and Mentoring and Communication and Support Scale as a whole were not considered to have test-retest reliability. 
Table 2

Test-Retest Coefficients, Significance Values, and Bootstrapped Confidence Intervals for the Mentoring and Communication Scale and subscales $(n=31)$

\begin{tabular}{lccc}
\hline Scales & $r$ & $p$ & $95 \%$ CI \\
\hline Mentoring and Communication Support Scale & .21 & .26 & $-.23, .69$ \\
Mentoring subscale & .20 & .29 & $-.27, .67$ \\
Coaching subscale & .03 & .86 & $-.36, .51$ \\
Social Support subscale & .18 & .33 & $-.25, .63$ \\
Task Support subscale & .42 & .02 & $.08, .73$ \\
& & & \\
\hline
\end{tabular}

\section{Descriptive Statistics}

Mentees $(n=48)$ completed an online survey that assessed their motivation to transfer learned knowledge and skills, the degree to which they attempted to transfer learned knowledge and skills, and the degree to which their mentors exhibited supportive behaviors. The descriptive statistics for these variables are presented in Table 3. The results suggest that mentees had high levels of transfer motivation $(M=24.25, S D=$ 4.31) and training transfer $(M=12.73, S D=1.70)$ as indicated by the close proximity of the mean scores to the maximum scores of 30 and 15 , respectively. The results also suggest that mentors exhibited mentoring behaviors the most $(M=19.19, S D=4.88)$, followed by task support $(M=14.19, S D=4.06)$, coaching $(M=13.54, S D=3.47)$, and social support $(M=12.02, S D=3.93)$ behaviors. 
Table 3

Descriptive Statistics for Transfer Motivation, Training Transfer, and Dimensions of Support $(n=48)$

\begin{tabular}{lccccc}
\hline Variable & $\begin{array}{l}\text { No. of } \\
\text { items in } \\
\text { scale }\end{array}$ & Min. & Max. & M & SD \\
\hline Transfer Motivation & 6 & 6.00 & 30.00 & 24.25 & 4.31 \\
Training Transfer & 3 & 3.00 & 15.00 & 12.73 & 1.70 \\
Mentoring & 6 & 6.00 & 30.00 & 19.19 & 4.88 \\
Coaching & 4 & 4.00 & 20.00 & 13.54 & 3.47 \\
Social Support & 4 & 4.00 & 20.00 & 12.02 & 3.93 \\
Task Support & 4 & 4.00 & 20.00 & 14.19 & 4.06 \\
\hline
\end{tabular}

Note: Scale values range from 1 (strongly disagree) to 5 (strongly agree).

Dimensions of Support and Training Transfer

Hypothesis 1. The first alternative hypothesis suggested that there would be a correlation between mentoring, as measured by the Mentoring and Communication Support Scale, and training transfer, as measured by the Importance, Transfer Achieved, and Performance Improvement (ITAPI) Scale. This hypothesis was tested using Pearson product-moment correlation coefficient. There was a medium, positive correlation between mentoring and training transfer, $r(46)=.41, \mathrm{p}=.004$. The bootstrapped, $95 \%$ confidence intervals $[0.14,0.62]$ did not contain zero and therefore confirmed that the correlation was significant.

Hypothesis 2. The second alternative hypothesis suggested that there would be a correlation between coaching, as measured by the Mentoring and Communication 
Support Scale, and training transfer, as measured by the Importance, Transfer Achieved, and Performance Improvement (ITAPI) Scale. This hypothesis was tested using Pearson product-moment correlation coefficient. There was a medium, positive correlation between coaching and training transfer, $r(46)=.39, \mathrm{p}=.006$. The bootstrapped, $95 \%$ confidence intervals $[0.12,0.60]$ did not contain zero and therefore confirmed that the correlation was significant.

Hypothesis 3. The third alternative hypothesis suggested that there would be a correlation between social support, as measured by the Mentoring and Communication Support Scale, and training transfer, as measured by the Importance, Transfer Achieved, Performance Improvement (ITAPI) Scale. This hypothesis was tested using Pearson product-moment correlation coefficient. There was a medium, positive correlation between social support and training transfer, $r(46)=.36, \mathrm{p}=.01$. The bootstrapped, $95 \%$ confidence intervals $[0.06,0.60]$ did not contain zero and therefore confirmed that the correlation was significant.

Hypothesis 4. The fourth alternative hypothesis suggested that there would be a correlation between task support, as measured by the Mentoring and Communication Support Scale, and training transfer, as measured by the Importance, Transfer Achieved, Performance Improvement (ITAPI) Scale. This hypothesis was tested using Pearson product-moment correlation coefficient. There was a medium, positive correlation between task support and training transfer, $r(46)=.39, p=.007$. The bootstrapped, 95\% confidence intervals $[0.12,0.61]$ did not contain zero and therefore confirmed that the correlation was significant. 


\section{Transfer Motivation as a Mediator}

Hypothesis 5. The fifth alternative hypothesis suggested that transfer motivation, as measured by the Transfer Motivation Scale, would mediate the relationships between mentoring, coaching, task support, and social support, as measured by the Mentoring and Communication Support Scale, and training transfer, as measured by the ITAPI Scale. Preacher and Hayes' (2004) SPSS script for simple mediation (using the nonparametric bootstrapping procedure) was used to determine if transfer motivation mediated the relationships between mentoring, coaching, task support, and social support, and training transfer.

There was a significant direct effect between mentoring and training transfer $(B=$ $0.14, p=.004)$. When transfer motivation was controlled for, the effect of mentoring on training transfer was still significant, but reduced $(B=0.09, p=.04)$. This suggests that transfer motivation partially mediates the relationship between mentoring and training transfer. The bootstrapped, $95 \%$ confidence intervals $[0.001,0.15]$ did not contain zero and therefore confirmed that transfer motivation mediates the relationship between mentoring and training transfer.

There was a significant direct effect between coaching and training transfer $(B=$ $0.19, p=.006$ ). When transfer motivation was controlled for, the effect of coaching on training transfer was no longer significant $(B=0.11, p=.09)$. This suggests that transfer motivation fully mediates the relationship between coaching and training transfer. The bootstrapped $95 \%$ confidence intervals $[0.01,0.21]$ did not contain zero and therefore confirmed that transfer motivation mediates the relationship between coaching and training transfer. 
There was a significant direct effect between social support and training transfer $(B=0.16, p=.01)$. When transfer motivation was controlled for, the effect of social support on training transfer was no longer significant $(B=0.09, p=.14)$. This suggests that transfer motivation fully mediates the relationship between social support and training transfer. The bootstrapped $95 \%$ confidence intervals $[0.005,0.20]$ did not contain zero and therefore confirmed that transfer motivation mediates the relationship between social support and training transfer.

There was a significant direct effect between task support and training transfer $(B$ $=0.16, p=.007)$. When transfer motivation was controlled for, the effect of mentoring on training transfer was still significant, but reduced $(B=0.11, p=.05)$. This suggests that transfer motivation partially mediates the relationship between task support and training transfer. However, the bootstrapped 95\% confidence intervals [-0.003, 0.20] contained zero suggesting that transfer motivation does not mediate the relationship between task support and training transfer.

\section{Types of Training and Training Transfer}

Hypothesis 6. The sixth alternative hypothesis suggested that there would be a statistically significant difference between the training transfer scores, as measured by the ITAPI Scale, of mentees who participated in both formal and informal new hire training and mentees who participated in informal new hire training alone. This hypothesis was tested using an independent-samples $t$-test. There was no significant difference in scores for mentees who participated in formal and informal new hire training $(M=12.76, S D=$ 1.70) and mentees who participated in informal new hire training alone $(M=12.57, S D=$ $1.81), t(46)=.26, p=.79$. The bootstrapped $95 \%$ confidence intervals $[-1.11,1.73]$ 
contained zero and therefore confirmed that the difference was not significant. In addition, the effect size of the difference was very small (eta squared $=.001$ ).

\section{Summary}

The quantitative results of this study confirmed that there are significant positive relationships between the dimensions of support (mentoring, coaching, social support, task support) and training transfer. The results also confirmed that transfer motivation mediates the relationships between mentoring, coaching, social support and training transfer, however, does not mediate the relationship between task support and training transfer. Finally, the results indicated that the type of training in which employees participate does not affect the degree to which they transfer learned knowledge and skills. In the next section, the qualitative results will be discussed.

\section{Qualitative Results}

The purpose of the qualitative portion of this study was to understand how mentees experienced the dimensions of support (mentoring, coaching, social support, and task support) and how those experiences influenced their motivation and attempts to transfer knowledge and skills learned in training. The purpose also was to determine how the type of training in which mentees participated influenced training transfer. This section includes a description of data collection and data analysis procedures that were used and an explanation of themes and sub-themes that emerged regarding each research question.

\section{Data Collection}

Five mentees and five mentors were selected for interviews. The mentees were selected based on their scores on the transfer motivation, training transfer, and support 
scales. Mentees who had the highest collective scores were invited to participate in interviews. Mentors were selected based on their experience providing support to mentees. Mentors who provided support to both mentees who participated in formal and informal new hire training and mentees who participated in informal new hire training only were invited to participate in interviews. All interviews were conducted via Skype and recorded using CallGraph. Interviews ranged in length from 45 minutes to 2 hours.

\section{Data Analysis}

I transcribed the interviews and emailed the transcripts to mentees and mentors for member checking. Two mentees and one mentor made slight edits to their transcripts to improve the accuracy of the content. The remaining mentees and mentors confirmed that their transcripts were accurate. Then, I uploaded the transcripts into Dedoose, a web application used for coding and analyzing qualitative data, and I coded the transcripts based on the research questions.

I reviewed and coded mentee transcripts first. I used descriptive coding to identify and label mentees' experiences of mentoring, coaching, social support, and task support. I used the following descriptive codes: MENT (mentoring), $\mathrm{COACH}$ (coaching), SOC (social support), and TASK (task support). I also used descriptive coding also to identify and label mentee responses related to transfer motivation and training transfer. I used the following codes: MOT (transfer motivation) and TRAN (training transfer). Next, I reviewed and coded mentor transcripts. I used descriptive coding to identify and label mentor responses related to the type of support they exhibited, the degree to which their mentees transferred learned knowledge and skills, and the influence of type of training on training transfer. I used the following codes: MENT (mentoring), COACH (coaching), 
SOC (social support), TASK (task support), TRAN (training transfer), FORM (formal training), and INFORM (informal training).

I extracted coded portions of each transcript and identified patterns which I used to construct individual narratives of each mentee's and mentor's experience. I emailed the narratives to mentees and mentors for member checking. All of the mentees confirmed that the narratives accurately captured their experiences. Three mentors provided clarifications, made small edits, and/or included additional information to improve the accuracy of their narratives. The remaining mentors confirmed the accuracy of their narratives as is. I compiled the mentee narratives into one document and reviewed it to identify themes related to how mentees experienced the dimensions of support and how those experiences influenced their motivation and attempts to transfer. I also compiled the mentor narratives into one document and reviewed it to identify themes related to the influence of type of training on training transfer.

During the coding and analysis processes, I used bracketing to separate my presuppositions and biases from mentors' and mentees' experiences. Given my prior experiences as both a mentee and mentor, I found that I had presuppositions and biases about which dimensions of support and which type of training were most useful for training transfer. As my presuppositions and biases emerged, I recorded them separately and shifted my focus back to understanding the meanings of mentees' and mentors' experiences. After I completed the mentee and mentor narratives and identified emergent themes, I revisited the presuppositions and biases I recorded to ensure that they did not inform the final results. The results, including the emergent themes and sub-themes, are presented in the following sections. 


\section{Mentees' Experiences of Support}

Research question 1. How do mentees experience specific dimensions of support (mentoring, coaching, task support, and social support), exhibited by their mentors, as they attempt to transfer learned knowledge and skills? The themes and sub-themes that emerged regarding how mentees experience each dimension of support are presented below. In addition, a summary of the themes and exemplar quotations related to mentees' experiences of support is included in Table 4 at the end of this section.

Mentoring. In this study, mentoring was defined as the practice of supporting, guiding, and facilitating a mentee's career development (Hill, Bahniuk, \& Dobos, 1989). The themes that emerged regarding mentees' experiences reflected the availability and willingness of mentors to support mentees as they attempted to transfer newly learned knowledge and skills and learn the job.

Theme 1: Mentees had access to their mentors. Mentees indicated that their mentors were always available when they had questions or needed assistance as they were learning the job. For instance, Mentee 2 said that his mentor "made it clear that she can help in any way even though I know she's really busy." He also said "I felt like any problem that came up that I didn't know how to handle. . I was sure I'd be able to reach [my mentor] fairly quickly and get guidance. So, that was a security blanket kind of feeling." Mentee 1 said that her mentor "was always there" and that "it was so easy to reach out [to her]" and Mentee 5 indicated that she had "daily" contact with her mentor.

Theme 2: Mentees felt taken care of by their mentors. Mentees reported that their mentors cared about their success on the job, their needs, and their well-being. For instance, Mentee 1 remarked that her mentor "went out of her way to take time to help 
me grow into my job" and Mentee 4 said that her mentor makes an effort to "check in [with her] all the time." In addition, Mentee 3 said that he felt his mentor was dedicated to helping "shape [his] behavior. . . and [his] writing." Mentees also commented that their mentors regularly met with them to discuss their needs and their wellbeing. For example, Mentee 4 said that her mentor set up regular meetings with her to get a "pulse check" and to find out how she was doing and how she was managing the multiple demands of the new job. Mentee 5 remarked that her mentor "really thought about how [she] wanted to onboard [new employees] and really tried to give. . . one-on-one support and chances to shadow."

Theme 3: Mentees were reassured by their mentors. The third and final theme that emerged related to mentoring was the reassurance mentees received from their mentors in the midst of the anxiety they felt about learning and mastering a new job. For instance, Mentee 3 said "[my mentor made] you feel like you matter, you're important, you're going to get it, and we're going to help you get it." Mentee 4 found it reassuring that her mentor did not expect her to master the job immediately. She remarked:

the thing that helped me most was the constant reassurance that this is crazy. Like we know. . you're not going to remember anything. We just want you to sort of get what the [job is] about. So it [gave me] the freedom to not know.

In addition, Mentee 2 indicated that he worried when he made mistakes; however, his mentor reassured him by talking about some of the mistakes he made when he was new to the job. His mentor said "when I started you should have seen the mistake I made. I made a pretty big blunder one time. .." 
Coaching. In this study, coaching was defined as the practice of teaching a mentee about the rules, goals, and politics of the organization (Hill, Bahniuk, Dobos, \& Rouner, 1989). The themes and sub-themes that emerged regarding mentees' experiences focused on receiving constructive feedback about how to apply departmental standards and receiving coaching on how to effectively work with organizational stakeholders.

Theme 1: Mentees received regular feedback from their mentors. Mentees reported that they regularly received feedback from their mentors. The feedback pertained to how well they applied a set of pre-defined departmental standards to their writing. The feedback was delivered in person (or over the phone if the mentee worked remotely or in another office) and/or via email. For instance, Mentee 4 said that his mentor would say "why don't you work on this. . . the first part of the [course] and then send me what you've done and let's get on a call. . and go over it and go over it in detail." Similarly, Mentee 5 said getting feedback was "a conversation where we talked about. . . where [the course] needs to be."

Sub-theme 1: The feedback mentees received was positive and friendly in tone. In general, mentees reported that the feedback they received was positive and friendly. For instance, Mentee 5 said that her mentor would give her: constructive suggestions for changes instead of being heavy handed, like "you must do it this way." I never heard her say, "well this is wrong." She would say, "well we do it this way here." So it was done in a very friendly and constructive manner." 
She also said that her mentor gave her positive feedback such as "you really hit the nail on the head with this." Similarly, Mentee 4 said that her mentor always pointed out when her work "was really good."

Sub-theme 2: The feedback mentees received was explained. Mentees reported that the feedback they received from mentors often was accompanied by a detailed explanation. Mentee 4 said that her mentor removed something from her course and followed up by explaining why. She said "we're going to tell you why so you get it." Similarly, Mentee 1 said that when her mentor gave her feedback about improving a part of her course, she would "explain what you have to do." In addition, Mentee 2 said that his mentor was "specific about why whatever I wrote just wasn't quite what was needed."

Sub-theme 3: The feedback mentees received was followed by suggestions for improvement. Mentees reported that most often their mentors would provide suggestions for how to improve a specific part of a course rather than simply rewriting it. Mentee 3 remarked that his mentor would "offer ideas but not really do it you know? At best a sentence or two to point me in the right direction." In addition, Mentee 5 said "we would read through it together and she would give me suggestions and we would tweak each [part of the course]."

Theme 2: Mentees were coached by their mentors on how to work with organizational stakeholders. When writing a course, mentees often collaborated with various organizational stakeholders. At times, working with stakeholders required mentees to be politically savvy. Mentees reported that their mentors coached them on what to do when they encountered politically-charged situations. For instance, Mentee 2 had an incident with a stakeholder and felt that, as a result, the stakeholder had "lost 
trust" in him. He felt "anxious" that his relationship with the stakeholder had deteriorated and remarked that "it was a real challenge for me." He also indicated that his mentor stepped in and coached him about how to proceed with the stakeholder saying "this is nothing to worry about, we'll get this fixed." Mentee 3 indicated that his mentor previewed emails he wrote before he sent them to stakeholders. In one particular instance, his mentor said "you really don't want to send that email because [the stakeholder is] going to interpret that the wrong way. Let's reword it."

Social support. Social support was defined as the practice of assisting a mentee with personal and professional challenges and problems (Downs, 1994; Hill, Bahniuk, Dobos, \& Rouner, 1989).

Theme 1: Mentees received assistance from their mentors when professional challenges and problems arose. Mentees reported that their mentors assisted them with professional challenges and problems. For instance, Mentee 3 was having difficulty with a course and said "I would just panic and go to [my mentor] and he would help me. ...I learned to depend on my [mentor] real fast." Mentee 5 said that at one point she confided to her mentor that she felt "backed into a corner" by an organizational stakeholder. After talking with her mentor about how she was feeling, she said she felt more "empowered." The same mentee also said that when she has "a problem with getting a response from [a stakeholder]," her mentor would often address the problem by "having conversations [with the stakeholders] on my behalf."

Task support. Task support was defined as assisting a mentee with work assignments (Downs, 1994; Hill, Bahniuk, Dobos, \& Rouner, 1989). 
Theme 1: Mentees were assigned small tasks by their mentors as a way to ease them into the job. Mentees' comments regarding task support were slightly different from the definition above. In most cases, mentees reported that their mentors assigned them small tasks which gave them the opportunity to use what they learned in training. Mentee 3 said, "[my mentor] eased me in a little bit by giving me [minor tasks] to work on." Mentee 2 said that his mentor gave him "the opportunity to work on parts of [a course] and "maybe add to it a little or edit it a little." Mentee 5's experience with task support was more substantial and better reflected the definition of task support. She said that she wrote her first course with her mentor and for "the two courses after that, she wrote half [of the course] and I wrote half." 
Table 4

Themes and Exemplar Quotes related to Mentees' Experiences of Support $(n=5)$

\begin{tabular}{|c|c|c|c|c|}
\hline $\begin{array}{l}\text { Dimensions } \\
\text { of Support }\end{array}$ & Themes & $\begin{array}{c}\text { No. of } \\
\text { participants } \\
\text { whose comments } \\
\text { pertained to } \\
\text { themes }\end{array}$ & $\begin{array}{l}\% \text { of } \\
\text { comments } \\
\text { that pertained } \\
\text { to themes }\end{array}$ & Exemplar Quotes \\
\hline Mentoring & $\begin{array}{l}\text { 1. Mentees could access their } \\
\text { mentors at any time. } \\
\text { 2. Mentees felt taken care of } \\
\text { by their mentors. } \\
\text { 3. Mentees were reassured by } \\
\text { their mentors. }\end{array}$ & 5 & 40.4 & $\begin{array}{l}\text { 1. "I felt like any problem that came up that I didn't know how to } \\
\text { handle. . I was sure I'd be able to reach [my mentor] fairly } \\
\text { quickly and get guidance. So, that was a security blanket kind of } \\
\text { feeling." } \\
\text { 2. "[my mentor] went out of her way to take time to help me } \\
\text { grow into my job." } \\
\text { 3. "[my mentor made] you feel like you matter, you're important, } \\
\text { you're going to get it, and we're going to help you get it." }\end{array}$ \\
\hline Coaching & $\begin{array}{l}\text { 1. Mentees received regular } \\
\text { feedback from their mentors. } \\
\text { 2. Mentees were coached by } \\
\text { their mentors on how to work } \\
\text { with organizational } \\
\text { stakeholders. }\end{array}$ & 5 & 33.7 & $\begin{array}{l}\text { 1. "[my mentor said] 'why don't you work on this. .. the first } \\
\text { part of the [course] and then send me what you've done and let's } \\
\text { get on a call. . . and go over it and go over it in detail.", } \\
\text { 2. "[my mentor said] 'you really don't want to send that email } \\
\text { because [the stakeholder is] going to interpret that the wrong } \\
\text { way. Let's reword it."” }\end{array}$ \\
\hline Social Support & $\begin{array}{l}\text { 1. Mentees received } \\
\text { assistance with professional } \\
\text { challenges and problems. }\end{array}$ & 4 & 11.5 & $\begin{array}{l}\text { 1. "I would just panic and go to [my mentor] and he would help } \\
\text { me... .I learned to depend on my [mentor] real fast." }\end{array}$ \\
\hline Task Support & $\begin{array}{l}\text { 1. Mentees were assigned } \\
\text { small tasks by their mentors. }\end{array}$ & 4 & 14.4 & $\begin{array}{l}\text { 1. "[my mentor gave me] the opportunity to work on parts of [a } \\
\text { course] and maybe add to it a little or edit it a little." }\end{array}$ \\
\hline
\end{tabular}




\section{Influence of Support on Transfer Process}

Research question 2. How do mentees' experiences of specific dimensions of support (mentoring, coaching, task support, and social support) influence their motivation to transfer learned knowledge and skills and their attempts to transfer learned knowledge and skills?

Transfer motivation. The theory of planned behavior suggests that motivation to perform a behavior, such as transferring a skill learned in training, is influenced by three independent determinants: attitude about the behavior, perception of behavioral control, and social pressure to perform the behavior. One or all of these determinants may predict motivation to perform a particular behavior in any given situation (Ajzen, 1991). An analysis of mentee responses revealed that mentoring influenced mentee attitudes about transferring learned knowledge and skills and social support influenced mentee perceptions of behavioral control. The themes and sub-themes are presented in the following sections. In addition, a summary of the themes and relevant quotations related to the influence of mentees' experiences on transfer motivation is provided in Table 5 at the end of this section.

\section{Theme 1: Mentoring influenced mentee feelings about transferring learned} knowledge and skills which, in turn, contributed to mentee attitudes about transferring learned knowledge and skills. An analysis of mentee responses revealed that mentoring fostered feelings of security among mentees and minimized their anxieties and fears related to transferring learned knowledge and skills. Feeling secure and calm seemed to help mentees develop positive attitudes about transferring learned knowledge and skills, 
even in challenging circumstances. For instance, Mentee 5 said that "without [my mentor]. . . I don't think . . . I would be able to handle what I'm facing now." Mentee 4 expressed similar feelings: "I just felt like. . . I can manage my way through [because] I always felt like there were people to whom I could go to ask questions."

Sub-theme 1: Having a mentor who was available fostered feelings of security. A common experience among mentees was that they felt their mentors were always available to answer their questions as they attempted to transfer newly learned knowledge and skills. This appeared to help mentees feel more secure as they were learning the job. For instance, Mentee 2 expressed the following:

[my mentor] was available almost all of the time. . . he made it clear whatever I needed never hesitate to call. . . it was just really important to feel like you're not there alone. There is somebody to go to and if he doesn't have the answer, he will help you find it. And it was rare that he didn't have an answer. That security blanket feeling was very important.

In addition, Mentee 5 indicated that some of the standards she learned about in training did not precisely apply to new components of the courses she was assigned to write. As a result, she had to apply the standards more generally which required creativity on her part. Despite this challenge, she never felt concerned because she "had so much support" and was "sheltered inside this perfect little team."

Feelings of security seemed to be particularly important to the success of mentees given the context in which this study took place. Both mentees and mentors talked about how challenging the work environment was at times because of frequent organizational 
changes. Mentees reported that it was challenging "to keep up with changes" particularly while trying to learn a new job. Frequent changes made it difficult for mentees to acclimate to the job because, as one mentor remarked, there was "a lack of understanding about what you're supposed to be doing."

Sub-theme 2: Having a mentor who is reassuring minimizes anxiety and fear. Another common experience among mentees was that their mentors were reassuring, which seemed to be particularly important given that many mentees had anxieties and fears about correctly applying what they learned in training once on the job. For instance, Mentor 1 noticed fear among some of her mentees: "There was always a sense of being afraid to screw up because [the mentees] thought they would get in a lot of trouble for it." She also remarked that some mentees are coming out of training "terrified" because now they have to "apply everything" they learned. Mentor 2 commented that one of her mentees worried: “if I don't do it exactly right like they did in training I'm going to get a bad review."

Mentees expressed how helpful it was to have mentors who were reassuring, especially given the volume of information they were expected to learn and apply. For instance, Mentee 4 commented:

The thing that helped me most was the constant reassurance that this is crazy and [the acknowledgement that] you don't know what is going on and it's so much. I think that just gave me the freedom to be like. . ok they get that I'm competent but they also get that this is like. . . hard. And it's going to take a really long time to be able to do the work. So it was really the freedom to not know. It gave me 
sort of the confidence to be able to figure out what I had to figure out. Because whenever I had a question I didn't feel stupid.

Similarly, Mentee 2 expressed how helpful it was to have reassurance from his mentor after he experienced a problem with an organizational stakeholder:

"[having the problem] made me very anxious and I wanted to make it better somehow. And [my mentor]. . . this is what [my mentor] brought several times... he is cool and calm. . . he doesn't get flustered whether by phone or emails or whatever. . . [he said] 'this is nothing to worry about, we'll get this fixed."'

Theme 2: Social support helped mentees overcome obstacles to transferring learned knowledge and skills which, in turn, improved perceptions of behavioral control. Perception of behavioral control refers to the degree to which one views a behavior, such as transferring learned knowledge and skills, as easy or difficult. Perceptions of ease or difficulty are influenced by the presence of obstacles (Ajzen, 1991). An analysis of mentee responses revealed that social support helped mentees overcome obstacles that otherwise would have made it difficult to successfully transfer learned knowledge and skills. For example, Mentee 3 indicated he occasionally suffered from writer's block which prevented him from developing a necessary portion of a course. When this happened, he said that he would go to his mentor for help: “. . . if I just got stuck, I would walk over and just go I don't know how to get started on this and he would usually throw out some ideas. Pretty quickly we would come up with something."

Mentee 2 also encountered obstacles and approached his mentor for help. In one specific instance, an organizational stakeholder was unavailable for an extended period of 
time and he was concerned about progressing without input from the stakeholder. He expressed his concerns to his mentor and he said "she was good about 'let's do this until you hear back from him and just forge ahead."' These examples illustrate how instrumental mentors were in helping mentees overcome obstacles that would have made transferring what they learned more difficult. 
Table 5

Themes and Exemplar Quotes related to Effects of Mentoring and Social Support on Transfer Motivation $(n=5)$

\begin{tabular}{|c|c|c|c|c|}
\hline \multirow[b]{2}{*}{$\begin{array}{c}\text { Dimensions } \\
\text { of } \\
\text { Support }\end{array}$} & \multicolumn{4}{|c|}{ Effects on Transfer Motivation } \\
\hline & Themes & $\begin{array}{l}\text { No. of participants } \\
\text { whose comments } \\
\text { pertained to } \\
\text { themes }\end{array}$ & $\begin{array}{c}\% \text { of comments } \\
\text { that pertained } \\
\text { to themes }\end{array}$ & Exemplar Quotes \\
\hline Mentoring & $\begin{array}{l}\text { Mentoring influenced mentee } \\
\text { feelings about transferring } \\
\text { learned knowledge and skills } \\
\text { which, in turn, contributed to } \\
\text { mentee attitudes about } \\
\text { transferring learned knowledge } \\
\text { and skills. }\end{array}$ & 5 & 9.6 & $\begin{array}{l}\text { "I just felt like. . . I can manage my way through } \\
\text { [because] I always felt like there were people to } \\
\text { whom I could go to ask questions." } \\
\text { "The thing that helped me most was the constant } \\
\text { reassurance that this is crazy. . . . I think that just } \\
\text { gave me the freedom to be like. . . ok they get that } \\
\text { I'm competent but they also get that this is like. . . } \\
\text { hard." } \\
\text { "[My mentor] was available almost all of the time. . . } \\
\text { he made it clear whatever I needed never hesitate to } \\
\text { call. . . it was just really important to feel like you're } \\
\text { not there alone. . . That security blanket feeling was } \\
\text { very important." }\end{array}$ \\
\hline $\begin{array}{l}\text { Social } \\
\text { Support }\end{array}$ & $\begin{array}{l}\text { Social support helped mentees } \\
\text { overcome obstacles to } \\
\text { transferring learned knowledge } \\
\text { and skills which, in turn, } \\
\text { increased perceptions of } \\
\text { behavioral control. }\end{array}$ & 4 & 8.6 & $\begin{array}{l}\text { ". . if I just got stuck, I would walk over and just go } \\
\text { I don't know how to get started on this and he would } \\
\text { usually throw out some ideas." } \\
\text { "[My mentor] was good about 'let's do this until you } \\
\text { hear back from him and just forge ahead."," }\end{array}$ \\
\hline
\end{tabular}


Training transfer. Mentees reported that they transferred most of what they learned in training once on the job. Specifically, they said they transferred knowledge and skills related to how courses are structured and how to write different components of courses. For instance, Mentee 3 said, "the easiest thing for me was writing the [components of the course]. Because of our training, I knew what I had to do." Some mentees indicated that they had difficulty transferring what they learned about operational processes. Both mentees and mentors described operational processes as "complex" and "nuanced" and indicated that at least one operational process had undergone significant changes. As a result, information presented in training about the processes may have been obsolete once changes occurred, making transfer impossible.

Mentors also confirmed that mentees transferred most of what they learned in training about how to write courses once on the job. For instance, Mentor 3 said that mentees "know what they're doing" and "can articulate what they're supposed to do" after participating in training. However, some mentors indicated that transfer is somewhat dependent upon individual differences, such as personality and prior job experience. For instance, Mentor 5 suggested that mentees who have an instructional design background tend to "be more ready" coming out of training compared to mentees who have a writing background.

In addition to confirming that training transfer occurred, an analysis of mentee responses revealed how their experiences of support influenced their attempts to transfer learned knowledge and skills. Two themes emerged related to the role of support in 
training transfer. The themes are presented in the sections below. A summary of the themes and relevant quotations also are presented in Table 6 at the end of this section.

Theme 1: Mentoring contributed to mentee perceptions of support which, in turn, may have increased the likelihood that mentees would reciprocate by transferring learned knowledge and skills. Mentees reported that their mentors were available, attentive, and reassuring. These characteristics appeared to contribute to the overall perception among mentees that their mentors cared about their well-being and success. For instance, Mentee 1 said that her mentor was "willing to take the time" to give her feedback and "went out of her way. . . to help me grow into my job" despite "being so busy." Similarly, Mentee 4 said, "I really felt taken care of." As mentees acknowledged how their mentors helped them, their comments reflected appreciation. For instance, Mentee 1 said, “[my mentor] is such a nurturing person. She just does it. I mean it's just who she is. So that was really lucky for me that there was somebody like that." Mentee 4 said, “[my mentor's] support was really like nonfailing. . . . as busy as she was. . . I felt completely supported by her."

Mentees' perceptions that their mentors cared about their well-being and their ensuing appreciation may have influenced how hard they worked to transfer learned knowledge and skills. Organizational support theory supports this assertion. This theory suggests that mentors often are thought of as personifications of the organization itself (Levinson, 1965; Rhodes \& Eisenberger, 2002). Therefore, when a mentee perceives that a mentor is supportive, he or she also is likely to perceive the organization as supportive as well. The more mentees perceive that an organization is supportive, the more likely 
they are to engage in behaviors that benefit the organization, such as transferring learned knowledge and skills to the job (Eisenberger et al., 1986; Eisenberger et al., 2002). This behavior is based on the norm of reciprocity which suggests that when employees are treated well by the organization, they feel obligated to repay the organization by improving their performance (Gouldner, 1960).

Theme 2: Coaching contributed to mentees' understanding of how to correctly transfer learned knowledge and skills. One of the primary goals of mentee training was to help mentees learn how to write courses that meet departmental standards. Once on the job, mentees reported that they attempted to apply what they learned about writing courses. They also reported that their mentors often coached them on how to further adjust or "tweak" their writing so that it better met departmental standards. For instance, Mentee 5 said that her mentor gave her the following feedback on her writing: "you might want to adjust this objective a little bit here because we like to have our objectives at this level." Similarly, Mentee 2 said, "[My mentor] was very good at teaching the concepts. . you know being specific about why whatever I wrote just wasn't quite what was needed."

Mentors confirmed that they gave their mentees a significant amount of feedback on their writing. For example, Mentor 1 said she would talk to her mentees about "why [their writing] does or does not meet the [standard]. . . and talk out loud or maybe give them some suggestions [to improve]." Mentor 2 reported that she helped her mentees understand how departmental standards applied to writing nonstandard courses. She said, "that was a little difficult with [the mentee] and it's taken longer to get her to understand 
'oh yes this is what I've learned in training but how do I take that and apply it to a. . . [nonstandard course]." Given that writing is a skill that typically develops over time, it appeared helpful that mentors provided ongoing feedback to mentees to help them correctly apply departmental standards to their writing. 
Table 6

Themes and Exemplar Quotes related to the Effects of Mentoring and Coaching on Training Transfer $(n=5)$

\begin{tabular}{|c|c|c|c|c|}
\hline \multirow[b]{2}{*}{$\begin{array}{l}\text { Dimensions of } \\
\text { Support }\end{array}$} & \multicolumn{4}{|c|}{ Effects on Training Transfer } \\
\hline & Themes & $\begin{array}{l}\text { No. of participants } \\
\text { whose comments } \\
\text { pertained to themes }\end{array}$ & $\begin{array}{c}\% \text { of comments } \\
\text { that pertained to } \\
\text { themes }\end{array}$ & Exemplar Quotes \\
\hline Mentoring & $\begin{array}{l}\text { Mentoring contributed } \\
\text { to mentee perceptions of } \\
\text { support which, in turn, } \\
\text { may have increased the } \\
\text { likelihood that mentees } \\
\text { would reciprocate by } \\
\text { transferring learned } \\
\text { knowledge and skills. }\end{array}$ & 5 & 13.5 & $\begin{array}{l}\text { "[my mentor's] support was really like } \\
\text { nonfailing. . . .as busy as she was. . . I felt } \\
\text { completely supported by her." } \\
\text { "[My mentor] went out of her way. . . to help } \\
\text { me grow into my job." }\end{array}$ \\
\hline Coaching & $\begin{array}{l}\text { Coaching contributed to } \\
\text { mentees' understanding } \\
\text { of how to correctly } \\
\text { transfer learned } \\
\text { knowledge and skills. }\end{array}$ & 5 & 22.1 & $\begin{array}{l}\text { "... we talked about the [departmental } \\
\text { standards] to get the. . . course where it needs to } \\
\text { be." } \\
\text { "We would read through [my writing] together } \\
\text { and [my mentor] would give me suggestions. } \\
\text { "[My mentor] was very good at teaching the } \\
\text { concepts. . . you know being specific about why } \\
\text { whatever I wrote just wasn't quite what was } \\
\text { needed." } \\
\text { "It was very confusing to me what goes in [that } \\
\text { part of the course]. . [my mentor] took the time } \\
\text { to help me with that." }\end{array}$ \\
\hline
\end{tabular}




\section{Type of Training and Training Transfer}

Research question 3. How does participation in formal and informal new hire training versus participation in informal new hire training alone influence training transfer among mentees, as perceived by mentors?

An analysis of mentor responses revealed that training transfer occurred both among mentees who participated in formal and informal new hire training and among mentees who participated in informal training alone. This was consistent with the quantitative results of this study. While the type of training did not influence whether training transfer occurred, it appeared to influence the ease and speed at which it occurred. For instance, Mentor 5 commented that mentees who participated in informal training alone generally transferred what they learned; however, "it wasn’t instant." Mentor responses suggested that formal new hire training provided mentees with some important benefits that made training transfer easier and more attainable. In the following section, themes related to the influence of type of training on the transfer process are

presented. A summary of the themes and exemplar quotations also are presented in Table 7 at the end of this section.

\section{Theme 1: Formal new hire training provided mentees with a clear set of} standards and expectations. Mentees who received formal new hire training participated in a two-day workshop on how to write courses. During the workshop, they received a hand-out of the departmental standards for writing courses. Once on the job, mentees could refer to the hand-out, and often did, as they attempted to apply what they learned about writing courses. For instance, Mentor 4 said: 
[mentees] could go back to written materials that they could look at or print out something and hang it on their wall to remind them. So, it's like a concrete learning that [they] can refer back to whereas the [mentees who participated in informal training only] didn't have that.

Mentor 5 commented on how helpful it was that mentees had a set of standards to refer to: "now we have the [standards] and that also helps greatly because that gives [mentees] an idea why they have to write a certain way." Mentor 2 agreed that the standards provided "a target that you were shooting for. . . you had an expectation to meet." Prior to the existence of formal new hire training, there was not a clear or universal set of standards or expectations. Mentor 2 indicated that information that mentees did receive was inconsistent at best: "whatever information you got depended on the person you asked and that depended how long had they been with the company." The lack of standards and expectations proved to be very frustrating to mentees. For instance, Mentor 2 said, "when you have no clear. . standard or target or direction, I think it became a very demoralizing situation for [mentees]. . . . They got so frustrated that. . . you're told that you're not meeting expectations but nobody can really tell you what that expectation is." Mentor 2 also said that because there was no clear set of standards, "the feedback I had to give was "no this isn't quite right,"” and as a result, some mentees “stopped trying." Similarly, Mentor 1 said:

back in the past when there wasn't any formalized training, that was one of the biggest complaints of [mentees]. . you know how can I change this if it is just in track changes and I don't know why it's changed. So, we had a lot of [mentees] 
who would just accept all changes and wouldn't look through them because it would be too hard for them to understand anyways.

The lack of clear standards seemed to influence mentees in two ways. First, as mentees attempted to transfer what they learned about writing courses, they had to try to remember what their mentor told them about writing specific components of courses rather than being able to refer to hand-out that outlined a set of standards. Second, mentees became frustrated as they attempted to transfer learned knowledge and skills because they did not know what was expected of them. This seemed to decrease mentees' transfer motivation given that some simply "stopped trying."

\section{Theme 2: Formal new hire training provided mentors and mentees with a}

common language from which to work. Mentors reported that one of the primary benefits of formal new training was that it created a common language they could use when coaching mentees. For instance, Mentor 2 said, "it was really helpful for me to know what the new person's frame of reference was, what key terms were they given, what was training calling something, what was the process that they were being given." Similarly, Mentor 4 recalled saying to mentees, "remember what you learned [in training] about writing [this part of the course]" as she was coaching them on their writing.

Prior to the existence of formal new hire training, many mentors recalled feeling frustrated by not having a common language. Mentor 2 said, "it was very frustrating both for me and frustrating for [the mentee] to talk about the writing because. . . I [could] recognize that this is not the [correct] way, but I can't specifically tell you why because again there was no common ground. She elaborated saying, "sometimes [before the 
existence of formal training] you weren't able to give that feedback because you didn't have a way to explain it or explain it in a way that the [mentee] could understand it in a meaningful way so that now they could improve their work." Having a common language from which to work seemed to help mentors more effectively articulate feedback to mentees about correctly applying learned knowledge and skills. 
Table 7

Themes and Exemplar Quotes related to the Effects of Formal Training on Training Transfer ( $n=5)$

\begin{tabular}{|c|c|c|c|}
\hline Themes & $\begin{array}{l}\text { No. of participants } \\
\text { whose comments } \\
\text { pertained to themes }\end{array}$ & $\begin{array}{l}\% \text { of comments that } \\
\text { pertained to themes }\end{array}$ & Exemplar Quotes \\
\hline $\begin{array}{l}\text { Formal new hire training } \\
\text { provided mentees with a clear } \\
\text { set of standards and } \\
\text { expectations. }\end{array}$ & 3 & 26.6 & $\begin{array}{l}\text { "[mentees] could go back to written materials that they could } \\
\text { look at or print out something and hang it on their wall to remind } \\
\text { them. So, it's like a concrete learning that [they] can refer back to } \\
\text { whereas the [mentees who participated in informal training only] } \\
\text { didn't have that." } \\
\text { "now we have the [standards] and that also helps greatly because } \\
\text { that gives [mentees] an idea why they have to write a certain } \\
\text { way." } \\
\text { "back in the past when there wasn't any formalized training, that } \\
\text { was one of the biggest complaints of [mentees]. . you know how } \\
\text { can I change this if it is just in track changes and I don't know } \\
\text { why it's changed. So, we had a lot of [mentees] who would just } \\
\text { accept all changes and wouldn't look through them because it } \\
\text { would be too hard for them to understand anyways." }\end{array}$ \\
\hline $\begin{array}{l}\text { Formal new hire training } \\
\text { provided mentors and mentees } \\
\text { with a common language from } \\
\text { which to work. }\end{array}$ & 3 & 46.6 & $\begin{array}{l}\text { "it was really helpful for me to know what the new person's } \\
\text { frame of reference was, what key terms were they given, what } \\
\text { was training calling something, what was the process that they } \\
\text { were being given." } \\
\text { "sometimes [before the existence of formal training] you weren't } \\
\text { able to give that feedback because you didn't have a way to } \\
\text { explain it or explain it in a way that the [mentee] could } \\
\text { understand it in a meaningful way so that now they could } \\
\text { improve their work." }\end{array}$ \\
\hline
\end{tabular}




\section{Summary}

The quantitative results of this study revealed three major findings: 1) there are significant positive relationships between the dimensions of support (mentoring, coaching, social support, and task support) and training transfer; 2) transfer motivation mediates the relationships between three of the four dimensions of support (mentoring, coaching, and social support) and training transfer; and 3) there are no significant differences in training transfer among mentees who participated in formal and informal new hire training and mentees who participated in informal new hire training alone. The qualitative results of this study also revealed three major findings that partially corroborate the quantitative results: 1) mentoring and social support influence transfer motivation; 2) mentoring and coaching influence training transfer; and 3) formal new hire training contributes to the ease and speed at which training transfer occurs.

In the Chapter 5, the quantitative and qualitative results are integrated and the outcomes of the study are presented in the context of existing theory and research. In addition, the limitations of this study are discussed and recommendations are made for future research and practice. Finally, the impact of the results of this study on social change is addressed. 
Chapter 5: Discussion, Conclusions, and Recommendations

\section{Introduction}

The primary purpose of this sequential explanatory mixed methods study was to examine the influence of specific dimensions of support (mentoring, coaching, social support, and task support) on transfer motivation and training transfer. Existing research does not provide conclusive evidence regarding the influence of supervisor support on training transfer. It also does not account for the differential effects of specific dimensions of support on transfer motivation or training transfer (Al-Eisa et al., 2008; Chiaburu, 2010; Chiaburu et al., 2010; Cromwell \& Kolb, 2004; Devos et al., 2007; Liebermann \& Hoffman, 2008; Nijman et al., 2006; Saks \& Belcourt, 2006; Sookhai \& Budworth, 2010; Velada et al., 2007). The findings from this study address these gaps in the research. The secondary purpose of this study was to determine if and how the type of training offered influenced training transfer.

During the first phase of this study, mentees who develop curriculum for a large educational organization were surveyed to assess their motivation to transfer knowledge and skills learned in training, their attempts to transfer knowledge and skills learned in training, and the degree to which their mentors exhibited coaching, mentoring, social support, and task support behaviors. During the second phase of this study, five mentees were interviewed to determine how their experiences of support influenced their motivation and attempts to transfer learned knowledge and skills. Five mentors were also interviewed to determine how the type of training in which mentees participated influenced their attempts to transfer learned knowledge and skills. In the third and final phase of this study, quantitative and qualitative findings were integrated and conclusions 
about the influence of dimensions of support and type of training on training transfer were drawn.

In mixed methods research, the integration of findings may lead to the following outcomes: quantitative and qualitative findings may converge, yielding the same conclusions; quantitative and qualitative findings may explain different aspects of the phenomenon being studied, and therefore, complement each other; or quantitative and qualitative findings may diverge, yielding contradictory conclusions (Erzberger \& Kelle, 2003). In this study, quantitative and qualitative findings converged and were complimentary in some instances, providing a more comprehensive picture of how dimensions of support and the type of training offered influence training transfer. In other instances, quantitative and qualitative findings diverged suggesting that additional research may need to be conducted.

\section{Summary and Interpretation of Findings}

The research question that guided this study was: How do dimensions of support (mentoring, coaching, social support, and task support) influence training transfer? To address this question, the survey data were analyzed to determine if there were relationships between the dimensions of support and training transfer and, if so, whether transfer motivation mediated those relationships. The interview transcripts also were analyzed to determine how mentees' experiences of the dimensions of support influenced their motivation and attempts to transfer knowledge and skills learned in training.

\section{Dimensions of Support and Training Transfer}

The findings from the correlation analysis indicated that there are significant positive relationships between the dimensions of support and training transfer. This 
suggests that higher levels of mentoring, coaching, social support, and task support are associated with higher levels of training transfer. This also is consistent with findings from Saks and Belcourt (2006) and Velada et al. (2007) which indicated that higher levels of supervisor support are associated with higher levels of training transfer. However, it is inconsistent with findings from Devos et al. (2007) which indicated no significant correlation between supervisor support and training transfer. Devos et al. expressed skepticism regarding their findings, suggesting that they may be inaccurate due, in part, to the low level of support provided at the organizations in which the study took place and the unlikelihood that it influenced behavior.

\section{The Mediating Role of Transfer Motivation}

The findings from this study indicated that transfer motivation mediates the relationships between three dimensions of support (mentoring, coaching, and social support) and training transfer. These findings are consistent with previous research that indicates that supervisor support is a significant predictor of transfer motivation (Al-Esia et al., 2008; Chiaburu et al., 2010) and training transfer (Saks \& Belcourt, 2006) and that transfer motivation is a significant predictor of training transfer (Bates et al., 2007; Chiaburu \& Lindsay; 2008; Devos et. al., 2007; Lieberman and Hoffman, 2008; Van den Bossche et al., 2010). These findings also extend previous research because they offer new information about how specific dimensions of support influence transfer motivation and training transfer. In the next several paragraphs, the mediation findings will be discussed in further detail, within the context of qualitative findings and existing research and theory. 
Mentoring. The findings from this study indicated that transfer motivation partially mediates the relationship between mentoring and training transfer. This suggests that mentoring affects training transfer both indirectly, through transfer motivation, and directly. This means that the more mentoring mentees receive the more likely they are to be motivated to transfer and make attempts to transfer learned knowledge and skills.

The qualitative results corroborated this finding. An analysis of mentee transcripts revealed that mentoring behaviors, such as being available and providing reassurance, influenced mentee motivation to transfer learned knowledge and skills. For instance, mentoring seemed to increase mentees' feelings of security and minimize their feelings of anxiety related to transferring newly learned knowledge and skills to the job which, in turn, may have contributed to their motivation to transfer. These findings are consistent with research that suggests that supervisors can encourage transfer efforts by decreasing anxiety about transferring newly learned knowledge and skills (Martin, 2010a). The theory of planned behavior also provides support for these findings because it suggests that one's attitudes and feelings about a behavior predict one's motivation to perform the behavior (Ajzen, 1991).

The qualitative results of this study also revealed that mentoring influences training transfer. For instance, an analysis of mentee transcripts revealed that mentoring influenced mentee perceptions of support. One mentee described her mentor's support as "nonfailing" while another indicated that her mentor "went out of her way. . . to help me grow into my job." Mentee perceptions that their mentors were supportive may have led them to "repay" their mentors by attempting to transfer learned knowledge and skills to the job. Organizational support theory supports this assertion suggesting that employees 
who feel supported by the organization and its leaders are more likely to engage in behaviors that ultimately benefit the organization, such transferring learned knowledge and skills (Eisenberger et al., 1986; Eisenberger et al., 2002; Rhoades \& Eisenberger, 2002).

Coaching. The findings from this study indicated that transfer motivation fully mediates the relationship between coaching and training transfer, suggesting that coaching influences training transfer through transfer motivation. The qualitative results did not corroborate this finding. No themes emerged that indicated that coaching influenced transfer motivation. The qualitative results also appeared to be somewhat contradictory to the findings because they suggest that coaching influences training transfer. Existing qualitative research supports this finding, suggesting that coaching employees about how to apply learned knowledge and skills facilitates training transfer (Austin et al., 2006; Gilpin-Jackson \& Busche, 2006).

Upon further analysis, however, it appeared that the qualitative findings addressed an aspect of training transfer that was not assessed during the quantitative portion of this study. For example, the qualitative results suggest that coaching helped mentees correctly transfer learned knowledge and skills. The survey, that was distributed in the quantitative phase of this study, did not assess whether participants correctly transferred learned knowledge and skills; rather, it assessed whether participants transferred learned knowledge and skills at all. Therefore, the qualitative results are not completely contradictory in this case. Even so, further research should be conducted to verify that transfer motivation fully mediates the relationship between coaching and training transfer. 
Social support. The findings from this study revealed that transfer motivation fully mediates the relationship between social support and training transfer, suggesting that social support influences training transfer indirectly through transfer motivation. The qualitative results corroborated this finding, suggesting that social support influenced transfer motivation through the elimination of obstacles to training transfer. The theory of planned behavior provides support for these findings because it suggests that the elimination of obstacles improves perceptions of behavioral control (ease or difficulty of the behavior) which, in turn, predicts motivation to perform the behavior (Ajzen, 1991).

Task support. The findings from this study indicated that transfer motivation does not mediate the relationship between task support and training transfer, rather task support influences training transfer directly. The qualitative results are somewhat contradictory to this finding because no themes emerged suggesting that task support influenced training transfer. However, most of the mentee comments regarding task support were not reflective of how the construct was assessed in the quantitative portion of this study. For instance, mentees indicated that their mentors assigned them small tasks to give them an opportunity to use what they learned in training, but in many cases did not help them complete the tasks as suggested in the survey.

\section{Type of Training and Training Transfer}

The findings from this study indicated that there were no significant differences in training transfer among mentees who participated in formal and informal new hire training and mentees who participated in informal new hire training alone. This suggests that the type of training offered does not affect training transfer. The qualitative results partially corroborate this finding. An analysis of mentor responses revealed that mentees 
who participated in informal new hire training alone transferred learned knowledge and skills just as often as mentees who participated in both formal and informal new hire training.

The qualitative results, however, provided further explanation about the effect of the type of training on training transfer that could not be gleaned from an independent samples t-test. These results suggest that formal new hire training positively influenced the ease and speed of training transfer because it provided mentees with a clear set of standards and expectations and a common language from which to work with mentors. Therefore, training transfer was easier and occurred more quickly among mentees who participated in formal new hire training.

\section{Limitations of the Study}

This study had several limitations; therefore, the findings should be interpreted with caution. One limitation of this study is that a cause and effect relationship between the dimensions of support, transfer motivation, and training transfer cannot be established. However, the results from the mediation analysis and the emergent themes provided some evidence for a cause and effect relationship between mentoring, coaching, and social support and transfer motivation, and between mentoring and coaching and training transfer.

Another limitation of this study was that convenience sampling was used to recruit participants from one specific organization. These participants may not have been representative of the population being studied. To address this limitation, the sample in this study was compared to larger random samples in similar studies on training transfer. The age distribution of participants was similar to that of previous studies, however, the 
sample in this study included more female participants and more educated participants. As a result, the sample in this study may not be representative of the population and the results may not be generalizable to employees who work in other organizations or other professions.

Other limitations of this study were the small sample size $(n=48)$ and nonnormal distributions among the transfer motivation, training transfer, and task support variables. To address these limitations, the bootstrapping methods were used. Bootstrapping methods are superior to other methods for testing mediation, such as the Sobel test and Baron and Kenny's (1986) steps for mediation analysis, because they are robust against violations of normality, have a higher statistical power, and have a lower risk of Type I errors (MacKinnon et al., 2002; Preacher \& Hayes, 2004; Preacher \& Hayes, 2008). For instance, in this study, bootstrapping results invalidated the initial mediation results that suggested that transfer motivation mediated the relationship between task support and training transfer.

Another limitation of this study was that the survey relied on self-report ratings to assess transfer motivation, training transfer, and support exhibited by mentors. As a result, mentees may have been more inclined to falsely report high levels of transfer motivation and training transfer particularly if they thought they would be viewed more favorably. Studies that rely only on self-report data to assess training transfer tend to have inflated effects (Taylor et al., 2009). To address this limitation, more than one rating source was used in this study. Mentors were interviewed about the degree to which mentees transferred learned knowledge and skills. Most mentors indicated that there was 
a high level of training transfer among mentees which was consistent with the self-report data.

One final limitation of this study is that the evidence suggests that the Mentoring and Communication Support Scale, used to assess the dimensions of support, was not reliable based on test-retest reliability results. This may be because the organization in which the study took place underwent a significant restructuring approximately three weeks before the surveys were distributed. The restructuring may have influenced mentee responses to the first and second surveys in two ways. First, research suggests that organizational change is associated with negative attitudes about one's job and the organization (Kuokkanen, Suominen, Harkonen, Kikkurainen, \& Doran, 2009; Rafferty \& Griffin, 2006; Yu, 2009). Given that employees often see individuals in leadership roles as personifications of the organization (Levinson, 1965), participants in this study may have transferred their negative attitudes about the organization to their mentors. Participants who had negative attitudes about their mentors may have underreported the level of support they received from them in one or both surveys. Second, during the time frame in which mentees completed the first and second surveys, work teams were disbanded and newly formed and many mentees were reassigned to different mentors. As a result, mentees may have completed the first survey with one mentor in mind and the second survey with another mentor in mind who may have provided a greater or lesser degree of support than the first mentor.

Even if mentees completed the surveys based on the same mentor, their mentor may have provided varying support from day to day. The mentors who were interviewed for the qualitative portion of this study indicated that it was challenging, at times, to 
provide as much support to mentees as they would have liked, particularly when their schedules were hectic. Therefore, mentees may have had different perceptions about the level of support they received from day to day and week to week.

\section{Recommendations for Future Research}

The focus of this study was on the multidimensional influence of supervisor support on transfer motivation and training transfer. To date, no other studies have examined the influence of mentoring, coaching, social support, and task support on transfer motivation and training transfer. Given the exploratory nature of this study, additional research is needed to replicate the findings. Additional research also is needed to assess the test-retest reliability of the Mentoring and Communication Support Scale in a stable context and to address the contradictory findings in this study regarding the influence of coaching and task support, in particular, on transfer motivation and training transfer. Mixed methods research should be used to conduct future research in this area. Mixed methods research is advantageous because it can address many of the limitations in the existing transfer research, such as common method variance and single-source bias (Blume et al., 2010; Taylor et al., 2009).

Future research also should be conducted with larger sample sizes, across other organizations and professions, and in other countries. This study was limited to one educational organization in the United States and the sample size was small. As a result, the findings cannot be generalized to employees in other organizations, other professions, or other countries. Previous transfer research that has been conducted in private and public organizations, in manufacturing, human services, and technology industries, and in countries such Germany, Belgium, and Saudi Arabia, provides evidence for the effects of 
supervisor support on transfer motivation and training transfer (Al-Eisa et al., 2008;

Austin et al., 2006; Chiaburu et al., 2010; Liebermann \& Hoffman, 2008; Nijman et al., 2006; Saks \& Belcourt). Researchers should attempt to replicate these findings by using a multidimensional conceptualization of supervisor support.

Lastly, other factors that influence training transfer should be taken into account in future research. For instance, this study did not take into account the individual, design, or environmental factors (such as self-efficacy, training design, and peer support), that have been found to influence transfer motivation and/or training transfer (Al-Eisa et al., 2008; Devos et al., 2007; Gilpin-Jackson-Busche, 2006; Martin, 2010a; Martin, 2010b; Velada et al., 2007). Existing models of training transfer incorporate many of these factors to explain how and why training transfer occurs (Baldwin \& Ford, 1988; Holton 1996; Lim \& Morris, 2006; Nijman et al., 2009). Researchers should examine how mentoring, coaching, social support, and task support fit into these models and whether other factors, such as self-efficacy, mediate or moderate the effects of the dimensions of support on transfer motivation and/or training transfer.

\section{Recommendations for Practice}

The findings from this study highlight the integral role that mentors and supervisors play in helping employees successfully transfer what they learned in training to the job. The findings also highlight the benefits of providing employees with formal training. Therefore, there are several implications for practice. First, training professionals should make arrangements for employees to receive post-training support to improve the likelihood that they will transfer what they learned. This is particularly 
important when employees are new because they will likely have many questions about how to apply what they learned in training.

Second, training professionals should educate mentors and supervisors about the specific behaviors they should exhibit to help employees transfer what they learned. The findings from this study suggest that behaviors such as providing feedback, being available to answer questions, and helping employees overcome obstacles can facilitate training transfer. Lastly, training professionals should consider offering new employees formal training that occurs in a classroom-type setting and provides them with hand-outs that they can refer to when attempting to transfer what they learned in training once back on the job. The findings from this study suggest that offering formal training to new employees may facilitate training transfer by providing them with a clear standards and expectations and a common language from which to work with their mentors and/or supervisors when they have questions and encounter challenges.

\section{Implications for Social Change}

There are several positive social change implications at the individual, organizational, and societal levels based on the findings from this study. First, the findings can be used to improve the training and job experiences of individual employees, particularly those who are new in their position. For instance, offering employees formal training, in which a clear set of standards and expectations is provided along with takeaway materials, can facilitate the transfer process. The findings from this study suggest that offering this type of training to employees improves the ease and speed at which they transfer learned knowledge and skills to the job. As a result, they may be less likely to experience frustration, stress, and anxiety related to their performance at a new job. 
The findings from this study also suggest that providing employees with mentoring, coaching, social support, and task support in the posttraining environment helps facilitate training transfer. Employees who receive these types of support are more likely to transfer what they learned and, in turn, more likely to improve their job performance. Improved job performance has been associated with a number of positive employee outcomes such as increased job satisfaction and promotion eligibility (Van Scotter, 2000). Improved job performance also has been associated with a number of positive organizational outcomes such as increased productivity, innovation, and quality of work (Kahya, 2008). Thus, there is a clear benefit to the organization as well.

Finally, in the context of curriculum development, the findings from this study have larger-scale, societal implications as well. Employees who successfully transfer what they learned from curriculum development training, such as knowledge about pedagogy, diverse learning styles, and assessment strategies, are more likely to develop academic programs and courses that better meet the learning needs of a diverse population of students. Offering superior academic programs and courses ultimately benefits universities because it contributes to their integrity, reputation, and eventual success.

\section{Conclusion}

Low training transfer rates among employees continue to plague training professionals, employees, supervisors, and organizations, costing billions of dollars annually (Patel, 2010). One factor that may be particularly useful in addressing low training transfer rates is posttraining supervisor support. Some existing studies suggest that supervisor support, as a unidimensional construct, positively affects training transfer 
(Austin, Weisner, Schrandt, Glezos-Bell, \& Murtaza, 2006; Gilpin-Jackson \& Busche, 2006; Saks \& Belcourt, 2006). However, such studies do not indicate the specific behaviors supervisors should exhibit to help their employees transfer what they learned. The findings from this study extend previous research by offering new insights about the multidimensional effects of supervisor support. Specifically, supervisors who exhibit mentoring, coaching, social support and task support behaviors are more likely to facilitate training transfer among their employees either directly or indirectly through transfer motivation. Ultimately, improved training transfer rates yield favorable outcomes for employees, organizations, and students who may benefit from higher quality academic programs and courses. 


\section{References}

Ajzen, I. (1991). The theory of planned behavior. Organizational Behavior and Human Decision Processes, 50(2), 179-211. doi:10.1016/0749-5978(91)90020-T

Al-Eisa, A.S., Furayyan, M.A., \& Alhemound, A.M. (2008). An empirical examination of the effects of self-efficacy, supervisor support and motivation to learn on transfer intention. Management Decisions, 47(8), 1221-1244. doi:10.1108/00251740910984514

Alliger, G.M., Tannenbaum, S.I., Bennett, W., Jr., Traver, H., \& Shotland, A. (1997). A meta-analysis of the relations among training criteria. Personnel Psychology, 50(2), 341-358. doi:10.1111/j.1744-6570.1997.tb00911.x

Arnold, J., Loan-Clarke, J., Coombs, C., Wilkinson, A., Park, J., \& Preston, D. (2006). How well can the theory of planned behavior account for occupational intentions? Journal of Vocational Behavior, 69(3), 374-390. doi:10.1016/j.jvb.2006.07.006

Arthur, W., Jr., Bennett, W., Jr., Stanush, P.L., \& McNelly, T.L. (1998). Factors that influence skill decay and retention: A quantitative review and analysis. Human Performance, 11(1), 57-101. doi:10.1207/s15327043hup1101_3

Austin, M.J., Weisner, S., Schrandt, E., Glezos-Bell, S., \& Murtaza, N. (2006). Exploring the transfer of learning from an executive development program for human services managers. Administration in Social Work, 30(2), 71-90. doi:10.1300/J147v30n02_06

Axtell, C.M., Maitlis, S., \& Yearta, S.K. (1997). Predicting immediate and longer-term transfer of training. Personnel Review, 26(3), 201-213. doi:10.1108/00483489710161413 
Baldwin, T.T. \& Ford, J.K. (1988). Transfer of training: A review and directions for future research. Personnel Psychology, 41, 63-105. doi:10.1111/j.1744-6570.1988.tb00632.x

Bandura, A. (1986). Social foundations of thought and action: A social cognitive theory. Englewood Cliffs, NJ: Prentice Hall.

Baron, R.M. \& Kenny, D.A. (1986). The moderator-mediator variable distinction in social psychological research: Conceptual, strategic, and statistical considerations. Journal of Personality and Social Psychology, 51(6), 1173-1182. doi:10.1037//0022-3514.51.6.1173

Barrick, M.R. \& Mount, M.K. (1991). The big five personality dimensions and job performance: A meta-analysis. Personnel Psychology, 44(1), 1-26. doi:10.1111/j.1744-6570.1991.tb00688.x

Bates, R. (2004). A critical analysis of evaluation practice: the Kirkpatrick model and the principles of beneficence. Evaluation and Program Planning, 27, 341-347. doi:10.1016/j.evalprogplan.2004.04.011

Bates, R., Kauffeld, S., \& Holton, E.F., III. (2007). Examining the factor structure and predictive ability of the German-version of the Learning Transfer Systems Inventory. Journal of European Industrial Training, 31(3), 195-211. doi:10.1108/03090590710739278

Bell, B.S. \& Kozlowski, S.W.J. (2008). Active learning: Effects of core training design elements on self-regulatory processes, learning, and adaptability. Journal of Applied Psychology, 93(2), 296-316. doi:10.1037/0021-9010.93.2.296 
Bhatti, M.A. \& Kaur, S. (2010). The role of individual and training design factors on training transfer. Journal of European Industrial Training, 34(7), 656-672. doi:10.1108/03090591011070770

Blackler, F. (1995). Knowledge, knowledge work and organizations: An overview and interpretation. Organization Studies, 16(6), 1021-1046.

doi:10.1177/017084069501600605

Blume, B.D., Ford, J.K., Baldwin, T.T., \& Huang, J.L. (2010). Transfer of training: A meta-analytic review. Journal of Management, 36(4), 1065-1105.

doi:10.1177/0149206309352880

Broad, L.M. \& Newstrom, W.J. (1992). Transfer of training. New York: AddisonWesley.

Bryman, A. (2006). Integrating quantitative and qualitative research: How is it done? Qualitative Research, 6(1), 97-113. doi:10.1177/1468794106058877

Burke, L.A. \& Hutchins, H.M. (2007). Training transfer: An integrative literature review. Human Resource Development Review, 6(3), 263-296. doi: $10.1177 / 1534484307303035$

Campbell, D.T. \& Fiske, D.W. (1959). Convergent and discriminant validation by the multitrait-multimethod matrix. Psychological Bulletin, 56(2), 81-105. doi:10.1037/h0046016

Chen, C. \& Chiu, S. (2008). An integrative model linking supervisor support and organizational citizenship behavior. Journal of Business Psychology, 23(1-2), 110. doi:10.1007/s10869-008-9084-y 
Chen, J. \& Silverthorne, C. (2008). The impact of locus of control on job stress, job performance and job satisfaction in Taiwan. Leadership \& Organization Development Journal, 29(7), 572-582. doi:10.1108/01437730810906326

Cheng, E.W.L. \& Hampson, I. (2008). Transfer of training: A review and new insights. International Journal of Management Reviews, 10(4), 327-341. doi:10.1111/j.1468-2370.2007.00230.x

Cheng, E.W.L. \& Ho, D.C.K. (2001). A review of transfer of training studies in the past decade. Personnel Review, 30(1), 102-118. doi:10.1108/00483480110380163

Chiaburu, D.S. (2010). The social context of training: coworker, supervisor, or organizational support? Industrial and Commercial Training, 42(1), 53-56. doi:10.1108/00197851011013724

Chiaburu, D.S., \& Lindsay, D.R. (2008). Can do or will do? The importance of selfefficacy and instrumentality for training transfer. Human Resource Development International, 11(2), 199-206. doi:10.1080/13678860801933004

Chiaburu, D.S. \& Marinova, S.V. (2005). What predicts skill transfer? An exploratory study of goal orientation, training self-efficacy and organizational supports. International Journal of Training and Development, 9(2), 110-123. doi:10.1111/j.1468-2419.2005.00225.x

Chiaburu, D.S. \& Tekleab, A. (2005). Individual and contextual influences on multiple dimensions of training effectiveness. Journal of European Industrial Training, 29(8), 604-626. doi:10.1108/03090590510627085 
Chiaburu, D.S., Van Dam, K., \& Hutchins, H.M. (2010). Social support in the workplace and training transfer: A longitudinal analysis. International Journal of Selection and Assessment, 18(2), 187-200. doi:10.1111/j.1468-2389.2010.00500.x

Colquitt, J.A., LePine, J.A., \& Noe, R.A. (2000). Toward an integrative theory of training motivation: A meta-analytic path analysis of 20 years of research. Journal of Applied Psychology, 85(5), 678-707. doi:10.1037//0021-9010.85.5.678

Creswell, J.W. (1998). Qualitative inquiry and research design. Thousand Oaks, CA: Sage Publications.

Creswell, J.W. \& Plano Clark, V.L. (2007). Designing and conducting mixed methods research. Thousand Oaks, CA: Sage Publications.

DeConinck, J.B. \& Johnson, J.T. (2009). The effects of perceived supervisor support, perceived organizational support, and organizational justice on turnover among salespeople. Journal of Personal Selling \& Sales Management, 29(4), 333-350. doi:10.2753/PSS0885-3134290403

Denison, D.R. (1996). What is the difference between organizational culture and organizational climate? A native's point of view on a decade of paradigm wars. Academy of Management Review, 21(3), 619-654. doi:10.2307/258997

Devos, C., Dumay, X., Bonami, M., Bates, R., \& Holton, E.F., III. (2007). The Learning Transfer System Inventory (LTSI) translated into French: internal structure and predictive validity. International Journal of Training and Development, 11(3), 181-199. doi:10.1111/j.1468-2419.2007.00280.x 
Downs, C.W. (1994). Mentoring and communication support scale. In R.B. Rubin, P. Palmgreen, \& H.E. Sypher (Eds.). Communication research measures (pp. 230233). New York: The Guilford Press.

Driscoll, D.L., Appiah-Yeboah, A., Salib, P., \& Rupert, D.J. (2007). Merging qualitative and quantitative data in mixed methods research: How to and why not. Ecological and Environmental Anthropology, 3(1), 19-28. Retrieved from http://eea.anthro.uga.edu/index.php/eea/article/viewFile/26/36

Drucker, P.F. (1999). Knowledge-worker productivity: The biggest challenge. California Management Review, 41(2), 79-94. doi:10.2307/41165987

Efron, B. \& Tibshirani, R. (1993). An introduction to the bootstrap. London: Chapman \& Hall.

Egan, T.M. (2008). The relevance of organizational subculture for motivation to transfer learning. Human Resource Development Quarterly, 19(4), 299-322. doi:10.1002/hrdq.1243

Egan, T.M., Yang, B., \& Bartlett, K.R. (2004). The effects of organizational learning culture and job satisfaction on motivation to transfer learning and turnover intention. Human Resource Development Quarterly, 15(3), 279-301. doi:10.1002/hrdq.1104

Eisenberger, R., Armeli, S., Rexwinkel, B., Lynch, P.D., \& Rhoades, L. (2001). Reciprocation of perceived organizational support. Journal of Applied Psychology, 86(1), 42-51. doi:10.1037//0021-9010.86.1.42

Eisenberger, R., Huntington, R., Hutchison, S., \& Sowa, D. (1986). Perceived organizational support. Journal of Applied Psychology, 71(3), 500-507. 
doi:10.1037//0021-9010.71.3.500

Eisenberger, R., Stinglhamber, F., Vandenberghe, C., Sucharski, I.L., \& Rhoades, L. (2002). Perceived supervisor support: Contributions to perceived organizational support and employee retention. Journal of Applied Psychology, 87(3), 565-573. doi:10.1037//0021-9010.87.3.565

Elangovan, A.R. \& Karakowsky, L. (1999). The role of trainee and environmental factors in transfer of training: An exploratory framework. Leadership and Organization Development Journal, 20(5), 268-276. doi:10.1108/01437739910287180

Elliot, M.A. \& Ainsworth, K. (2012). Predicting university undergraduates' bingedrinking behavior: A comparative test of the one- and two-component theories of planned behavior. Addictive Behaviors, 37(1), 92-101.

doi:10.1016/j.addbeh.2011.09.005

Elliott, M.A., Armitage, C.J., \& Baughan, C.J. (2007). Using the theory of planned behaviour to predict observed driving behaviour. British Journal of Social Psychology, 46(1), 69-90. doi:10.1348/014466605X90801

Erzberger, C. \& Kelle, U. (2003). Making inferences in mixed methods: The rules of integration. In A. Tashakkori \& C. Teddie (Eds.). Handbook of mixed methods in social and behavioral research (pp. 457-488). Thousand Oaks, CA: Sage.

Facteau, J.D., Dobbins, G.H., Russell, J.E.A., Ladd, R.T., \& Kudisch, J.D. (1995). The influence of general perceptions of the training environment on pretraining motivation and perceived training transfer. Journal of Management, 21(1), 1-25. doi:10.1016/0149-2063(95)90031-4 
Fowler, F.J., Jr. (2009). Survey research methods ( $4^{\text {th }}$ ed.). Thousand Oaks, CA: Sage Publications.

Gegenfurtner, A., Veermans, K., Festner, D. \& Gruber, H. (2009). Motivation to transfer training: An integrative literature review. Human Resource Development Review, 8(3), 403-423. doi:10.1177/1534484309335970

Georgenson, D.L. (1982). The problem of transfer calls for partnership. Training \& Development Journal, 36(10), 75-78.

Gilpin-Jackson, Y. \& Bushe, G.R. (2006). Leadership development training transfer: A case study of post-training determinants. Journal of Management Development, 26(10), 980-1004. doi:10.1108/02621710710833423

Gouldner, A.W. (1960). The norm of reciprocity: A preliminary statement. American Sociological Review,25(2), 161-178. doi:10.2307/2092623

Handy, L.A. (2008). The importance of the work environment variables on the transfer of training. (Doctoral dissertation). Retrieved from ProQuest Dissertations and Theses database. (UMI No. 33066657).

Hawley, J.D. \& Barnard, J.K. (2005). Work environment characteristics and implications for training transfer: A case study of the nuclear power industry. Human Resource Development International, 8(1), 65-80. doi:10.1080/1367886042000338308

Hill, S.E.K., Bahniuk, M.H., \& Dobos, J. (1989). The impact of mentoring and collegial support on faculty success: An analysis of support behavior, information adequacy, and communication apprehension. Communication Education, 38(1), $15-33$. 
Hill, S.E.K., Bahniuk, M.H., Dobos, J., \& Rouner, D. (1989). Mentoring and other communication support in the academic setting. Group \& Organization Management, 14(3), 355-368.

Hofstede, G. (1998). Identifying organizational subcultures: An empirical approach. Journal of Management Studies, 35(1), 1-12. doi:10.1111/1467-6486.00081

Holton, E.F., III. (1996). The flawed four-level evaluation model. Human Resource Development Quarterly, 7(1), 5-21. doi:10.1002/hrdq.3920070103

Holton, E.F., III. (2005). Holton's evaluation model: New evidence and construct elaborations. Advances in Developing Human Resources, 7(1), 37-54. doi:10.1177/1523422304272080

Holton, E.F., III, Bates, R.A., Bookter, A.I., Yamkovenko, V.B. (2007). Convergent and divergent validity of the learning transfer system inventory. Human Resource Development Quarterly, 18(3), 385-419. doi:10.1002/hrdq.1210

Holton, E.F., III, Bates, R.A., \& Ruona, W.E.A. (2000). Development of a generalized learning transfer system inventory. Human Resource Development Quarterly, 11(4), 333-360. doi:10.1002/1532-1096(200024)11:4<333::AID-HRDQ2>3.0.CO;2-P

Holton, E.F., III, Bates, R.A., Seyler, D.L., \& Carvalho, M.B. (1997). Toward a construct validation of a transfer climate instrument. Human Resource Development Quarterly, 8(2), 95- 113. doi:10.1002/hrdq.3920080203

Huchting, K., Lac, A., \& LaBrie, J.W. (2008). An application of the theory of planned behavior to sorority alcohol consumption. Addictive Behaviors, 33(4), 538-551. doi:10.1016/j.addbeh.2007.11.002 
Ivankova, N.V., Creswell, J.W., \& Stick, S.L. (2006). Using mixed-methods sequential explanatory design: From theory to practice. Field Methods, 18(3), 3-20. doi:10.1177/1525822X05282260

Jick, T.D. (1979). Mixing qualitative and quantitative methods: Triangulation in action. Administrative Science Quarterly, 24(4), 602-611. doi:10.2307/2392366

Johnson, R.B. \& Onwuegbuzie, A.J. (2004). Mixed methods research: A research paradigm whose time has come. Educational Researcher, 33(7), 14-26. doi:10.3102/0013189X033007014

Johnson, R.B., Onwuegbuzie, A.J., \& Turner, L.A. (2007). Toward a definition of mixed methods research. Journal of Mixed Methods Research, 1(2), 112-133. doi:10.1177/1558689806298224

Judge, T.A. \& Bono, J.E. (2001). Relationship of core self-evaluations traits—selfesteem, generalized self-efficacy, locus of control, and emotional stability-with job satisfaction and job performance: A meta-analysis. Journal of Applied Psychology, 86(1), 80-92. doi:10.1037//0021-9010.86.1.80

Judge, T.A. \& Ilies, R. (2002). Relationship of personality to performance motivation: A meta-analytic review. Journal of Applied Psychology, 87(4), 797-807. doi:10.1037//0021-9010.87.4.797

Kahya, E. (2008). The effects of job performance on effectiveness. International Journal of Industrial Ergonomics, 39(1), 96-104. doi:10.1016/j.ergon.2008.06.006

Kaplan, S., Bradley, J.C., Luchman, J.N., \& Haynes, D. (2009). On the role of positive and negative affectivity in job performance: A meta-analytic investigation. Journal of Applied Psychology, 94(1), 162-176. doi:10.1037/a0013115 
Kauffeld, S. \& Lehmann-Willenbrock (2009). Sales training: effects of spaced practice on training transfer. Journal of European Industrial Training, 34(1), 23-37. doi:10.1108/03090591011010299

Keith, N. \& Frese, M. (2005). Self-regulation in error management training: Emotion control and metacognition as mediators of performance effects. Journal of Applied Psychology, 90(4), 677-691. doi:10.1037/0021-9010.90.4.677

Keith, N. \& Frese, M. (2008). Effectiveness of error management training: A metaanalysis. Journal of Applied Psychology, 93(1), 59-69.

doi:10.1037/0021-9010.93.1.59

Keith, N., Richter, T., \& Naumann, J. (2010). Active/exploratory training promotes transfer even in learners with low motivation and cognitive ability. Applied Psychology: An International Review, 59(1), 97-123. doi:10.1111/j.1464-0597.2009.00417.x

Kelle, U. (2006). Combining qualitative and quantitative methods in research practice: purposes and advantages. Qualitative Research in Psychology, 3(4), 293-311. doi:10.1177/1478088706070839

Kirkpatrick, D.L. (1976). Evaluation of training. In R.L. Craig (ed.) Training and development handbook (2 ${ }^{\text {nd }}$ ed.) (pp. 18-1-18-27). New York: McGraw-Hill.

Kirwan, C. \& Birchall, D. (2006). Transfer of learning from management development programmes: testing the Holton model. International Journal of Training and Development, 10(4), 252-268. doi:10.1111/j.1468-2419.2006.00259.x 
Kuokkanen, L., Suominen, T., Harkonen, E., Kukkurainen, M., \& Doran, D. (2009). Effects of organizational change on work-related empowerment, employee satisfaction, and motivation. Nursing Administration Quarterly, 33(2), 116-124.

Levinson, H. (1965). Reciprocation: The relationship between man and organization. Administrative Science Quarterly, 9(4), 370-390. doi:10.2307/2391032

Liebermann, S. \& Hoffman, S. (2008). The impact of practical relevance on training transfer: evidence from a service quality training program for German bank clerks. International Journal of Training and Development, 12(2), 74-86. doi:10.1111/j.1468-2419.2008.00296.x

Lim, D.H. \& Johnson, S.D. (2002). Trainee perceptions of factors that influence learning transfer. International Journal of Training and Development, 6(1), 36-48. doi:10.1111/1468-2419.00148

Lim, D.H. \& Morris, M.L. (2006). Influence of trainee characteristics, instructional satisfaction, and organizational climate on perceived learning and training transfer. Human Resource Development Quarterly, 17(1), 85-115. doi:10.1002/hrdq.1162

Machin, M.A. \& Fogarty, G.J. (2004). Assessing the antecedents of transfer intentions in a training context. International Journal of Training and Development, 8(3), 222236. doi:10.1111/j.1360-3736.2004.00210.x

MacKinnon, D.P., Lockwood, C.M., Hoffman, J.M., West, S.G., \& Sheets, V. (2002). A comparison of methods to test mediation and other intervening variable effects. Psychological Methods, 7(1), 83-104. doi:10.1037//1082-989X.7.1.83 
Maertz, C.P., Jr., Griffeth, R.W., Campbell, N.S., \& Allen, D.G. (2007). The effects of perceived organizational support and perceived supervisor support on employee turnover. Journal of Organizational Behavior, 28(8), 1059-1075.

doi:10.1002/job.472

Martin, H.J. (2010a). Improving training impact through effective follow-up: techniques and their application. Journal of Management Development, 29(6), 520-534. doi:10.1108/02621711011046495

Martin, H.J. (2010b). Workplace climate and peer support as determinants of training transfer. Human Resource Development Quarterly, 21(1), 87-104. doi:10.1002/hrdq. 20038

Martineau, J.W. (1995). A contextual examination of the effectiveness of a supervisory skills training program (Doctoral dissertation). Retrieved from ProQuest Dissertations and Theses database. (UMI No. 9600217).

Mertler, C.A. \& Vannatta, R.A. (2005). Advanced and multivariate statistical methods $\left(3^{\text {rd }}\right.$ ed.).Glendale, CA: Pyrczak Publishing.

Miles, M.B. \& Huberman, A.M. (1994). Qualitative data analysis (2 ${ }^{\text {nd }}$ ed.). Thousand Oaks, CA: Sage Publications.

Moustakas, C. (1994). Phenomenological research methods. Thousand Oaks, CA: Sage Publications.

Murnaghan, D.A., Blanchard, C.M., Rodgers, W.M., LaRosa, J.N., MacQuarrie, C.R., MacLellan, D.L., \& Gray, B.J. (2010). Predictors of physical activity, health eating and being smoke-free in teens: A theory of planned behaviour approach. Psychology \& Health, 25(8), 925-941. doi:10.1080/08870440902866894 
Naquin, S.S. \& Holton, E.F., III. (2002). The effects of personality, affectivity, and work commitment on motivation to improve work through learning. Human Resource Development Quarterly, 13I(4), 357-376. doi:10.1002/hrdq.1038

Nardi, P.M. (2003). Doing survey research. Boston, MA: Pearson.

Ng, T.W.H. \& Sorensen, K.L. (2008). Toward a further understanding of the relationships between perceptions of support and work attitudes: A meta-analysis. Group \& Organization Management, 33(3), 243-268. doi:10.1177/1059601107313307

Ng, T.W.H., Sorensen, K.L., \& Eby, L.T. (2006). Locus of control at work: A metaanalysis. Journal of Organizational Behavior, 27(8), 1057-1087. doi:10.1002/job.416

Nijman, D.J.M., Nijhof, W.J., Wognum, A.A.M., \& Veldkamp, B.P. (2006). Exploring differential effects of supervisor support on transfer of training. Journal of European Industrial Training, 30(7), 529-549. doi:10.1108/03090590610704394

Nikandrou, I., Brinia, V., \& Bereri, E. (2009). Trainee perceptions of training transfer: an empirical analysis. Journal of European Industrial Training, 33(3), 255-270. doi:10.1108/03090590910950604

Noe, R.A. (1986). Trainees' attributes and attitudes: Neglected influences of training effectiveness. Academy of Management Review, 11(4), 736-749. doi:10.2307/258393

Noe, R. A. \& Schmitt, N. (1986). The influence of trainee attitudes on training effectiveness: A test of a model. Personnel Psychology, 39(3), 497-523. doi:10.1111/j.1744-6570.1986.tb00950.x 
Paradise, A. \& Patel, L. (2009). 2009 state of the industry report. Alexandria, VA: American Society for Training and Development.

Patel, L. (2010). ). 2010 state of the industry report. Alexandria, VA: American Society for Training and Development.

Patton, M.Q. (2002). Qualitative research and evaluation methods ( $3^{\text {rd }}$ ed.). Thousand Oaks, CA: Sage Publications.

Pazy, A. \& Ganzach, Y. (2008). Pay contingency and the effects of perceived organizational and supervisor support on performance and commitment. Journal of Management, 35(4), 1007-1025. doi:10.1177/0149206307312505

Phillips, J.J. \& Phillips, P.P. (2010). Confronting CEO expectations about the value of learning. Training and Development, 64(1), 52-57.

Podsakoff, P.M., MacKenzie, Lee, \& Podsakoff (2003). Common method biases in behavioral research: A critical review of the literature and recommended remedies. Journal of Applied Psychology, 88(5), 879-903. doi:10.1037/0021-9010.88.5.879

Podsakoff, P.M. \& Organ, D.W. (1986). Self-reports in organizational research: Problems and prospects. Journal of Management, 12(1), 531-544. doi:10.1177/014920638601200408

Preacher, K.J. \& Hayes, A.F. (2004). SPSS and SAS procedures for estimating indirect effects in simple mediation models. Behavior Research Methods, Instruments, \& Computers, 36(4), 717-724. doi:10.3758/BF03206553 
Preacher, K.J. \& Hayes, A.F. (2008). Asymptotic and resampling strategies for assessing and comparing indirect effects in multiple mediator models. Behavior Research Methods, 40(3), 879-891. doi:10.3758/BRM.40.3.879

Pugh, K.J. \& Bergin, D.A. (2006). Motivational influences on transfer. Educational Psychologist, 41(3), 147-160. doi:10.1207/s15326985ep4103_2

Rafferty, A.E. \& Griffin, M.A. (2006). Perceptions of organizational change: A stress and coping perspective. Journal of Applied Psychology, 91(5), 1154-1162. doi:10.1037/0021-9010.91.5.1154

Rhoades, L. \& Eisenberger, R. (2002). Perceived organizational support: A review of the literature. Journal of Applied Psychology, 87(4), 698-714. doi:10.1037//0021-9010.87.4.698

Rhodes, R., Blanchard, C.M., Matheson, D.H. (2006). A multicomponent model of the theory of planned behavior. British Journal of Health Psychology, 11(1), 119-137. doi:10.1348/135910705X52633

Riggle, R.J., Edmondson, D.R., \& Hansen, J.D. (2009). A meta-analysis of the relationship between perceived organizational support and job outcomes: 20 years of research. Journal of Business Research, 62(10), 1027-1030. doi:10.1016/j.jbusres.2008.05.003

Rise, J., Sheeran, P., \& Hukkelberg, S. (2010). The role of self-identity in the theory of planned behavior: A meta-analysis. Journal of Applied Social Psychology, 40(5), 1085-1105. doi:10.1111/j.1559-1816.2010.00611.x 
Rivis, A., Sheeran, P., \& Armitage, C.J. (2009). Expanding the affective and normative components of the theory of planned behavior: A meta-analysis of anticipated and moral norms. Journal of Applied Social Psychology, 39(12), 2985-3019. doi:10.1111/j.1559-1816.2009.00558.x

Roberson, L., Kulik, C.T., \& Pepper, M.B. (2009). Individual and environmental factors influencing the use of transfer strategies after diversity training. Group \& Organization Management, 34(1), 67-89. doi:10.1177/1059601108329732

Rouiller, J.Z. \& Goldstein, I.L. (1993). The relationship between organizational transfer climate and positive transfer of training. Human Resource Development Quarterly, 4(4), 377-390. doi:10.1002/hrdq.3920040408

Rowold, J. (2007). The impact of personality on training-related aspects of motivation: Test of a longitudinal model. Human Resource Development Quarterly, 18(1), 931. doi:10.1002/hrdq. 1190

Sackett, P. R., Gruys, M. L., \& Ellingson, J. E. (1998). Ability-personality interactions when predicting job performance. Journal of Applied Psychology, 83(4), 545556. doi:10.1037//0021-9010.83.4.545

Saks, A.M. \& Belcourt, M. (2006). An investigation of training activities and transfer of training in organizations. Human Resource Management, 45(4), 629-648. doi:10.1002/hrm.20135

Salas, E. and Cannon-Bowers, J.A. (2001). The science of training: A decade of progress. Annual Review of Psychology, 5(2), 471-99. 
Sanders, P. (1982). Phenomenology: A new way of viewing organizational research. Academy of Management Review, 7(3), 353-360. doi:10.5465/AMR.1982.4285315

Schein, E. H. (1990). Organizational culture. American Psychologist, 45(2), 109-119. doi:10.1037//0003-066X.45.2.109

Shanock, L.R. \& Eisenberger, R. (2006). When supervisors feel supported: Relationships with subordinates' perceived supervisor support, perceived organizational support, and performance. Journal of Applied Psychology, 91(3), 689-695. doi:10.1037/0021-9010.91.3.689

Shapiro, S.S. \& Wilk, M.B. (1965). An analysis of variance test for normality. Biometrika, 52(3), 591- 599. doi:10.1093/biomet/52.3-4.591

Shrout, P.E. \& Bolder, N. (2002). Mediation in experimental and nonexperimental studies: New procedures and recommendations. Psychological Methods, 7(4), 422-445. doi:10.1037//1082-989X.7.4.422

Smith-Jentsch, K.A., Salas, E., \& Brannick, M.T. (2001). To transfer of not to transfer? Investigating the combined effects of trainee characteristics, team leader support, and team climate. Journal of Applied Psychology, 86(2), 279-292. doi:10.1037//0021-9010.86.2.279

Sookhai, F. \& Budworth, M. (2010). The trainee in context: Examining the relationship between self-efficacy and transfer climate for transfer of training. Human Resource Development Quarterly, 21(3), 257-272. doi:10.1002/hrdq.20044 
Spector, P.E. \& Brannick, MT. (2009). Common method variance or measurement bias? The problem and possible solutions. In D.A. Buchanan \& A. Bryman (Eds.), The sage handbook of organizational research methods (pp. 346-362). London: Sage.

Starks, H. \& Trinidad, S.B. (2007). Choose your method: A comparison of phenomenology, discourse analysis, and grounded theory. Qualitative Health Research, 17(10), 1372-1380. doi:10.1177/1049732307307031

Stone, T.H., Jawahar, I.M., Kisamore, J.L. (2009). Using the theory of planned behavior and cheating justifications to predict academic misconduct. Career Development International, 14(3), 221-241. doi:10.1108/13620430910966415

Tabachnick, B.G. \& Fidell, L.S. (2001). Using multivariate statistics $\left(4^{\text {th }}\right.$ ed.). Needham Heights, MA: Allyn \& Bacon.

Tabachnick, B.G. \& Fidell, L.S. (2007). Using multivariate statistics (5 ${ }^{\text {th }}$ ed.). Boston, MA: Pearson.

Taylor, P.J., Russ-Eft, D.F., \& Taylor, H. (2009). Transfer of management training from alternative perspectives. Journal of Applied Psychology, 94(1), 104-121. doi:10.1037/a0013006

Thorndike, E.L. \& Woodworth, R.S. (1901). The influence of improvement in one mental function upon the efficiency of other functions. Psychological Review, 8(3), 247261. doi: $10.1037 / \mathrm{h} 0074898$

Tracey, J.B., Tannenbaum, S.I., \& Kavanagh, M.J. (1995). Applying training skills on the job: The importance of the work environment. Journal of Applied Psychology, 1995, 80(2), 239-252. doi:10.1037//0021-9010.80.2.239 
Tracey, J.B. \& Tews, M.J. (2005). Construct validity of a general training climate scale. Organizational Research Methods, 8(4), 353-374. doi:10.1177/1094428105280055

Tziner, A., Fisher, M., Senior, T., \& Weisberg, J. (2007). Effects of trainee characteristics on training effectiveness. International Journal of Selection and Assessment, 15(2), 167-174. doi:10.1111/j.1468-2389.2007.00378.x

Van den Bossche, P., Segers, M., and Jansen, N. (2010). Transfer of training: the role of feedback in supportive social networks. International Journal of Training and Development, 14(2), 81-94. doi:10.1111/j.1468-2419.2010.00343.x van der Klink, Gielen, \& Nauta, C. (2001). Supervisory support as a major condition to enhance transfer. International Journal of Training and Development, 5(1), 5263. doi:10.1111/1468-2419.00121

Van Scotter, J.R. (2000). Relationships of task performance and contextual performance with turnover, job satisfaction, and affective commitment. Human Resoruce Management Review, 10(1), 79-95. doi:10.1016/S1053-4822(99)00040-6

Velada, R., Caetano, A., Michel, J.W., Lyons, B.D., \& Kavanagh, M.J. (2007). The effects of training design, individual characteristics and work environment on transfer of training. International Journal of Training and Development, 11(4), 282-294. doi:10.1111/j.1468-2419.2007.00286.x

Vroom, V. (1964). Work and motivation. New York: Wiley.

White, K.M., Smith, J.R., Terry, D.J., Greenslade, J.H., \& McKimmie, B.M. (2009). Social influence in the theory of planned behaviour: The role of descriptive, 
injunctive and in-group norms. British Journal of Social Psychology, 48(1), 135158. i:10.1348/014466608X295207

Yamkovenko, B. \& Holton, E.F., III. (2010). Toward a theoretical model of dispositional influences on transfer of learning: A test of a structural model. Human Resource Development Quarterly, 21(4), 381-410. doi:10.1002/hrdq.20054

Yamkovenko, B.V., Holton, E.F., III, \& Bates, R.A. (2007). The learning transfer system inventory (LTSI) in Ukraine: The cross-cultural validation of the instrument. Journal of European Industrial Training, 31(5), 377-401. doi:10.1108/03090590710756819

Yamnill, S. \& McLean, G.N. (2001). Theories supporting transfer of training. Human Resource Development Quarterly, 12(2), 195-208. doi:10.1002/hrdq.7

Yu, M. (2009). Employees' perception of organizational change: The mediating effects of stress management strategies. Public Personnel Management, 38(1), 17-32. 
Appendix A: Demographic Survey Questions

Thank you for taking the time to complete this survey. It consists of 39 items and should take you approximately 10-15 minutes to complete.

Please note that your identity will be kept confidential and your responses will be used for research purposes only.

Instructions: Read each statement or question carefully. Then fill in a response or select the response that best reflects your answer.

1. I have read the informed consent form and agree to participate in this study.
True
False

2. What is your name?

3. What is your age?

4. What is your gender?
Female
Male

5. What is the highest level of education you have completed?
Bachelor's degree
C. Master's degree
D Doctoral degree

6. How many years have you worked at please indicate how many months you have worked at

Years

Months 
7. How many years have you worked as a curriculum developer at $\square$ ? If less than one year, please indicate how many months you have worked as a curriculum developer at

Years

Months

8. How many years of curriculum development experience do you have? If less than one year, please indicate how many months of curriculum development experience you have.

Years

Months

9. What type of new hire training (formal and informal or informal only) have you participated in?

Formal new hire training is defined as the structured two-week immersion training (during which boot camps and intensives are offered) conducted by individuals on the training and development team.

Informal new hire training is defined as unstructured training that occurs on the job in the absence of a formal trainer. Examples include shadowing peers and/or mentors, observing meetings and other job-related activities, and asking questions.

\section{Formal and informal new hire training \\ Informal new hire training only}

10. How many years has it been since you participated in formal and/or informal new hire training? If less than one year, please indicate how many months it has been since you participated in formal and/or informal new hire training.

Years

Months

11. How many years did your mentor provide support to you following your participation in formal and/or informal training. If less than one year, please indicate how many months your mentor provided support to you.

Support may include some or all of the following: assistance with completing work assignments; instruction about the rules, goals, and politics of the organization; advice 
regarding personal and/or professional challenges; guidance about your career development.

Years

Months

12. Would you like to be contacted to participate in a 1-hour, confidential interview to discuss your responses to this survey in further detail?
Y Yes
(C) No 
Appendix B: Interview Questions for Mentees

1. Describe your prior job experience in curriculum development.

2. Describe your experience being trained, as a new employee.

a. What topics covered in training were most familiar to you? Least familiar to you?

3. Describe your initial experience on the job as a new employee.

a. What parts of the job were easiest for you? Most difficult for you?

4. Explain how your mentor has supported you in your role.

a. What specific supportive behaviors did he or she exhibit?

b. Which supportive behaviors were most helpful to you as new employee trying to learn the job? Least helpful? Why?

c. What additional types of support, if any, would you have liked your mentor to provide? Why?

5. Is there anything else you would like to add? 
Appendix C: Interview Questions for Mentors

1. Describe your experience being trained, as a new employee.

a. How important do you think training is to the success of employees?

2. Describe the support you received from your supervisor as a new employee.

a. How important do you think support is to the success of employees?

3. Describe your experience providing support to the mentees with whom you work.

a. What specific supportive behaviors did you engage in?

b. What kinds of support do you think were most helpful to mentees? Least helpful? Why?

c. How long did you provide support to the mentees? What factors influenced your decision about the length of time you provided support?

4. Think for a moment about the mentees with whom you work that participated in both formal (structured two-week training) and informal new hire training (onthe-job training). Describe your experience providing support to these mentees.

a. Did they effectively apply what they learned in training once on the job? If so, what behaviors did they exhibit that made you think so? If not, why not?

b. What challenges did they encounter?

c. What challenges did you encounter while providing support to these mentees?

5. Think for a moment about the mentees with whom you work that participated in informal new hire training (on-the-job training) only. Describe your experience providing support to these mentees. 
a. Did they effectively apply what they learned in training once on the job? If so, what behaviors did they exhibit that made you think so? If not, why not?

b. What challenges did they encounter?

c. What challenges did you encounter while providing support to these mentees?

6. Is there anything else you would like to add? 
Curriculum Vitae

\section{Education}

\section{Laura A. Schindler}

Doctor of Philosphy in Psychology

Specialization: Organizational Psychology

Walden University, 2013

Master of Science in Psychology

Specialization: Industrial/Organizational Psychology

Walden University, January 2007

Bachelor of Science in Psychology

Minor: Sociology

Towson University, January 2001

\section{Summary of Skills, Expertise, and Knowledge}

- Knowledge of adult learning principles and best practices for online course design

- Experience developing online courses for Bachelors, Masters, and $\mathrm{PhD}$ programs

- Ability to collaborate with faculty and subject matter experts

- Excellent written communication skills

- Experience with Blackboard, eCollege, Adobe eLearning Suite, Dreamweaver, and HTML

\section{Professional Experience}

Adjunct Faculty September 2012 - present

University of Liverpool

- Currently teach Biological, Psychological, and Social Bases of Health and Behaviour in the online MSc in Applied Psychology programme

\section{Consultant}

June 2012 - present

- Conduct quality reviews of academic programs to ensure they meet university standards and exemplify excellence and innovation in design and instruction

Director, Product Training and Development December 2010 - September 2011

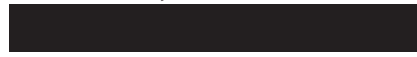

- Designed and developed instructor-led trainings, web-based training modules, and job aids related to the design and development of online courses

- Led and co-led trainings held in multiple sites

- Managed training resources and tracked employee participation in training delivered through the Employee Learning Management System (ELMs) 
- Collected data to assess the effectiveness of instructor-led trainings and web-based training modules

Senior Course Developer/Course Developer $\quad$ November 2007 - December 2010

- Supervised outside venders in the design and development of online courses for adult learners

- Taught and mentored course developers in the design and development of online courses

- Reviewed online courses developed by outside venders and internal course developers in accordance with quality standards

- Collaborated with subject matter experts and faculty to design online courses for adult learners

- Edited and wrote online course content in accordance with quality standards

- Worked with media producers to design and develop instructional media to enhance student learning

Admissions Manager

February 2006 - October 2007

- Oversaw admission decisions and transfer of credit for the Schools of Psychology, Social Services, Nursing, and Health Services

- Worked with faculty to determine the admissibility of applicants

- Collaborated with student service departments to implement university initiatives and resolve student issues

- Resolved conflict between enrollment advisors and admissions staff regarding admission policies and procedures

Admissions Specialist/Support Specialist

November 2003 - January 2006

- Determined admissibility of applicants

- Evaluated and awarded transfer of credit

- Responded to inquiries from applicants, students, faculty, and student service departments regarding admission decisions and transfer of credit awards

- Managed the tracking, clearing, and withdrawals of conditionally admitted students

- Corresponded with faculty regarding student program plans

Teacher Assistant

June 2001 - October 2003

The Arrow Project

- Provided individual and group instruction to emotionally disturbed and learning disabled students from grades 6-12 
- Developed lesson plans

- Met with treatment team to discuss psychological and educational progress of students

- Assisted in the timely completion of all necessary paperwork to accurately record student progress

- Co-led weekly music therapy group 